\title{
Peripheral arterial occlusive disease: clinical course and effectiveness of aspirin : a primary care based study
}

Citation for published version (APA):

Kaiser, V. (2000). Peripheral arterial occlusive disease: clinical course and effectiveness of aspirin : a primary care based study. [Doctoral Thesis, Maastricht University]. Datawyse / Universitaire Pers Maastricht. https://doi.org/10.26481/dis.20000526vk

Document status and date:

Published: 01/01/2000

DOI:

10.26481/dis.20000526vk

Document Version:

Publisher's PDF, also known as Version of record

\section{Please check the document version of this publication:}

- A submitted manuscript is the version of the article upon submission and before peer-review. There can be important differences between the submitted version and the official published version of record.

People interested in the research are advised to contact the author for the final version of the publication, or visit the DOI to the publisher's website.

- The final author version and the galley proof are versions of the publication after peer review.

- The final published version features the final layout of the paper including the volume, issue and page numbers.

Link to publication

\footnotetext{
General rights rights.

- You may freely distribute the URL identifying the publication in the public portal. please follow below link for the End User Agreement:

www.umlib.nl/taverne-license

Take down policy

If you believe that this document breaches copyright please contact us at:

repository@maastrichtuniversity.nl

providing details and we will investigate your claim.
}

Copyright and moral rights for the publications made accessible in the public portal are retained by the authors and/or other copyright owners and it is a condition of accessing publications that users recognise and abide by the legal requirements associated with these

- Users may download and print one copy of any publication from the public portal for the purpose of private study or research.

- You may not further distribute the material or use it for any profit-making activity or commercial gain

If the publication is distributed under the terms of Article $25 \mathrm{fa}$ of the Dutch Copyright Act, indicated by the "Taverne" license above, 
(c) V. Kaiser, Maastricht 2000

ISBN 9052782768

Vormgeving en druk: Datawyse | Universitaire Pers Maastricht 


\section{Peripheral arterial occlusive disease: clinical course and effectiveness of aspirin}

\section{A primary care based study}

Proefschrift

ter verkrijging van de graad van doctor

aan de Universtiteit Maastricht,

op gezag van de Rector Magnificus,

Prof. Dr. A.C. Nieuwenhuijzen Kruseman, volgens het besluit van het College van Decanen, in het openbaar te verdedigen op vrijdag 26 mei 2000 om 12.00 uur

door

Victor Kaiser

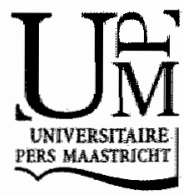




\section{Promotores}

Prof. dr. J.A. Knottnerus

Prof. dr. P.J.E.H.M. Kitslaar

\section{Co-promotor}

dr. H.E.J.H. Stoffers

\section{Beoordelingscommissie}

Prof. dr. P. W. de Leeuw (voorzitter)

Prof. dr. F. Buntinx

Prof. dr. F.G.R. Fowkes (University of Edinburgh, Scotland)

Prof, dr. J.M.J.P. van der Linden

Prof. dr. J.A. Rauwerda (Vrije Universiteit Amsterdam)

The study presented in this thesis was peformed at the institute ExTra, part of the Netherlands School of Primary Care Research (CaRe) acknowledged in 1995 by the Royal Netherlands Academy of Sciences (KNAW). This study was supported by a grant of the former "Praeventiefonds" (no 28-1323), now "Zorg Onderzoek Nederland" and the Netherlands Organisation of Scientific Research (900-715.154). 


\section{Contents}

CHAPTER 1

Introduction

CHAPTER 2

Prevalence in general practice

CHAPTER 3

Risk management of patients with peripheral arterial vascular disease

CHAPTER 4

Drug treatment of patients with peripheral arterial vascular disease

\section{CHAPTER 5}

The influence of experience on the reproducibility of the anklebrachial systolic pressure ratio in peripheral arterial occlusive disease

\section{CHAPTER 6}

Evaluation of the effect of aspirin on the course of peripheral arterial occlusive disease. A population based randomised controlled trial in a general practice setting

\section{CHAPTER 7}

Prognostic indicators for outcome of peripheral arterial occlusive disease in general practice

CHAPTER 8

Conducting a clinical trial in a primary health care setting

CHAPTER 9

General discussion

Summary

Samenvatting

Dankwoord 
$1 \mid$ Introduction

\section{Introduction}

\section{Background}

Peripheral Arterial Obstructive Disease (PAOD) of the legs is the most important peripheral vascular disease in the elderly patient. Clinically we can distinguish several stages of disease according to Fontaine: 1 asymptomatic, 2 intermittent claudication, 3 rest pain, nocturnal pain and trofic disorders, 4 gangrene.

General practitioners are generally confronted with patients in stage 2 or 3. Prevalence rates of intermittent claudication determined with questionnaires vary from 1.2 to 2.2 percent in the total population. With rising age the prevalence rates increases to 5.4 percent in male and 3.6 percent in female at the age of 75 years ${ }^{12}$

With the introduction of the non-invasive Doppler ultrasound bloodstream detector the general practitioner is able to assess the stage of PAOD in patients irrespective of their complaints. The measurement of the Ankle Brachial Pressure Index $(A B P I)$ has proven to be a good parameter for assessing the severity of PAOD. Compared with arteriography as a standard the sensitivity and the specificity are very high. ${ }^{34}$

In the eighties several studies reported hat there are some evident risk factors for having PAOD. ${ }^{5-7} \mathrm{New}$ surgical techniques saved many patients from an amputation. ${ }^{8}$ In addition, more attention was paid to the preventive and early conservative management of PAOD. Exercise programs and cessation of smoking seemed to be worthwhile ${ }^{9-11}$ Drug treatment of PAOD was still an issue of great controversion. ${ }^{12}$ Studies on platelet inhibition with aspirin showed promising results. ${ }^{13}$

With these issues in mind They Lemmens, an experienced general practitioner at the Maastricht University, discussed the diagnostic and therapeutical problems of PAOD with his colleagues at the Department of General Practice in 1984. From this conferences the group published a proposal on the management of PAOD in general practice. ${ }^{13}$ The financing fund (Praevention fund) of the "Protocol Project" recommended to transform this protocol to a research project on the natural course and treatment of PAOD. Together with several experts in this field a randomised clinical trial was designed to study the effect of aspirin on the natural course of PAOD in general practice. The ABPI measured with a Doppler device was chosen as the major outcome measure. In the phase of the study design the research questions were extended with a second study on the prevalence and clin- 
ical diagnosis of PAOD in general practice. The results of this study are published in a thesis and international publications ${ }^{14-19}$ The third project that started in 1994 was the Limburg PAOD Longitudinal Study, on the natural course and prognostic determinants of symptomatic and asymptomatic PAOD. The cohort was derived from the diagnostic study and follow-up was measured after seven years. The results of this study are published in a thesis. 2021

The study on the natural course and the treatment of PAOD with aspirin is called the Limburg PAOD study part 2 and is subject of this thesis.

\section{Aims}

The aims of the Limburg PAOD study part 2 are:

1. to study the natural course of symptomatic and asymptomatic PAOD in general practice.

2. to investigate the effect of aspirin on the natural course of PAOD in general practice.

In relation to these research questions the results of a study on the reproducibility of the ABPI in general practice are reported. Additionally reviews on the risk management and drug treatment in PAOD are presented.

\section{Structure of the thesis}

In chapter 2 an outline of the results of the study on prevalence from the Limburg PAOD Study part 1 is given.

In chapter 3 a survey of the literature on the risk management of PAOD is presented.

Chapter 4 is a review of the literature on the drug treatment of PAOD.

Chapter 5 describes the result s of a study on the reproducibility of the ABPI in general practice. The influence of experience in measuring the ABPI by general practitiomers and their assistants will be discussed.

Chapter 6 gives the results of the randomised clinical trial on the natural history and the effect of aspirin on the clinical course in PAOD.

Chapter 7 presents the results of a study on the prognostic determinants in PAOD with three years of follow-up.

In chapter 8 several issues in conducting a clinical trial in the setting of general practice are discussed.

In chapter 9 the general discussion, the results of the study are summarised and a discussion of the methodology is presented. Implications for general practice and suggestions for further research are given. 


\section{References}

1. Lamberts $\mathbb{H}$. Morbidity in general practice. Diagnosis related information from the monitoring Project. Utrecht: Huisartsenpers, 1984.

2. Hoogen HJM van den, Huygen FJA, Schellekens JWG, Straat JM, Van der Velden HGM. Morbidity figures from general practice. Data from four general practices 1978-1982. Nijmegen :NUHI; 1985.

3. Bernstein $\mathrm{EF}$, Fronek A. Current status of noninwasive tests in the diagnosis of peripheral arteriall disease. Surg Clin North America 1982; 62: 473-487.

4. Fowkes FGR. The measurement of atherosclerotic peripheral arterial disease in epidemiological surveys. Int Epidemiol 1988; 17:248-54.

5. Kannel WB, McGee DL. Update on some epidemiological features of intermittent claudication: the Framingham study. I Am Geriatr Soc 1985; 33: 13-18.

6. Hughson WG, Mann JI, Tibbs DJ, Woods HF, Walton I. Intermittent claudication: factors determining outcome. BM] 1978; 1 : $1377-9$.

7. Jelnes R, Gaardsting O, Hougaard Jensen K, Bakgaard N, Tonessen KH, Schrouder T. Fate in intermittent claudication: outcome and risk factors. BMJ 1986; 293: 1137-40,

8. Jeans WD, Armstrong S, Cole SE, Horrocks M, Baird RN. Fate of patients undergoing transluminal angioplasty for lower-limb ischemia. Radiology, 1990;177(2): 559-64.

9. Jonason $T$, Bergstrom R. Cessation of smoking in patients with intermittent claudication. Effects on the risk of peripheral vascular complications, myocardial infarction and mortality. Acta Med Scand 1987; 221: 253-60.

10. Quick CR, Cotton LT. The measured effect of stopping smoking on intermittent claudication. Br I Surg 1982; 69(suppl): S24-6.

11. Andriessen MP, Barendsen GJ, Wouda $\mathrm{AA}_{\mu}$ de Pater $\mathrm{L}$. The effect of six months intensive physical training on the circulation in the legs of patients with intermittent claudication. Vasa. $1989 ; 18(1): 56-62$.

12. Cameron HA, Walter PC, Ramsay LE. Drug treatment of intermittent claudication: a critical analysis of the methods and findings of published clinical trials, $1965-1985$. Br J Clin Pharm 1988; 26: 569-76.

13. Hess $H$, Mietaschk $A_{\text {, }}$ Deischel $G$. Drug induced inhibition of platelet function delays progression of peripheral occlusive arterial disease: a prospective double-blind arteriographically controlled trial. Lancet 1985; 332: 415-9.

14. Stoffers HEJH, Kaiser V, Kester ADM, Schouten HJA, Knottnerus JA. Peripheral arterial occlusive disease in general practice: the reproducibility of the ankle-arm systolic pressure ratio. Scand J Prim Health Care 1991;9:109-14.

15. Henri EJH Stoffers. Peripheral arterial occlusive disease. Prevalence and diagnostic management in general practice [PhD Thesis]. University Maastricht, 1995.

16. Stoffers HEIH, Kester ADM, Kaiser V, Rinkens PELM, Kitslaar PJEHM, Knottmerus IA. The diagnostic value of the measurement of the ankle-brachial systolic pressure index in primary health care. I Clin Epidemiol 1996;49(12):1401 -5. 
$10 \mid$ Chapter

17. Stoffers HEJH, Rinkens PELM, Kester ADM, Kailser V, Knottmerus JA. The prevalence of asymptomatic and unrecognized peripheral arterial occlusive disease. Int I Epidemiol $1996 ; 25: 282-90$

18. Stoffers HEJH, Kaíser V. [Treament of distal arterial vascular diseases (letter; comment)] Behandeling van distale arteriële vaatafwijkingen. Comment on: Ned Tijdschr Geneeskd 1994 Oct 15;138(42):2089-92 Ned Tijdschr Geneeskd, 1994 Dec 3; 138(49): 2459-60.

19. Stoffers HEJH, Kester ADM, Kaiser V, Rinkens PELM, Knottnerus JA. Diagnostic value of signs and symptoms associated with peripheral arterial occlusive disease seen in general practice: a multivariable approach. Med Decis Making 1997;17:61-70.

20. Hooi ID. Peripheral arterial occlusive disease: incidence, prognosis and determinants. A population-based study in a primary care setting [ $\mathrm{PhD}$ Thesis]. Maastricht: Unigraphic, 1998.

21. Hool JD, Stoffers HEJH, Kester ADM, Rinkens PELM, Kaiser V, van Ree JW, Knottnerus JA. Risk factors and cardiovascular diseases associated with asymptomatic peripheral arterial occlusive disease. The Limburg PAOD Study. Peripheral Arterial Occlusive Disease. Scand I Prim. Health Care 1998;16(3):177-82. 


\section{$2 \mid$ Prevalence in general practice}

HEIH Stoffers, Kaiser V, Knottnerus IA

published in: Fowkes FGR (ed.) Epidemiology of peripheral vascular disease. Landon etc.: Springer, 1991: 109-15 


\section{Importance of Peripheral Vascular Disease in General Practice}

Peripheral vascular disease is a term often used loosely to describe the manifestathon of atherosclerosis below the bifurcation of the abdominal aorta. It is the most frequent disease affecting peripheral arteries in the elderly. The population is ageing in western societies, therefore the prevalence of atherosclerotic disease will rise and the diagnostic and therapeutic management of this chronic disease will become more important to general practitioners.

Although coronary artery disease and cerebrovascular disease get more attenthon in popular and medical publications " peripheral vascular disease is a relevant subject to general practice. From results published in the literature it can be concluded that intermittent claudication has a relatively benign course in $75 \%$ of cases. ${ }^{1}$ Only in a minority of cases will serious complications occur: reduced mobility, severe pain at rest or gangrene, for which percutaneous transluminal angioplasty, vascular surgery or amputation might be indicated. ${ }^{1}$ The presence of intermittent claudication is one of the major predictors of disability in later life. ${ }^{2}$

A progressive course of the disease cannot be predicted in individual cases at the time of diagnosis ${ }^{34}$ and, therefore, it is necessary to examine the patient at regular intervals, especially in the first year after diagnoses. ${ }^{5} 6$ Conservative therapy of intermittent claudication - "start walking and stop smoking" ${ }^{37}$ - has been proven effective and should be the task of the general practitioner. ${ }^{89}$ Thus, referral to a vascular surgeon can be restricted to progressive cases.

Furthermore a high prevalence of vascular co-morbidity and mortality has been reported among patients with intermittent claudication. ${ }^{10-16}$ Recognising and treating intermittent claudication - being an indicator of general cardiovascullar risk - will reduce vascular risk and thus will contribute to the prevention of atherosclerotic complications.

All these tasks - adequate diagnosis, regular follow-up, conservative therapy, preventive measures and selection for referral - belong to the domain of the general practitioner. Knowledge of the prevalence ("prior probability") is important in the diagnostic process of the general practitioner. Prevalence figures also depict the workload which a chronic disease entails. In this chapter the prevalence of peripheral vascular disease is described. Results from the literature and first results from our own research will be presented and discussed.

\section{Methods of Estimating Prevalence}

Figures on the prevalence of peripheral vascular disease differ depending on the study population and the diagnostic criteria that were used. Three types of study can be distinguished.

In morbidity studies by general practitioners symptomatic patients, i.e. patients suffering from intermittent claudication, who visit their general practitioner are 
considered for inclusion. ${ }^{17-19} \mathrm{~A}$ positive diagnosis is established by the general practitioner in dialogue with the patient. In many cases the diagnosis probably will not meet the exact definition of intermittent claudication according to the "Rose questionnaire". ${ }^{20}$ In these studies the prevalence of intemittent claudication varied from $0.2 \%$ to $0.7 \%$ of the total practice population.

In population studies on intermittent claudication, generally questionnaires or interviews based on the Rose questionnaire are used. Relevant to general practice are those studies in which the study population is not highly selected by age, sex, risk factors or stage of the disease. $101221-23$ In these studies the prevalence of intermittent claudication, whether known or not known to a (family) doctor varied between $1.7 \%$ and $4.8 \%$ of the study population.

In a number of population studies non-invasive diagnostic techniques were used. ${ }^{21}$ 24-27 In these studies symptomatic and asymptomatic cases were observed. The prevalence of peripheral vascular disease in the study of Criqui ${ }^{21}$, being the only study without a (highly) selected study population, was $11.7 \%$.

\section{The Limburg Peripheral Arterial Occlusive Disease (PAOD) Study}

Since many clinical features of peripheral vascular disease relevant to general practice, such as prevalence, diagnostic features, prognostic indicators, and effects of conservative therapy are not known in sufficient detail ${ }^{28}$, a study was set up by the University of Limburg to investigate some of these aspects.

The first part of the "Limburg PAOD Study" is a cross-sectional survey among 3654 subjects aged 40-79 years. Main research questions are "What is the prevalence of peripheral vascular disease?" and "What is the diagnostic value of typical signs and symptoms?". The patients were selected and sampled from a study base of approximately 30.000 patients (18 general practices). All patients in the study population were examined by their general practitioner. The general practitioners based their clinical diagnosis on medical history (an extensive questionnaire filled in by the patient), physical examination and data abstracted from the patient's record. Independently of the general practitioner the practice assistants assessed the ankle-brachial systolic pressure ratio ("AB-Ratio") using a pocket Doppler device and a mercury sphygmomanometer. A patient with an $A B-$ Ratio lower than 0.95 , measured twice within a week, was considered to have peripheral vascular disease. Results will be published in detail in 1992.

The second part of the study is a randomised controlled trial which is designed to answer the question whether aspirin has a therapeutic effect in peripheral vascular disease. ${ }^{29}$ Studies on the reproducibility ${ }^{30}$ and the validity of the AB-Ratio using a pocket-Doppler device have also been carried out. A study on the long-term prognosis of peripheral vascular disease is currently in preparation. 
Table 1. Estimated prevalence of peripheral vascular disease, standardised for age, in different types of study

\begin{tabular}{|c|c|c|}
\hline Type of study & Description of cases & $\begin{array}{l}\text { Prevalence (per thousand) } \\
\min -\max ^{\mathrm{a}}\end{array}$ \\
\hline
\end{tabular}

\begin{tabular}{|c|c|c|}
\hline \multirow[t]{2}{*}{$\begin{array}{l}\text { Marbidity registration in } \\
\text { general practice }\end{array}$} & $\begin{array}{l}\text { Intermittent claudication not } \\
\text { following strict Rose criteria } \\
\text { presented to the general }\end{array}$ & \\
\hline & practitioner & $2-8$ \\
\hline \multirow{3}{*}{$\begin{array}{l}\text { Population studies using } \\
\text { the Rose questionnaire }\end{array}$} & $\begin{array}{l}\text { Intermittent claudication } \\
\text { following }\end{array}$ & \\
\hline & strict Rose criteria & $4-12$ \\
\hline & less strict criteria & $19-25$ \\
\hline $\begin{array}{l}\text { Population study using } \\
\text { non-invasive techniques }\end{array}$ & $\begin{array}{l}\text { Symptomatic and asymptomatic } \\
\text { pertpheral vascular disease }\end{array}$ & 27 \\
\hline
\end{tabular}

\section{Comparison of Prevalences in Different Studies}

The prevalence figures from different studies cannot be compared directly. In order to make an adequate comparison we estimated minimum and maximum age-standarclised prevalence figures by adding data from different studies for different age categories. The results of this "educated guess" is presented in table 9.1 In table 9.2 a similar comparison is presented on empirical data from the "Limburg Peripheral Arterial Occlusive Disease (PAOD) Study".

Table 9.3 shows the prevalence of peripheral vascular disease in the elderly according to the different types of study mentioned above. In Table 9.4 results from our own research are presented.

Table 9.1 shows a difference between the number of symptomatic patients in the population and the number of symptomatic patients who visited their general practitioner ("tip of the iceberg"). This suggests that there is a group of patients suffering from intermittent claudication which the general practitioner is not aware of. This is in accordance with data from an English population study which was conducted in two general practices: only half of the people with intermittent claudication had consulted a doctor for their complaints. ${ }^{12}$ In a review by Dormandy et al. 1 it was suggested that probably only half of the patients with intermittent claudication are known as such to a doctor. Table 9.2 shows that in our study, in which patients did not come spontaneously to the office of their general practitioner but were invited by him to take part in the study, approxi- 
Table 2. Estimated prevalence of peripheral vascular disease, standardised for age, using different criteria in the Limburg peripheral arterial occlusive disease (PAOD) study

\begin{tabular}{lll}
\hline Variable & Inclusion criterion & Prevalence (per thousand) \\
\hline $\begin{array}{l}\text { Intermittent claudication } \\
\text { "Rose" }\end{array}$ & $\begin{array}{l}\text { Strict criteria of Rose } \\
\text { questionnaire }\end{array}$ & 5 \\
$\begin{array}{l}\text { according to general } \\
\text { practitioner }\end{array}$ & $\begin{array}{l}\text { Diagnosed during research } \\
\text { project } \\
\text { all cases } \\
\text { new cases } \\
\text { Ankle-brachial ratio }<0.95\end{array}$ & $\begin{array}{l}2-3 \\
\text { Peripheral Vascular }\end{array}$ \\
\hline
\end{tabular}

aStandardised to the age distribution of the Dutch population 1 January 1989. The prevaltence for the age category " $<45$ years" was considered to be zero and for the age category " $>75$ years" was extrapolated linearly from previous age categories.

mately one-third of all patients who had been diagnosed by their general practitioner as a case of intermittent claudication, were "new" cases (2-3/8).

Tables 9.1 and 9.2 also show a large difference between the number of cases with symptomatic peripheral vascular disease, i.e. intermittent claudication diagnosed by general practitioners or intermittent claudication according to the Rose questionnaire, and the number of cases with "objective" peripheral vascular disease, i.e. based on the results of non-invasive tests. "The same difference can be observed in Tables 9.3 and 9.4. Many patients with "objective" peripheral vascular disease are not known as such to the general practitioner. Among these hidden patients there will be symptomatic and asymptomatic (or atypical) cases, and Table 9.4 suggests that the difference between "objective" and symptomatic patients is larger among females than among males.

\section{Questions for Further Study}

Some questions arise. What is the relevance of asymptomatic disease? If longitudinal studies confirm the suggestion that asymptomatic peripheral vascular disease is a risk factor for coronary artery disease or cerebrovascular disease 31 , or if it is demonstrated which asymptomatic patients eventually become symptomatic, it will be important to identify these patients in order to take preventive measures. Then a pocket Doppler device could become an important instrument in general practice.

Another question is whether the Rose questionnaire for intermittent claudication adequately describes the spectrum of peripheral vascular disease relevant to general practitioners. Maybe the "asymptomatic" stage does have 
Table 3. Prevalence of peripheral vascular disease among the elderly in different types of study

\begin{tabular}{|c|c|c|c|c|c|c|}
\hline \multirow[t]{2}{*}{ Reference } & \multirow[t]{2}{*}{ Method } & \multirow[t]{2}{*}{ Sex } & \multicolumn{4}{|c|}{ Prevalence (\%) } \\
\hline & & & $65-6$ & & $70-74 \mathrm{yr}$ & $75+\mathrm{yr}$ \\
\hline \multirow[t]{3}{*}{ Hoogen et al. 1985} & \multirow{3}{*}{$\begin{array}{l}\text { General practice } \\
\text { morbidity registration }\end{array}$} & Male & & 5.4 & & 9.6 \\
\hline & & Female & & 1.5 & & 3.6 \\
\hline & & Total & & 3.2 & & 5.9 \\
\hline \multirow[t]{3}{*}{ Evans 1988} & \multirow{3}{*}{$\begin{array}{l}\text { Population study, } \\
\text { Rose criteria }\end{array}$} & Male & 4.9 & & 5.6 & 9.6 \\
\hline & & Female & 3.6 & & 4.7 & 2.8 \\
\hline & & Total & 4.2 & & 5.1 & 5.5 \\
\hline \multirow[t]{2}{*}{ Criquil et al. $\mathbb{1 9 8 5}$} & \multirow{2}{*}{$\begin{array}{l}\text { Population study, } \\
\text { non-invasive tests }\end{array}$} & Male & 12 & & 19 & 23 \\
\hline & & Female & 12 & & 12.5 & 21.5 \\
\hline
\end{tabular}

Table 4. Prevalence of peripheral vascular disease in different age categories, using different criteria in the Limburg peripheral arterial occlusive disease (PAOD) study ${ }^{\text {a }}$

\begin{tabular}{llllll}
\hline \multirow{2}{*}{ Criterion } & Sex & \multicolumn{2}{l}{ Prevalence } \\
\cline { 3 - 4 } & & $45 \leq 55 \mathrm{yr}$. & $55 \leq 65 \mathrm{yr}$. & $65 \leq 75 \mathrm{yr}$. & All \\
\hline Intermittent claudication & Male & 0.6 & 2.5 & 8.8 & 3.0 \\
according to & Female & 0.6 & 1.6 & - & 0.8 \\
General practitioner & Total & 0.6 & 2.0 & 3.4 & $1.8^{\mathrm{c}}$ \\
Intermittent claudication & Male & 0.7 & 3.0 & 5.0 & 2.5 \\
'Rose' & Female & 0.7 & 0.5 & - & 0.4 \\
\multirow{3}{*}{ AB-Ratio $<0.955^{\text {b }}$} & Total & 0.7 & 1.6 & 2.0 & 1.4 \\
& Male & 0.6 & 6.2 & 18.8 & 6.7 \\
& Female & 4.5 & 5.6 & 6.9 & 5.6 \\
& Total & 2.7 & 6.0 & 11.6 & 6.1 \\
\hline
\end{tabular}

"Calculated for the study base population: age $45 \leq 75$ yr." males $=8926$, females $=9958$. b AB-Ratio: Ankle-brachial systolic pressure ratio using a pocket Doppler device. ${ }^{C}$ New cases: $0.5 \%$.

certain symptoms after all and maybe there are less typical complaints which can be associated with peripheral vascular disease.

Data on the prevalence of peripheral vascular disease among females do not yield uniform conclusions. Does peripheral vascular disease present in a less typical way in females? Is the course of the disease in females more benign?

Cross-sectional and longitudinal research is necessary to answer these and other questions regarding diagnosis, prognosis and treatment of peripheral vascular disease. 


\section{Acknowledgements}

The "Limburg PAOD Study" is funded by the "Nederlandse Organisatie woor Wetenschappelijk Onderzoek" (900-715.154) and the "Praeventiefonds" (281323). Doppler devices were financed by DAGRA-Pharma B.V.

\section{References}

1. Dormandy J, Mahir M, Ascady $G$ et al. Fate of the patient with chronic leg ischaemia. I Cardiovasc Surg 1989;30:50-7.

2. Lammi UK, Kivelä SL, Nissinen A, Punsar S, Puska P, Karvonen M. Predictors of dísability in elderly Finnish men - a longitudinal study. J Clin Epidemiol 1989;42:1215-25.

3. Jonason T, Ringqvist I. Factors of prognostic importance for subsequent rest pain in patients with intermittent claudication. Acta Med Sicand 1985;218:27-33.

4. Rosenbloom MS, Flanigan DP, Schuler IJ et al. Risk factors affecting the natural history of intermittent claudication. Arch Surg 1988;123:867-70.

5. Jelnes $R$, Gaardsting $O$, Hougaard Jensen $\mathbb{K}$, Baekgaard $N$, Tonnessen $\mathbb{K H}$, Schroeder T. Fate in intermittent claudication: outcome and risk factors. Br Med J 1986;293:1137-40.

6. Naschitz JE, Ambrosio DA, Chang JB. Intermittent claudication: predictors and outcome.Angiology 1988;39:16-21.

7. Housley E. Treating claudication in five words. Br Med J 1988;296:1483-4.

8. van Vroonboven TJ. Juist ook voor patiënten met claudicatio intermittens geldt: de een is de ander niet. Ned Tijdschr Geneeskd 1986;130:1345-8.

9. Blomberry PA. Intermittent claudication. An update on management. Drugs 1987;34: 404-10.

10. Reunanen A, Takkunen H, Aromaa A. Prevalence of intermittent claudication and its effect on mortality. Acta Med Scand 1982;21 1:249-56.

11. Dormandy IA, Mahir MS. The natural history of peripheral atheromatous disease of legs [congress-paper]. Department of vascular surgery, St James' and St George's Hospitals, London.

12. Hughson $\mathrm{VM}$ Mann $\mathrm{II}_{*}$ Garrod A. Intermittent claudication: prevalence and risk factors. Br Med J 1987;294:1379-81.

13. Müller-Bühl U, Diehm $C$, Sieben U et al. Prảvalenz und Risikofaktoren von peripher arterielier Verschlusskrankheit und koronarer Herzkrankheit. Vasa 1987;21 (Suppl): $1-46$.

14. Allardice JT, Allwright GJ, Wafula JMC, Wyatt AP. The prevalence of abdominal aortic aneurysm in men with peripheral vascular disease. Screening by ultrasonography. Br I Surg 1988:75:140-2.

15. Bengtsson $H$, Ekberg $O_{v}$ Aspelin $P$, Källerö $S$, Bergqvist D. Ultrasound screening of the abdominal aorta in patients with intermittent claudication. Eur J Vasc Surg 1989;3:497-502.

16. Collin J, Walton J, Araujo L, Lindsell D. Oxford screening programm for abdominal aortic aneurysm in men aged 65-74 years. Lancet 1988:613-15. 
17. Lamberts H. Morbidity in general practice. Diagnosis-related information from the Monitoring Project. 1984; Huisartsenpers, Utrecht.

18. Hoogen HJM van den, Huygen EJA, Schellekens WWG, Straat JM, Van der Velden HGM. Morbidity figures from general practice. Data from four general practices 1978-1982. Dept. of General Practice, University of Nijmegen, Nijmegen

19. Lamberts H. Transition Project. 1987; Dept. of General Practice, University of Amsterdam Amsterdam.

20. Rose GA, Blackburn H, Gülum RF, Prineas RI. Cardiovascular survey methods, 2nd edn. 1982 World Health Organization, Geneva.

21. Criqui MH, Fronek A, Barret-Connor E, Klauber MR, Gabriel $S_{s}$ Goodman D. The prevalence of peripheral arterial disease in a defined population. Circulation 1985; 71:510-15.

22. Hale WE, Marks RG, May EE, Moore MT, Stewart RB. Epidemiology of intermittent claudication: evaluation of risk factors. Age Ageing 1988;17:57-60.

23. Evans JG. Intermittent claudication. Age Ageing 1988;17:139.

24. Schroll M, Munck $O$. Estimation of peripheral arteriosclerotic disease by ankle blood pressure measurements in a population of 60 -year-old men and women. I Chron Dis $1981 ; 34: 261-9$.

25. Cammer Paris BE, Libow LS, Halperin JL, Mulvihill MN. The prevalence and one-year outcome of limb arterial obstructive disease in a nursing home population. I Am Geriatr Soc $1988 ; 36: 607-12$.

26. Hiatt WR, Marshall WA, Baxter I et al. Diagnostic methods for peripheral arterial disease in the San Luis Valley Diabetes Study. J Clin Epidemiol 1990;43:597-606.

27. Newman AB, Sutton-Tyreli K, Rutan GH, Locher J, Kuiller LH. Lower extremity arterial disease in elderly subjects with systalic hypertension.J Chron Epidemiol 1991;44:15-20.

28. Stoffers HEJH, Kaiser $V_{*}$ Lemmens TGJ, Knotmerus JA Perifeer arterieel obstructief vaatlijden in de huisartspraktijk: een verborgen ziektebeeld? [Peripheral arteriall occlusive vasculopathy in general practice: a hidden disease?] Huisarts Wet 1988;31:202-6. \|summary in English

29. Kaiser V, Stoffers HEJH. Peripheral arterial obstructive disease in general practice: diagnosis, natural history and intervention. Algemein Medizin 1988; 17: Heft 1, S3 (Abstract).

30. Stoffers HEJH, Kaiser V, Kester ADM, Schouten HA, Knotmerus JA. Peripheral arterial occlusive disease in general practice: the reproducibility of the ankle-arm systolic pressure ratio. Scand I Prim Health Care 1991;9:109-14.

31. Widmer LK, Biland L, Defley A, Da Silva A. Zum Stellenwert der peripherer arteriellen Verschlusskrankheit in der Praxis. Schweiz Med Wochenschr 1983;113:1924-7. 
$3 \mid \begin{aligned} & \text { Risk management of patients with } \\ & \text { peripheral arterial vascular disease }\end{aligned}$

Kaiser $\mathrm{V}$, Wollersheim $\mathrm{H}$

published: Kaiser V, Wollersheim H. Conservatieve behandeling van claudicatio intermittens, Hartbulletin 1997; 28:199-203 


\section{Introduction}

In the treatment of heart and vascular diseases, a lot of attention is focused on reducing risk. Risk factors which can be influenced are: smoking, diabetes mellitus, hypertension, hypercholesterolemia and overweight. Risk factors which camnot be infuenced are: male sex, ageing and family predisposition. The most important risk factors for peripheral arterial vascular disease are smoking and diabetes mellitus.

Risk factors seldom occur singly. However, most large studies focus on the effect of risk reduction by looking at a single risk fackor. This ignores the fact that a number of risk factors usually occur together. ${ }^{1}$

\section{Smoking}

Smoking is the biggest risk factor for the development of intermittent claudication, worsening of the condition and the occurrence of complications. Most studies on how smoking and stopping smoking affect the course of peripheral vascular disease are observational studies. ${ }^{23} 75-90 \%$ of patients with demonstrated peripheral vascular disease are or have been smokers.

The ankle-brachial index in patients continuing to smoke drops in comparison with patients who do not smoke or have stopped; in the last group the anklebrachial index remains constant. 45 The number of re-occlusions after peripheral bypass operations is 3-4 times as high among smokers as among non-smokers or patients who have stopped smoking. 67

In a prospective study, an improvement in walking distance was observed in $85 \%$ of patients who stopped smoking compared with $20 \%$ among those who did not stop. There was a clear increase in the distance walked before symptoms arose for $40 \%$ of those who stopped smoking, compared with no increase among those continuing to smoke. Smokers (patients who continued to smoke) were significantly more likely to experience a worsening of symptoms, particularly rest pain, and to require amputation, than non-smokers. This also applied to patients who had stopped smoking. 4

Stopping smoking also had a beneficial effect on morbidity and death rates as a result of other cardiovascular disorders. 8

The life expectancy of smokers is on average $8-10$ years less than that of non-smokers. ${ }^{1011}$ people with peripheral vascular disease are 2-3 times as likely as the rest of the population to die of a coronary disease within five years. Stopping smoking cuts this risk by half. 11

The number of patients with peripheral vascular disease who actually do stop smoking is low: in a study of 340 patients with claudication, only $11 \%$ had stopped smoking after a year. ${ }^{12}$ This was in contrast to patients with a myocardial infarc- 
tion, of whom around $50 \%$ stopped permanently and achieved a clear reduction of $40 \%$ in their risk of premature death. 13

The effectiveness of strategies for giving up smoking is disappointing. "The numbers stopping varies from $5 \%$ an being advised once, to $26 \%$ among patients following an intensive support programme as well as using nicotine patches. In general practices, the maximum number stopping is around $18 \%$. The added effect of nicotine patches or chewing gum is limited to the first three months. After one year there is no relevant difference between the numbers of users and non-users managing to stop smoking. ${ }^{14}$

A meta-analysis of a large number of studies looking at the effect of advice to give up smoking showed that the best way to motivate patients to give up smoking is to keep repeating the message of what can be achieved by giving up smoking, in personal conversations with the treating doctor (consultations) and explaining the possible consequences of not giving up smoking. ${ }^{12}$

\section{Hypertension}

Hypertension considerably increases the risk of peripheral vascular disease. ${ }^{10}$ 15-18 Every $5 \mathrm{~mm}$ Hg increase in blood pressure doubles the risk of developing intermittent claudication. ${ }^{19}$ Treating hypertension reduces the incidence of cerebrovascular accidents and, to a lesser extent, of less commonly occurring coronary diseases. ${ }^{20}$ Non-pharmacological treatment of hypertension according to the CBO consensus (currently being reviewed, expected at the end of 1997) and the NHG standard is an integral part of risk reduction: stopping smoking, regular exercise, reducing body weight, low-calorie diet, reducing salt intake. ${ }^{21}$ The preventive effect of reducing blood pressure, for claudication and blood flow in the leg, has only been shown directly in one study. ${ }^{22}$

The literature on the treatment of hypertension in patients with peripheral vascular disease is mostly limited to the effectiveness of drugs and their side effects. Most attention is focused on beta-blockers. These drugs have scarcely any effect on the symptoms, or on walking distance. However, patients do report being disturbed by cold feet, as is often the case with beta-blockers. $23-29$

Other antihypertensives should be considered for patients presenting with hypertension for the first time. Comparative studies have not convincingly demonstrated the theoretical advantages of calcium antagonists and ACE inhibitors compared with beta-blockers. There are also insufficient arguments for stopping the use of a beta-blocker or calcium antagonist where blood pressure is well regulated and the claudication is stable. ${ }^{30-34}$ The high prevalence of renal artery stenosis among patients with intermittent claudication means that ACE inhibitors are not the first choice except where there is also diabetes. ${ }^{35}$ Diuretics and then ACE inhibitors seem to be the drugs indicated for treatment of hypertension in patients with intermittent claudication. The choice of antihypertensive is partly 
determined by the presence of co-morbidity Idiabetes mellitus, chronic nonspecific respiratory disease, gout), ${ }^{21}$

\section{Diabetes Mellitus}

Intensive treatment and support of patients with type I diabetes mellitus (insulin-dependent) results in a reduction in mainly microvascular complications. One can probably extrapolate from this to patients with diabetes mellitus type II. The effects of good control on the course of macrovascular complications were less clear. ${ }^{36}$

\section{Hypercholesterolemia}

Patients with high cholesterol levels (above $6.5 \mathrm{mmol} / \mathrm{l}$ ) are twice as likely as patients with low cholesterol levels to develop intermittent claudication. Hughson found no significant difference in cholesterol walues between patients with and without intermittent claudication, although the first group did have significantly higher triglyceride levels. ${ }^{37}$

The many studies on cholesterol reduction have focused mainly on cardiac and cerebral vascular disease. ${ }^{38-40}$ Only a few studies have addressed the effects of cholesterol reduction on the progression of peripheral vascular disease. The effects on clinical parameters of intermittent claudication were small. ${ }^{41-43}$

The introduction of HMG-CoA reductase inhibitors (statins) has allowed a more effective reduction in cholesterol concentration. So far, the effect on the progression of peripheral vascular disease appears to be minor. However an extreme reduction in cholesterol concentration does result in regression of atherosclerosis. ${ }^{44}$

\section{Being overweight}

Being overweight is a significantly less important risk factor for peripheral vascular disease than for coronary or cerebral vascular disease.

The effect of being overweight on claudication is difficult to assess because factors affecting weight, such as diet and exercise, also affect peripheral vascular disease directly. Theoretically, excess weight limits walking distance. One study looked at this effect by 'adding' extra weights to the patients in the study. Each added kilogram reduced the distance walked at which symptoms arose by around 10 metres.

Weight control by a calorie-controlled diet and encouraging exercise should form part of the secondary prevention of vascular disease. ${ }^{45}$ 


\section{Homocysteinemia}

For patients with early atherosclerotic vascular disease (under 50 years), one should be prepared for raised plasma concentration of homocysteme as a risk factor. ${ }^{46}$ Administering folic acid also appears to reduce the risk for patients with heterozygous homocysteinemia. It is not yet clear whether homocysteinemia should be actively checked for. 47

\section{References}

1. Smit AJ. Combined cardiovascular risk intervention: a bridge between primary and secondary prevention? Neth J Med 1996:48:125-7.

2. Kannel WB, McGee DL. Update on some epidemiological features of intermittent claudication: the Framingham study. J Am Geriatr Soc 1985;33:13-18.

3. Jonason $T$, Bergstrom $R$. Cessation of smoking in patients with intermittent claudication. Effects on the risk of peripheral vascular complications, myocardial infarction and mortality. Acta Med Scand 1987;221:253-60.

4. Cole CW, Hill GB, Farzad E, Bouchard A, Moher D, Rody K, et al Cigarette smoking and peripheral arterial occlusive disease. Surgery 1993;114:753-6.

5. Quick CR, Cotton LT. The measured effect of stopping smoking on intermittent claudication. Br I Surg 1982; 69(suppl): S24-6.

6. Ameli FM, Stein CM, Aro L, Provan JL, Prosser R. The effect of postoperative smoking on femoropopliteal bypass grafts. Ann Vasc Surg 1989;3:20-5.

7. Myers KA, King RB, Scott DF, Johnson N, Morris PI. The effect of smoking on the late patency of arterial reconstructions in the legs. Br J Surg 1978;65:267-71.

8. Blomberry PA. Intermittent claudication. An update on management. Drugs 1987;34: 404-10.

9. Birkenstock WE, Louw $\mathrm{JH}$, Terblanche J, Inmelman EJ, Dent DM, Baker PM. Smoking and other factors affecting the conservative management of peripheral vascular disease. SA Mediese Tydskrif 1975;11:29-32.

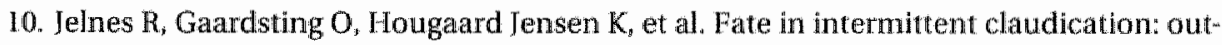
come and risk factors. BMJ 1986;293:1137 41 .

11. Cavender IB, Rogers WJ, Fischer LD, Gersh BJ, Coggin CJ, Myers WO. Effects of smoking on survival and morbidity in patients randomized to medical or surgical therapy in the Coronary Artery Study (CAS); 10 year follow-up. J Am Coll Cardiol 1992;20:287-92.

12. Kottke TE, Battista RN, Defriese GH, Brekke ML. Attributes of successful smoking cessation interventions in medical practice. A meta-analysis of 39 controlled trials. JAMA $1988 ; 259: 2883-9$.

13. Deckers JW. Agema WRP. Effecten van stoppen met roken van sigaretten bij patiênten met coronairlijden. Hart Bulletin 1994;25:3-8.

14. Pieterse ME, Boekema AG, Mudde NA, et al. Stoppen met roken via de huisartspraktijk. Huisarts Wet 1992;35:338-41. 
15. Kannel WB, MCGee DL. Update on some epidemiological features of intermittent claudication: the Framingham study. I Am Geriatr Soc 1985;33:13-18.

16. Hughson WG, Mann JI, Tibbs DI, Woods HP, Walton I. Intermittent claudication: factors detemining outcome. BMJ 1978:1:1377-9.

17. Lassila $\mathrm{R}$, Lepäntalo $\mathrm{M}$, Lindfors $\mathrm{O}$. Peripheral arterial disease-natural outcome. Acta Med Scand 1986;220:295-301.

18. Rosenbloom MS, Preston Flanigan D, Schuler J], Meyer JP, Durham JR, EldrupJorgensen J, et al. Risk factors affecting the natural history of intermittent claudication. Arch Surg 1988;123;867-70.

19. Dagenais GR, Maurice S, Robitaille NM, Gingras S, Lupien PJ. Intermittent claudication in Quebec men from 1974-1986: the Quebec Cardiovascular Study. Clin Invest Med 1991;14:93-100.

20. Collins R, Peto R, MacMahon S, et al. Blood pressure, stroke and coronary heart disease. Short-term reductions in blood pressure: overview of randomised drug trialls in their epiclemiologicall context. Lancet 1990;335:827-38.

21. Nederlands Huisartsen Genootschap. Standaard Hypertensie. Huisarts Wet 1991;34: 389.

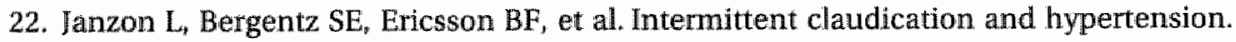
Ankle pressure and walking distance in patients with well-treated and non-treated hypertension. Angiology 1981;32:175-9.

23. Hiatt WR, Stoll S, Nies AS. Effect of $\beta$-adrenergic blockers on the peripheral circulation in patients with peripheral vascular disease. Circulation 1985;72:1226-31.

24. Lepäntalo $M$, von Knorring J. Walking capacity of patients with intermittent cllaudication during chronic antihypertensive treatment with metoprolol and methyldopa. Clin Physiol. 1984;4:275-82.

25. Lepäntalo M, Aromaa A, Klaukka T, Lukkari E. Does beta-blockade provoke intermittent claudication? Acta Med Scand 1985;218:35-9.

26. Svendsen TL, Jelnes $R$, Tonessen $K H$. The effects of acebutolol and metoprolol on walking distances and distal blood pressure in hypertensive patients with intermittent claudication. Acta Med Scand 1986;219:161-5.

27. Bostrom PA, Janzon L, Ohlsson O, Westergren A. The effect of $\beta$-blockade on leg blood flow in hypertensive patients with intermittent claudication. Angiology 1986;37:149-53.

28. Bogaert MG, Clement DL. Lack of influence of propranolol and metoprolol on walking distance in patients with chronic intermittent claudication. Eur Heart J 1983;4:203-4.

29. Lenders JWM, Thieu $\mathrm{T}$. Koude handen en voeten tijdens behandeling van hypertensie met beta-blokkerende middelen. Ned Tijdschr Geneeskd 1984;128:2318-21.

30. Roberts DH, Tsao Y, McLoughlin GA, Breckenridge A. Placebo-controlled comparison of captopril, atenolol, labetolol and pindolol in hypertension complicated by intermittent claudication. Lancet 1987:337:650-53.

31. Solomon SA, Ramsay LE, Yeo WW, et all B Blockade and intermittent claudication: placebo controlled trial of atenolol and nifedipine and their combination. BMJ 1991;303: 1100-4. 
32. Olin JW. Antihypertensive treatment in patients with peripheral vascular disease. Cleve Clin J Med 1994;61:337-44.

33. Ven LL van de, Van Leeuwen JT, Smit Al. The influence of chronic treatment with betablockade and angiotensin converting enzyme inhibition on the peripheral blood flow in hypertensive patients with and without concomittant intermittent claudication. A comparative cross-over trial. Vasa 1994;23:357-62.

34. Roberts DH, Tsao $Y_{\text {, Linge } K}$, McLoughlin GA, Breckenridge A. Double-blind comparyson of captopril with nifedipine in hypertension complicated by intermittent claudication. Angiology 1992;43:748-56.

35. Choudhri AH, Cleland JGF, Rowlands $\mathrm{PC}_{n}$ et al. Unsuspected renal artery stenosis in peripheral vascular disease. BMJ 1990;301:1 197-8.

36. The diabetes control and complications trial research group. The effect of intensive treatment of diabetes on the development and progression of long-term complications in insulin dependent diabetes mellitus. N Engl J Med 1993;329:977-86.

37. Hughson WG, Mann JI, Garrod A. Intermittent claudication: prevalence and risk factors. BMI 1978;1:1379-81.

38. Rossouw JE, Lewis B, Rifkind BM. The value of lowering cholesterol after myocardial infarction. N Engl I Med 1990;323:1112-9.

39. Scandinavian Simvastatin Survival Study Group. Randomised trial of cholesterol lowering in 4444 patients with coronary heart disease: the 4 S study. Lancet $1994 ; 344: 1383-9$.

40. Levine GN, Keaney Jr JF, Vita JA. Cholesterol reduction in cardiovascular disease. Clinical benefits and possible mechanisms. N Eng J Med 1995;332:512-21.

41. Groot E de, Jukema JW, Boven AJ van, Reiber JH. Zwinderman AH, Lie KI, et al. Effect of pravastin on progression and regression of coronary atherosclerosis and vessel wall changes in carotid and femoral arteries; a report from the Regression Growth Evaluation Statin Study. Am I Cardiol 1995;76:40C-46C.

42. Salonen R, et al. Kuopi Atherosclerosis Prevention Study (KAPS). A population-based primary preventive trial of the effect of LDL lowering on atherosclerotic progression in carotid and femoral arteries. Circulation 1995;92:1758-64.

43. Pastlewaite JC, Dormandy JA. Results of ankle systolic pressure measurements in pa* tients with intermittent claudication being treated with ciofibrate. Am Surg 1975;181: 799-802.

44. Kroon AA, Asten WNIC van, Stalenhoef AFH. The effect of LDL-apheresis on peripheral vascular disease in hypercholesterolemic patients with coronary artery disease. Ann Intern Med 1996;125:945-54.

45. Wyatt MG, Scotte PMJ, Scott DJA, Poskitt K, Baird RN, and Horrocks M. Effect of weight on claudication distance. Br J Surg 1991;78:1386-8.

46. Mölgaard J, Malinow MR, Lassvik C, Holm AC, Upson B, Olsson AG. Hyperhomocyst(e)inaemia: an independent risk factor for intermittent claudication. I Int Med 1992;231: 273-9.

47. Boushley C], Beresford SAA, Omenn GS, Motulski AG. A quantitative assessment of plasma homocysteine as a risk factor for vascular disease. probable benefits of increasing folic acid intakes. JAMA 1995;274:1049-57. 



\section{$4 \mid$ Drug treatment of peripheral arterial vascular disease}

Kaiser $\mathrm{V}$, Wollersheim $\mathrm{H}$

published: Kaiser $V$, Wollersheim $H$. Conservatieve behandeling van claudicatio intermittens, Hartbulletin 1997; 28:199-203 


\section{Introduction}

Various drugs are used to treat intermittent claudication. This chapter discusses the factors affecting the choice of remedy, the physiology of the peripheral arterial circulation and the advantages and disadvantages of vasodilators and rheolagical remedies.

Since claudication takes a different course with each patient, conservative measures such as walking training and giving up smoking are effective and a considerable placebo effect is involved, it is difficult to ascertain the efficacy of drug treatments with any clarity.

\section{Methods}

Medline was searched for articles dating from after 1965 with the key words: claudication and lower limb ischemia in combination with pharmacotherapy, drug (treatment) or randomised trial. This resulted in reports of 236 studies, of which 52 were placebo controlled and were assessed for this chapter.

The studies selected were limited to those with at least 50 patients, at least a three-month follow-up, randomisation according to Fontaine category and other measures, and which took as their primary measure of outcome the subjective effect on walking distance or the measured pain-free or maximum achievable walking distance, assuming a certain walking speed.

\section{Outcome measures}

A problem with measuring walking distance using a treadmill is the lack of agreement on standardisation of walking speed and gradient. Walking distance as described subjectively is presumably the most clinically relevant measure, as it gives an indication of the degree of disability.

There is room for doubt as to the clinical relevance of some results. An improvement of walking distance to $1 \mathrm{~km}$ or more, or a doubling of the walking distance, may be seen as clinically relevant. Patient selection, selective observation (researcher bias) or a faulty methodological design play a role here. ${ }^{12}$ Besides the therapeutic effect, side effects, costs and the burden on the patient must also be weighed up.

Blood flow in tissue is determined by vascular diameter and to a lesser degree by rheological characteristics (viscosity) and the local perfusion pressure. Bllood viscosity is determined by the number of erythrocytes and a number of substances dissolved in the plasma (triglyceride, fibrinogen). In the capillaries, the plasticity of the erythrocytes plays an important role due to the cells' large size relative to the capillary. Blood flow is influenced locally by vasoactive factors, muscular activity, 
hypoxia, hypercapnia and infections. The most important local factors are nitrogen oxide from the endothelium ('endothelial derived relaxing factor'), endothelin, prostaglandins and thromboxane, derived from thrombocytes.

Vascular diameter can be reduced in the short term by vasoconstriction (smooth muscle cell activity) and thrombosis. Vascular tonus is primarily influenced by the sympathetic nervous system, which develops its effect by $\alpha_{1}, \alpha_{2}$ (arteriole constriction, particularly in the skin and splanchnic area) and $\beta_{2}$ adrenoreceptors (arteriole dilation, particularly in the striated skeletal muscles, heart and brains) in the vascular wall.

In the long term, vascular diameter is primarily reduced by atherosclerosis, the process of atherome formation with later sclerosis. Subintimal cholesterol influx resulting in "fatty streaks" appears to be the initial process. Fatty streaks consist of oxidised 'low density lipoproteins' which are found in macrophages which are transformed into 'foam cells'. The endothelium above these foam cells then secretes less vasodilator and anti-thrombotic substances. Growth factors are secreted under the foam cells, and these cause the migration and proliferation of smooth muscle cells and fibroblasts with increased collagen production. This fibrous cap bulges out into the lumen. Where there is vigorous growth or bleeding, fissures appear on the surface with thrombus formation.

\section{Results}

Symptoms resulting from a fixed arterial obstruction are difficult to treat with drugs, $^{3}$ so that a three-month trial treatment can only be given when exercise training and giving up smoking have failed to bring results.

The drugs used to improve peripheral blood flow impairment can be divided into two groups according to how they function: vasodilators and rheological drugs.

\section{Vasodilators}

In theory it is difficult to understand how vascular walls already pathologically altered and therefore stiffer, can still react to vasodilatory stimuli. Vasodilators can also fail if they have more effect on healthy vascular tissue than on the pathological, fixed part with maximal vasodilatation already present behind it caused by hypoxia. The drug"s effect then goes to the healthy tissue, so that blood is withdrawn from the ischemic area. This is known as the 'steal effect', although it has never been demonstrated convincingly. Nor has anyone shown the improvement it is claimed vasodilators can effect by stimulating the formation of collaterals. In fact, vasodilators are often ineffective with atherosclerotic narrowing, and may even be contra-indicated. ${ }^{45}$ 
Furthermore, vasodilators often produce side effects, such as orthostatic dizziness, flushing, throbbing headaches, oedema of the ankles and palpitations. In the long term, the reflex tachycardia observed primarily with vasodilators with a short half-life, probably has an adverse effect on the heart. ${ }^{67}$

In conclusion, vasodilators should be used conservatively and limited to circutlation disorders involving a clear spastic component. ${ }^{4}$

The various different vasodilators can be divided into sympatholytics, calcium antagonists, non-specific vasodilators and prostacyclin analogues.

\section{Sympatholytics}

Sympatholytics such as alpha-blockers (e.g. prazosin) on their own or combined witth drugs with other characteristics (such as isoxsuprine). Prazosin blocks $\alpha_{1}$ and probably $\alpha_{2}$ receptors, which results in vasodilatation particularly in the skin. Isoxsuprine not only blocks $\alpha$ receptors; it also has a stimulating effect on $\beta_{2}$ receptors, producing slight vasodilatation. Sympatholytics have not been subjected to controlled trials in patients with intermittent claudication, and therefore should not be prescribed.

\section{Non-specific vasodilators}

Nicotinic acid derivatives such as nicotinyl alcohol and xanthinol nicotinate are converted into nicotinic acid once resorbed. This produces vasodilatation in the blood vessels in the skin of the upper body (face, neck, arms and muscle vessels) by stimulating prostacyclin synthesis, inhibiting platelet aggregation and by a fibrinolytic effect. Nicotinic acid lowers the plasma concentration of triglycerides and cholesterol. Cyclandelate is thought to have a direct effect similar to papaverine on the smooth muscle tissue of the vascular wall. Side effects are transient flushing of the face and neck when taken before a meal, with other signs of vasodilatation and sometimes nausea, diarrhoea, tingling, itching and skin rashes. There have been no double-blind placebo controlled studies demonstrating a convincing effect of these non-specific vasodilators on walking distance in claudication. ${ }^{45}$

\section{Calcium antagonists}

Calcium antagonists may be divided into three groups based on their chemical structure: dihydropyridines (e.g. amlodipine and nifedipine), benzothiazepines (diltiazem) and phenylalkylamines (verapamill). Of these drugs, dihydropyridines are the most effective vasodilators; they inhibit the slow influx of calcium ions through the cell membranes of smooth muscie cells in the walls of coronary and peripheral arteries, so that vasoconstriction is reduced and blood flow is increased. No controlled study has shown that this vasodilatation has a beneficial 
effect on claudication " probably because the improved blood flow occurs primarily in the skin and not the muscles. The effect of calcium antagonists on patients with claudication and hypertension will not be discussed here. Extensive controlled research is now being carried out into the possible anti-atherogenic properties of dihydropyridines. 8

The side effects of vasodilatation appear mainly at the beginning of treatment, in particular palpitations and serious angina pectoris (caused by a 'steal' effect).

\section{Prostacyclin analogues}

Iloprost is currently only administered in hospital or in out-patient care with simultaneous observation of blood pressure. The observed pharmacological effects are: dilation of arterioles and venules, inhibition of thrombocyte aggregation, raised capillary density, reduction in increased capillary permeability, activation of fibrinolysis, inhibition of adhesion and migration of mononuclear blood cells to endothelial lesions and a reduction in the release of free oxygen radicals. The elimination half-life is 30 minutes. The vasodilatory effect is very varied and sometimes short-lived. The effect on thrombocyte function is possibly longer lasting.

A large-scale double-blind controlled study showed a beneficial effect of iloprost on patients with thromboangiitis obliterans (Buerger's disease) and serious ischemia in the extremities for whom reconstructive vascular surgery was not indicated. ${ }^{9}$ Iloprost was shown in six controlled studies to be effective in Fontaine stages III and IV. ${ }^{10}$ Unfortunately, these studies used fairly weak end points (pain, ulcer healing). In a placebo controlled parallel study, four weeks of iloprost administered intravenously resulted in significantly better ulcer healing (23 versus 62\%) and pain reduction in 109 diabetes patients (mostly non-insulin dependent). ${ }^{11}$ The results of other double-blind placebo controlled studies, mostly on non-diabetics, are less convincing: there was improvement on some measures (sometimes ulcer healing, often pain), but not others (ankle-brachial index, transcutaneously measured oxygen differential).12-15

Contra-indications are disorders involving the risk of bleeding (peptic ulcer, intracranial haemorrhage). The side effects are signs of vasodilatation and phlebitis at the place of infusion. Depending on individual tollerance, $0.5-2 \mathrm{ng} / \mathrm{kg}$ per minute are infused for 6 hours daily for a maximum of 4 weeks.

The effects of iloprost on walking distance in patients with claudication have not been adequately investigated, so that it has no rolle at present in relation to Fontaine stage $\mathrm{II}^{16}$ Although it is not entirely convincing, the application of iloprost is limited to the clinical treatment (possibly out-patient treatment) of patients with serious thromboangiitis obliterans or critical ischemia, where reconstructive vascular surgery is not possible. 


\section{Drugs with primarily rheological properties}

\section{Buflomedil}

Buflomedil has various effects such as inhibiting $\alpha$ receptors; inhibiting thrombocyte aggregation, increasing erythrocyte plasticity and reducing blood viscosity. It is not certain what mechanism is responsible for the in any event disputed and minor improvement in walking distance in patients with claudication. In a few published double-blind placebo controlled studies of buflomedil with patients with a maximum walking distance of 400 metres, walking distance increased by $25-40 \%$ as compared with $7-25 \%$ in the placebo group. ${ }^{17}$ Although this is a statistically significant improvement, it cannot be regarded as clinically relevant. The studies did not compare the effect of buflomedil with that of exercise training. Where effective, the effect on pain-free walking distance is observed within 2-4 weeks. The side effects are signs of vasodilatation.

\section{Pentoxifylline}

The dimethylxanthine derivative pentoxifylline has slightly vasodilatory properties, inhibits thrombocyte aggregation and lowers the fibrinogen level. Its positive effect on peripheral blood flow, particularly in the microcirculation is primarily attributed to the increased plasticity of the erythrocytes. Although a large controlled study of claudication showed a statistically significant improvement in walking distance, ${ }^{18}$ the statistical analysis method and the clinical relevance (22 metres added to the pain-free walking distance) are disputed. There have also been controlled studies which failed to show an effect produced by pentoxifylline. ${ }^{19}$ One survey of placebo controlled studies estimated that treatment with pentoxifylline led to an improvement in walking distance of $51 \%$ compared with a placebo. ${ }^{\mathrm{L}}$ The small studies in the survey found more significant effects than the large ones. The advantages of pentoxifylline may have been overestimated by publication selection. ${ }^{2}$

Furthermore, the symptoms in each study were different, and there was little correspondence between the measurement methods. The different results could therefore not be summarised in a useful way, and it was not possible to make a proper estimate of the effect. ${ }^{20}$ If the effect is insufficient after three months, there is no point in continuing. The side effects are minor and not serious, such as minor signs of vasodilatation, stomach complaints, rarely bleeding.

Although some (not very convincing) controlled studies have been carried out with naftidrofuryl , these will not be discussed here as the drug is not registered in the Netherlands. 
In conclusion, the above rheological drugs are no substitute for more causal therapy such as physical exercises, or where indicated, losing weight, giving up smoking, or radiological or surgical intervention.

\section{Experimental treatments}

There exists a wide range of experimental and "alternative" unproven pharmacological treatments, which unfortunately are still used, even by ordinary doctors. Alternative clinics, but also ordinary hospitals in the Netherlands often administer some of the ineffective vasodilators discussed (especially sympatholytics and non-specific vasodilators) in intravenous cocktails with other drugs.

There are very tentative indications that improving muscular metabolism with the help of L-carnitine can lead to an improvement in walking distance. The research in this area certainly does not allow any practical applications.

Chelation therapy is one of the best known and most disputed treatments for intermittent claudication. ${ }^{21}$ It is thought to work by mobilising calcium ions from plaques and binding the ions in the circulation with the help of intravenously administered edetate which is believed to be excreted as calcium edetate. 22 Independently of whether such a mechanism is plausible, the effect has never been demonstrated convincingly in controlled studies. ${ }^{23} 24$ Furthermore, significant side effects were observed (impaired renal function, acute hypocalcemia).

Apart from the application to acute ischemia caused by thrombosis and use after reconstructive vascular surgery, the effect of anticoagulants as a treatment for stage II claudication has not been adequately researched. There is a controlled Dutch study demonstrating a positive effect with phenprocoumon, but the data description is too vague to justify basing conclusions on it. ${ }^{26}$

Ketanserin, a serotonin-2-antagonist which, besides vasodilatation, also inhibits the platelet aggregation induced by serotonin, has been studied in relation to claudication. The two controlled studies yielded different results. 2728 Ketanserin has hardly been used since then, as a controlled study on patients with hypertension showed raised cardiovascular morbidity connected with heart arrhythmia, induced by a lengthening of the QT interval. ${ }^{29}$

\section{Conclusions}

The treatment of choice for a patient with intermittent claudication depends on the stage of the disease, its progression, the pain and social limitations experienced, any concomitant cardiovascular risk factors and co-morbidity.

With Fontaine stage II and without rapid progression, conservative measures are at the forefront (walking exercises, improvement of general condition, stopping smoking, foot care). Besides patient education (possibly backed up by leaf- 
lets) on the favourable prognosis, the relationship with possible cardiovascular risk factors is explained and taken up with the patient.

Drug therapy is indicated where progression is rapid, the patient is suffering a lot of pain or social limitation with insufficient reaction to walking exercises and stopping smoking, and there are contra-indications to invasive treatments (bypass surgery, percutaneous transluminal angioplasty). Vasodilators are contra-indicated. Pentoxifylline may be given for a trial period of 3 months. Patients with thromboangiitis obliterans and critical ischemia may be given illoprost intravenously for a trial period of 3 weeks. Aspirin seems to be mainly indicated as a prophylactic where there is known cerebrovascular or cardiovascular disease. Contra-indications are chronic obstructive pulmonary diseases and gastro-intestinal diseases involving bleeding. There is presently no role for anticoagulants in cases of chronic ischemia, although of course they do have a role with acute thrombotic events and probably in the prevention of re-stenosis after interventions.

\section{References}

1. Bevan EG, Waller PC, Ramsay LE. Pharmacological approaches to the treatment of intermittent claudication. Drugs Ageing 1992;2:125-36.

2. Cameron HA, Walter PC, Ramsay LE. Drug treatment of intermittent claudication: a critical analysis of the methods and findings of published clinical trials, 1965-1985. Br J Clin Pharm 1988;26:569-76.

3. Coffman ID. Intermittent claudication. Be conservative. N Engl I Med 1991;325:577-8.

4. Coffman JD. Vasodilator drugs in peripheral vascular disease. N Engl I Med 1979; 300: $313-7$.

5. Offerhaus L. Geneesmiddelen voor de behandeling van arteriële doorstromingsstoornissen. Ned Tijdschr Geneeskd 1988;132:51-3.

6. Zwieten PA van, Tijssen IGP, Lie KI, Leeuw PW de, Langdurige behandeling met calciumantagonisten: nuttige effecten en risico's. Ned Tijdschr Geneeskd 1995;139: 2715-21.

7. Wallace WA, Wellington KL, Chess MA, Chang Seng Liang. Comparison of nifedipine gastrointestinal therapeutic system and atenolol on antianginal efficacies and exercise hemodynamic responses in stable angina pectoris. Am J Cardiol 1994; 73:23-8.

8. Weinstein DB, Heider JG. Antiatherogenic properties of calcium antagonists. Am I Med $1989 ; 86: 27-32$.

9. Fiessinger $J \mathrm{~N}$, Schäfer $\mathrm{M}$. Trial of iloprost versus aspirin treatment for critical limb ischaemia of thromboangiitis obliterans. Lancet 1990;335:555-7.

10. Loosemore TM, Chalmers TC, Dormandy JA. A meta-analysis of randomized placebo control trials in Fontaine stages III and IV peripheral occlusive arterial disease. Int Angiol 1994;13:133-42. 
11. Brock FE, Abri O, Baitsch $G$, Bechara $G$, Beck $K$, Corovic $D$, et al, lloprost in der Behandlung ischämischer Gewebsläsionen bei Diabetikern. Schweiz Med Wschr 1990;120:1477-82.

12. Guilmot $\mathrm{L}_{*}$ Diot E. Treatment of lower limb ischaemia due to atherosclerosis in diabetic and nondiabetic patients with iloprost, a stable analogue of prostacyclin. Drug Invest 1991;3:351-9.

13. Norgren L, Alwmark A, Angqvist KA, Hedberg B, Bergcvist D, Takslander $R_{\text {, }}$ et al. A stable prostacyclin analogue (lloprost) in the treatment of ischaemic ulcus of the lower limb. A Scandinavian-Polish placebo controlled randomised multicentre study. Eur I Vasc Surg 1990:4:463-7.

14. Diehm $C$, Abri O, Baitsch $G$, Bechara $G$, Beck $K$, Breddin HK, et al. lloprost, ein stabilis Prostacyclinderivat, bei arterieller Verschlußkrankheit im Stadium IV. Eine placebo kontrollierte Multizenterstudie. Dtsch Med Wsch 1989;114:783-8.

15. Uk Severe Limb Ischaemia Study Group. Treatment of limb threatening ischaemia with intravenous iloprost: a randomised double-blind placebo controlled study. Eur I Vasc Surg 1991;5:511-6.

16. Grant SM, Goa KL. Iloprost. A review of its pharmacodynamic and pharmacokinetic properties, and therapeutic potentials in peripheral vascular disease, myocardial ischaemia and extracorporeal circulation procedures. Drugs 1992;43:889-924

17. Clissold SP, Lynch S, Sorkin EM. Buflomedil. A review of its pharmacodynamic and pharmacokinetic properties, and therapeutic efficacy in peripheral and cerebral vascular diseases. Drugs 1987;33:430-60.

18. Porter JM, Cutler BS, Lee BY, et al. Pentoxifylline efficacy in the treatment of intermittent claudication: multicenter controlled double-blind trial with objective assessment of chronic occlusive arterial disease patients. Am Heart J 1982;104:66-72.

19. Gallus AS, Gleadow $F$, Dupont $P$, Walsh I, Morley $A A_{1}$, Wenzel $A$, et al. Intermittent claudication: a double-blind cross-over trial of pentoxifylline. Aust NZ Med J 1985;15: 4.02-9.

20. Radack $\mathrm{K}$, Wyderski RJ. Conservative management of intermittent claudication. Ann Int Med 1990;113:135-46.

21. Gezondheidsraad. Advies inzake Edeteaat-Chelatiebehandeling. Den Haag: Staats* toezicht op de Volksgezondheid, 1984.

22. Rathman KL, Golightly LK. Chelation therapy of atherosclerosis. Drug Intell Clin Pharm $1984 ; 18: 1000-3$.

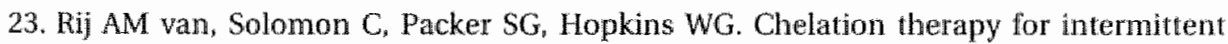
claudication. A double-blind, randomized, controlled trial. Circulation 1994;90:1194-9.

24. Guldager $B$, Je]nes $R$, Jorgensen SJ, et al. EDTA treatment of intermittent claudication, a double-blind, placebo-controlled study. I Intern Med 1992;231:261-7.

25. Hess H, Mietaschk A, Deischell G. Drug induced inhibition of platelet function delays progression of peripheral occlusive arterial disease: a prospective double blind arteriographically controlled trial. Lancet 1985:330:415-9.

26. Smit P de. Orale anticoagulantia en perifeer vaatlijden. Hartbulletin $1995: 26: 178-80$. 
36 Chapter 4

27. De Cree I, Leempoels J, Geuken H, Verhaegen H. Placebo-controlled double blind trial of ketanserin in treatment of intermittent claudication. Lancet 1984;329:775-9.

28. Bounameaux $\mathrm{H}$, Holdtich $\mathrm{T}$, Hellemans $\mathrm{H}_{v}$ Berent A, Verhaeghe R. Placebo-controlled, double-blind, two-centre trial of ketanserin in intermittent claudication. Lancet $1985 ; 330: 1268-70$.

29. Prevention of atherosclerotic complications with ketanserin trial group. Prevention of atherosclerotic complications: controlled trial of ketanserin. BMJ 1989;298:424-30. 


\section{$5 \mid$ The influence of experience on the reproducibility of the ankle-brachial systolic pressure ratio in peripheral arterial occlusive disease}

Kaiser V, Kester ADM, Stoffers HEJH , Kitslaar PJEHM , Knottnerus JA

Published: Kaiser V, Kester AD, Stoffers HEJH, Kitslaar PJEHM, Knottnerus $J A$. The infuence of experience on the reproducibility of the ankle-brachial systolic pressure ratio in peripheral arterial occlusive disease Eur J Vasc Endowasc Surg. 1999 Jul; 18(1):25-9 


\begin{abstract}
Objectives; "The ankle-brachial systolic pressure ratio (ABPI) is a quantitative measurement used in diagnostic and therapeutic studies on peripheral arterial occlusive disease (PAOD) and in clinical practice. This study was performed to estimate the intra observer variability of the measurement of the ABPI and to compare the reproducibility of the measurements by very experienced vascular laboratory assistants and by less experienced general practice personnel.

Design: repeated measurement of ABPI by general practitioners (GPs), GP-assistants and vascular laboratory assistants using a pocket Doppler device and a random zero sphygmomanometer.

Methods/materials: ABPI was measured in 6 patients with various degrees of PAOD by 2 experienced observers (vascular laboratory assistants) and by 24 less experienced observers (18 practice assistants, $6 \mathrm{GPs}$ ).

Results: Total number of measurements was 354 . The overall intra-observer variability estimate was $11.8 \%$ ABPI. The intra-observer variability was $7.3 \%$ in the experienced observers and $12.0 \%$ in the less experienced observers. The difference of variability between experienced and less experienced observers was significant.

Conclusions; the ABPI is suitable in follow-up studies where repeated measurements are needed. Gain in certainty about differences between measurements can be achieved by performüg repeated measurements or to use more experienced observers.
\end{abstract}




\section{Introduction}

Peripheral arterial occlusive disease (PAOD) is the manifestation of atherosclerosis in the arteries to the lower limbs distal from the abdominal aorta. In the diagnosis of PAOD general practitioners (GPS) often have to rely on history taking and physical examination. ${ }^{2}$ The introduction of a hand-held Doppler device made it possible to determine the severity of PAOD in a quantitative manner by measuring the ankle-brachial systolic pressure ratio (ABPI). PAOD can be detected in an early, even asymptomatic stage of the disease. It has been established that PAOD is a strong predictor of morbidity and mortality from other cardio-vascular disease. Early and reliable diagnosis of PAOD is important in order to detect patients at risk and take effective preventive measurements. ${ }^{4}$

In a previous study we determined the observer variability of the ABPI measurement with a pocket Doppler device in a group of GPs and their assistants who participate in the Limburg PAOD study. ${ }^{5}$ In that study we derived an estimate of the intra-observer variability of $10.5 \%$ from a statistical model which agrees with other studies on reproducibility of ABPI measurement. ${ }^{67}$ This intra-observer variability means that the difference between two measurements of the same patient by the same observer should be at least $29 \%$ to have an $95 \%$ certainty that this difference is not due to intra-observer error. With a degree of certainty of $80 \%$ the difference should be at least $19 \%$.

In the present study we investigated the intra-observer variability of the ABPI measurement by using random zero sphygmomanometers. The influence of experience was studied by comparing the reproducibility of very experienced vascular laboratory assistants with less experienced GPs and practice assistants.

\section{Material and methods}

\section{Design}

In order to measure the intra-observer variability in a direct manner we had to achieve independence between two consecutive measurements by the same observer on the same patients. To avoid a large biological effect the measurements had to take place in a short time interval. Therefore patients were measured twice by the same observer on one evening session, using random zero sphygmomanometers which were reset between the observation rounds.

The measurements took place in the "Skillslab", Faculty of Medicine Maastricht University in a time period of six weeks, in six evening sessions. The patients were the same at all sessions. 
Table 1. Patients

\begin{tabular}{lllll}
\hline Patient & Gender & $\begin{array}{l}\text { Age } \\
\text { (years) }\end{array}$ & Symptoms & $\begin{array}{l}\text { History of PTA } \\
\text { vascular surgery }\end{array}$ \\
\hline A & f & 79 & $\begin{array}{l}\text { intermittent claudication } \\
\text { left and right }\end{array}$ & + \\
B & $\mathrm{m}$ & 49 & $\begin{array}{l}\text { asymptomatic } \\
\text { intermittent claudication }\end{array}$ & + \\
$\mathrm{C}$ & $\mathrm{m}$ & 59 & $\begin{array}{l}\text { left } \\
\text { intermittent claudication }\end{array}$ & - \\
$\mathrm{D}$ & $\mathrm{f}$ & 76 & $\begin{array}{l}\text { left and right } \\
\text { asymptomatic }\end{array}$ & - \\
$\mathrm{E}$ & $\mathrm{m}$ & 69 & asymptomatic & - \\
\hline
\end{tabular}

\section{Patients}

Three male and three female patients, aged 49-79, participated in the study. They were selected from patients registered at the Vascular Laboratory of the Maastricht University Hospital. Selection criteria were the possibility to measure the ABPI in these patients and complaints of intermittent claudication or an ABPI $<95 \%$ at one or both legs, thus representing the type of patients a GP would see in daily practice. In table 1 the patient characteristics are given.

\section{Observers}

Twenty-six observers (18 GP practice assistants, 6 GPs and 2 vascular laboratory assistants) participated in the study.

On the basis of their experience in measuring the ABPI the observers were divided in two groups: experienced and less experienced. The experienced observers (two vascular laboratory assistants) measure more than $10 \mathrm{ABPIs}$ in a week, less experienced (six GPs, eighteen assistants) 5-15 in a month. Each observer participated in one evening session, except for the Vascular Laboratory (VL) assistants who participated each evening.

'The observers were unaware of any detail of the patients' medical history.

\section{Measurements}

All observers measured three patients twice, the second time in a different order.

The patients were lying supine in separate, heated rooms. Before the examination they rested for 10 minutes.

Pocket Doppler devices ( $8 \mathrm{Mhz}$, Hundleigh D500) and random zero sphygmomanometers (Hawksley \& Son Ltd, Lancing, Surey, UK) were used to measure both 
the ankle and the arm systolic blood pressure in the following order: lleft arm, left foot, right foot and right arm. The ABPI was defined as the systolic pressure of the posterior tibial artery at the ankle divided by the highest systolic arm pressure expressed as a percentage. If there was no signal at the posterior tibial artery the dorsalis pedis artery was measured.

The random zero sphygmomanometers were used in order to achieve independence between two consecutive measurements by one observer. The zeropoint of the manometer, which was blinded for the observer during the whole procedure, was reset before the repeat measurements. By using this procedure the random zero meter could be used as an ordinary sphygmomanometer, but the observers were unaware of the real pressure they were measuring during the tests.

\section{Statistical Analysis}

The ABPI variation can be attributed to different sources of variation: short-term and long-term biological variation, systematic measurement variation between observers and remaining variation. In statistical terms factors in the design were Day, Patient, Leg, Observer and Repeat, where, Leg was nested in Patient. The Repeat effect represents the influence of resetting the random-zero sphygmomanometer between the two observation rounds. Since each patient had one manometer assigned to him or her, it represents short-time biologic variation as well, and the factor Repeat was nested in Patient by Day. Not to complicate the analysis further, we refrained from estimating the between-day biologic variation and thus estimated Leg by Day as a fixed effect. Furthermore, we treated the measurement errors of the VL assistants -the only observers to contribute on more than one day-as independent between days. Therefore, Observer was nested in Day. The estimated variance components were thus restricted to Observer (Day), Observer by Patient, Observer by Leg, Repeat(Patient by Day), Repeat by Leg, Repeat by Observer and Repeat by Observer by Leg (residuat).

In order to analyse the difference between most and less experienced observers, we introduced separate components for the last two factors per experience category. Since each patient was observed by no more than one VL assistant however, the component for Observer could not be estimated and was set to zero. All variance components were estimated simultaneously using the restricted maximum likelihood algorithm available in BMDP $5 V .910$ Differences of variances were tested using the likelihood ratio test. 


\section{Results}

In one measurement, the $A B$ ratio was more than $100 \mathrm{AB}-\%$ lower than in its repeat by the same observer. This could have been a registration error with interchanged arm and ankle measurements, though further evidence of this was not found. Nevertheless, this value was considered unrealistically low and omitted from the analysis. Together with a few missing values this brings the number of measurements to 354 out of a possible 360 . The range in mean $A B$ ratios was from 60 to $136 \%$. Averages for each leg over all observation days are given in table 2 .

In the analysis of the variance components, it turned out that the estimates for Observer by Patient and for Repeat by Leg were very small and non significant. We assumed these components to be zero, as well as the component for Repeat by Observer in the most experienced category, which came out slightly negative. Table 3 gives the estimated variances for each factor. The large variance due to the Repeat effect was unexpected. Apparently, resetting the random-zero sphygmomanometers and/or the elapsed time (short-time biologic variability) had an effect on the measurement of the $\mathrm{AB}$ ratio. There was, however, no significant rela* tion between the difference of the two measurements and the difference in offset of the manometers.

Comparing the variance components between most and less experienced observers resulted in significantly smaller variances for the most experienced observers $(\mathrm{p}=0.02)$,

The variance components can be combined to give measurement SDs for different situations. A short list of calculated SDs is given in table 4. For single measurements, the standard deviation of the intra-observer variability was $7.3 \%$ ABPI for most experienced and $12.0 \%$ for less experienced observers. The reported intra-observer variability implies that a difference of at least $21.7 \% \mathrm{AB}$ ratio between visits is beyond chance with $80 \%$ confidence, for less experienced observers. This threshold reduces to $13.2 \%$ for the most experienced observers.

"The inter-observer SD was estimated to be $10.0 \mathrm{AB}$ ratio $\%$ for most experienced, $13.8 \%$ for less experienced observers.

Upon examination of the data, it appeared that the errors of right and left legs were of a different magnitude. In a separate exploratory analysis using again the BMDP $5 \mathrm{~V}$ program, the difference of the SDs for left and right legs was tested. Using separate components for left and right legs, it appeared that the residual variance was mainly due to the right legs' measurements, the difference of the variances of right and left legs being significant $(p<0.001)$. We could also show that this difference itself was smaller for most experienced observers than for less experienced $(p=0.035)$. 
Table 2. Mean ABPIs and standard deviations

\begin{tabular}{|c|c|c|c|c|}
\hline Patient & $\begin{array}{l}\text { Leg } \\
\mathrm{L} / \mathrm{R}\end{array}$ & $\begin{array}{l}\text { Number of } \\
\text { measurements }\end{array}$ & $\begin{array}{l}\text { Mean } \\
\text { ABPI } \\
(\%)\end{array}$ & $\begin{array}{l}\text { Standard } \\
\text { Deviation }\end{array}$ \\
\hline \multirow[t]{2}{*}{ A } & $\mathrm{L}$ & 29 & 65.8 & 11.1 \\
\hline & $\mathrm{R}$ & 30 & 73.8 & 11.9 \\
\hline \multirow[t]{2}{*}{ B } & $\mathrm{L}$ & 30 & 85.7 & 11.5 \\
\hline & $\mathrm{R}$ & 29 & 134.1 & 25.4 \\
\hline \multirow[t]{2}{*}{$\mathrm{C}$} & $\mathrm{L}$ & 28 & 77.6 & 18.3 \\
\hline & $\mathrm{R}$ & 28 & 97.2 & 11.1 \\
\hline \multirow[t]{2}{*}{$\mathrm{D}$} & $\mathrm{L}$ & 30 & 67.3 & 9.5 \\
\hline & $\mathrm{R}$ & 30 & 60.1 & 14.0 \\
\hline \multirow[t]{2}{*}{$E$} & $\mathrm{~L}$ & 30 & 100.9 & 7.8 \\
\hline & $\mathrm{R}$ & 30 & 90.4 & 14.0 \\
\hline \multirow[t]{2}{*}{ F } & $\mathrm{L}$ & 30 & 87.9 & 9.6 \\
\hline & $\mathrm{R}$ & 30 & 103.6 & 10.1 \\
\hline
\end{tabular}

Table 3. Estimated variance components

\begin{tabular}{llrl}
\multirow{2}{*}{ Nr } & Effect & \multicolumn{2}{c}{ Estimated variance dependent on level of experience } \\
\cline { 3 - 4 } & & most & less \\
\hline 1 & Obs. by Leg(Pat.) & 46.6 & 46.6 \\
2 & Repeat(Pat. by Day) & 30.8 & 30.8 \\
3 & Repeat by Obs. & 0.0 & 61.7 \\
4 & Residual & 22.3 & 52.0 \\
\hline
\end{tabular}

The difference between experience categories of components 3 and 4 is significant $(p=0.02)$

Table 4. Calculated SDs for intra and inter observer measurement error

\begin{tabular}{|c|c|c|c|}
\hline \multirow[t]{2}{*}{ Situation } & \multirow[t]{2}{*}{ variance components } & \multicolumn{2}{|c|}{$\begin{array}{l}\mathrm{SD}=\psi \text { variance } \\
(\% \mathrm{ABPI})\end{array}$} \\
\hline & & mosit & lesss \\
\hline Intra observer SD & $2+3+4$ & 7.3 & 120 \\
\hline \multicolumn{4}{|l|}{ Inter observer SDs: } \\
\hline One observer, one measurement & $1+2+3+4$ & 10.0 & 13.8 \\
\hline One obs., two measurements & $1+(2+3+4) / 2$ & 8.6 & 10.9 \\
\hline One obs., three measurements & $1+(2+3+4) / 3$ & 8.0 & 9.7 \\
\hline Two obs., one meas, each & $1+2+3+4) / 2$ & 7.1 & 9.8 \\
\hline Two obs., two meas. each & $1+(2+3+4) / 2) / 2$ & 6.0 & 7.7 \\
\hline
\end{tabular}




\section{Discussion}

The intra-observer variability of the ABPI measurement was our main study focus. In the single-observer-situation as is usual in the clinical evaluation of PAOD patients this is of special interest. Our estimate of the intra-observer variability of $11.8 \%$ for ABPI measurements is higher than reported by Buth $(6.5 \%){ }^{10}$ Fowkes made a distinction of a variability in diseased $(7.2 \%)$ and in normal subjects $(10.4 \%) .{ }^{7}$ Buth, in contrast with Fowkes, did not mention whether the consecutive measurements were independent as we have achieved using random zero manometers which may have introduced some bias in the direction of a lower variability.

The difference in intra-observer variability between the experienced and less experienced observers was significant. The vascular laboratory assistants measure ABPIs more than twice a day. In contrast to this the GPS and practice assistants measure 2-4 times a week. Gain in experience can decrease the intra-observer variability.

Although we introduced the random zero sphygmomanometer in our study to ensure independent consecutive measurements within observers, we found a large effect on the variance due to the "repeat effect". There was no significant relation however between the differences in ABPIs (first minus second measurement of one observer) and differences in offset (starting zeropoint) of the manometers. The randlom zero sphygmo manometer has shown some inaccuracy in repeated readings by underestimating systolic pressure readings with $2-4 \mathrm{~mm} \mathrm{Hg}$ compared with a standard sphygmomanometer. In the determination of the ABPI the systolic pressures of arm and leg are divided and an underestimation of the ABPI can be neglected. A possible problem is a slight change of the zeropoint in the first minutes after resetting due to construction of the mercury reservoir. In repeated pressure measurements inadequate handling of the zero muddler may lead to greater variation. ${ }^{11-13}$ However, in our design we changed the zeropoint only twice each evening session and after every change we let the manometers rest for ten minutes. Therefore we may assume that the variation due to the instrument was small and that independence of consecutive measurements was warranted. A possible source of variance could be short time biological variance in bloodpressure in the patients.

Duplicate observations by two independent observers will reduce the SD by a factor of $1 / \sqrt{2}$. Duplicate observations by the same observer would only result in an appreciably smaller SD when the observations would be independent, in other words, when the observer would be able to perform the repeat measurement unbiased by his/her knowledge of the first. In the present (laboratory-scale) study this independence was achieved through the use of random zero sphygmomanometers, but in larger studies this may not be feasible.

A remarkable finding was the difference of variability in right and left legs. Fowkes found a similar difference and suggested the difficulty of different 
measurement techniques due to the position of the patient and the position of the hand of the observer between left and right legs as a part of the explanation. ${ }^{7}$ The smaller difference of variance estimates between right and left legs in more experienced observers may support this explanation.

There are no published data available on the changes in reproducibility of the $\mathrm{ABPI}$ in the same observers over time. The estimate from our present study is only slightly higher than the predicted $10.5 \%$ intra-observer variability in our former reproducibility study. ${ }^{5}$ In that study there was no large difference in experience between the participating observers. The participating general practice assistants and GPs of the first study were the same persons as the less experienced observers in the present study. From this we may conclude that in the time period between both studies the reproducibility of the measurement of the ABPI was quite stable over time within the same observers. This is of interest for the validity of the results of follow-up studies using changes in ABPIs as endpoint. ${ }^{14}$

From our studies on the reproducibility and validity of the ABPI measurement it can be concluded that the ABPI measurement is suitable in epidemiological, diagnostic and in follow-up studies of patients with PAOD. The reported intraand inter observer SDs can be important in the planning of studies based on the $\mathrm{AB}$ ratio. ${ }^{15}$ For large studies with multiple observers one would not likely assume that observers could become very experienced, and then the 'less experienced' between-observer SD (13.8\%) should be used in the planning of the study. For smaller studies maybe all measurements could feasibly be done by the same -to become 'most experienced'- observer, one might use the smaller 'most experienced' intra-observer SD (7.3\%) in planning.

In the setting of the general practitioner the use of the ABPI in diagnosing PAOD has shown to be valid in a. study in which the level of experience of the observers was comparable with that in the present study. ${ }^{16}$ It is important that ABPI measurements should be performed by one or two assistants per group of $3000-4000$ patients only in order to maintain a reasonable level of experience.

In conclusion, the level of experience in measuring ABPI is of more importance than the decrease in reproducibility in the course of time.

\section{References}

1. Diagnostic value of signs and symptoms associated with peripheral arterial occlusive disease seen in general practice: a multivariable approach. Stoffers HEJH, Kester ADM, Kaiser V, Rinkens PELM, Knottnerus JA. Med Decis Making, 1997;17(1):61-70.

2. Criqui MH. FronekA, Klauber MR et al. The sensitivity, specificity and predictive value of traditional clinical evaluation of peripheral arterial disease: results from non-invasive testing in a defined population. Circulation 1985;71:516-22.

3. Thulesius $O$, Gjores IA. Use of Doppler shift detection for determining peripheral arterial blood pressure. Angiology 1971;22:594-603. 
4. Vogt MT, Wolfson SK, Kuller LH. Lower extremity arterial disease and the ageing process; a review. J Clin Epidemiol 1992;45:529-42.

5. Stoffers HEJH, Kaiser V, Kester ADM, Schouten HIA, Knotmerus JA. Peripheral arterial occlusive disease in general practice: the reproducibility of the ankle-arm systalic pressure ratio. Scand Prim Health Care 1991;9:109-14.

6. Johnston KW, Hosang MY, Andrews DF. Reproducibility of noninvasive vascular laboratory measurements in the peripheral circulation. I Vasc Surg 1987;6:147-51.

7. Fowkes FGR, Housley $\mathrm{E}$, Macintyre CCA, Prescott RJ, Ruckley CV. Variability of ankle and brachial systolic pressures in the measurement of atherosclerotic peripheral arterial disease. Epidemiol Community Health. 1988;42(2):128-33.

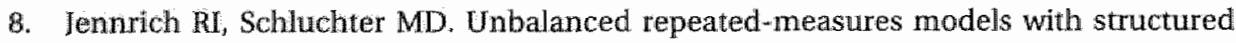
covariance matrices. Biometrics 1986;42:805-20.

9. Dixon WJ (chief editor): BMDP statistical software: to accompany the 7.0 software release. Berkeley: University of California Press, 1992.

10. Buth J. Het vasculaire laboratorium [The vascular laboratory] [PhD Thesis]. Amsterdam: Universiteit van Amsterdam, 1978.

11. de Gaudemaris R, Folsom AR, Prineas RJ, Luepker RV. The random-zero versus the standard mercury sphygmomanometer: a systematic blood pressure difference. Am J Epidemiol 1985;121(2):282-90.

12. Mackie $A$, Whincup $P$, McKinnon $M$. Does the Hawksley random zero sphygmomanometer underestimate blood pressure, and by how much? I Hum Hypertens 1995;9(5): $337-43$.

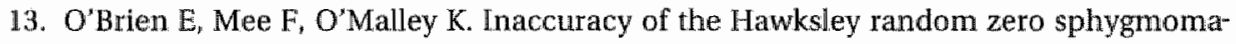
nometer. Lancet 1990;336:1465-8.

14. Kaiser V, Stolfers HEJH, Knottnerus JA. Peripheral arterial acclusive disease in general practice: natural course and intervention (the Limburg PAOD study, part II). CVD Newsletter 1991/1992;47:48-9.

15. Fowkes FGR. The measurement of atherosclerotic peripheral arterial disease in epidemiological surveys. Int J Epidemiol 1988;17(2):248-54.

16. Stoffers HEJH, Kester ADM, Kaiser V, Rinkens PELM, Kitslaar PJEHM, Knotmerus JA. The diagnostic value of the measurement of the ankle-brachial systolic pressure index in primary health care. J Clin Epidemiol 1996;49(12):1401-5. 
6 Evaluation of the effect of aspirin on the course of peripheral arterial occlusive disease A population based randomised controlled trial in a general practice setting

Kaiser V, Stoffers HEJH, Kester ADM, Kitslaar PJEHM, Knottnerus JA 
Objectives: to investigate the effect of aspirin on the course of symptomatic and asymptomatic peripheral arterial occlusive disease in general practice. Design: randomised controlled trial, recruited from a population based cohort.

Setting: 22 general practices in Limburg, the Netherlands.

Subjects: 265 patients aged 45-70 years with an ankle brachial systolic pressure index (ABPI) lower than $95 \%$ at two consecutive measurements.

Interventions: $300 \mathrm{mg}$ aspirin, placebo or 'lifestyle' advice only.

Outcome measures: primary endpoint: change in ankle brachial systolic pressure index after two years of follow up Secondary endpoints: changes in symptoms, cardiovascular morbidity and total mortality. Using a repeated measures model the treatment effect was tested correcting for missing data and first visit covariates.

Results: after two years there were no differences in the mean $\mathrm{ABPI}$ between the intervention groups. Mean ABPI improved from $77 \%$ to $85 \%$. High age, smoking and low ABPI at start contributed most to deterioration of the ABPI. There were no differences in morbidity and mortality between the intervention groups.

Conclusion: aspirin has no effect on the course of PAOD measured with the ABPI. Future research would probably best focused on optimising walking exercise and smoking cessation strategies in the conservative management of PAOD. 


\section{Introduction}

Peripheral arterial occlusive disease (PAOD) is a common disease of the older patient. Intermittent claudication is the first clinical sign of atherosclerosis of the legs. Prevalence figures for intermittent claudication registered in general practice vary from 0.7-6.1\%. 2 Prevalence of PAOD measured with a Doppler device revealed prevalence figures of $6.9-19 \% \%^{3-5}$

The conservative management of PAOD is focused on changes in lifestyle. Treatment of risk factors like hypertension, diabetes mellitus, hypercholesterolemia and overweight is recommended. The keystone of treatment can be summarised as "stop smoking and keep walking". 6

Efficacy of drug treatment is still in debate. Vasodilating drugs have not proven to be effective in reducing complaints and improving walking distance. ${ }^{7}$ Rheologic agents have been intensively studied in the last decades but promising first results were not confirmed by larger randomised trials. ${ }^{8}$ Anticoagulant drugs are successfully used in acute occlusions, but in the treatment of intermittent claudication the effect is not convincing. The number of thromboembolic complications in intermittent claudication is small and possible side effects of anticoagulant drugs do not justify the use of these drugs in intermittent claudication. 9 The benefits of using aspirin in secondary prevention of myocardial infarction and stroke have been convincingly shown in some larger studies. The effect on plaque and thrombi formation results in a lower incidence of myocardial and cerebrovascular morbidity. ${ }^{10}$ In the late eighties these promising results led to the hypothesis that platelet inhibitory drugs could help in the treatment of PAOD. ${ }^{11}$ Hess et al. studied the combination of aspirin and dipyridamol in patients with moderate to severe PAOD from a hospital population. Angiographically they showed a positive effect of aspirin on the degree of obstruction. ${ }^{12}$ Patients for his study were recruited from a hospital-based population. Further the efficacy of platelet inhibition has not intensively been investigated.

Considering the effect of platelet inhibition in the prophylaxis of secondary events in patients with cardio - and cerebrovascular disease, it seemed usefull to further investigate the effect of platelet inhibition on blood flow, the course of complaints and the occurrence of peripheral vascular incidents in patients with PAOD. If such an effect could be demonstrated, the general practitioner could treat early detected PAOD and prevent progression of the disease and possible complications in the future.

Therefore, a double blind randomised controlled trial in general practice was carried out to investigate the effect of aspirin in the treatment of PAOD. Primary endpoints were changes in the ankle brachial pressure ratio (ABPI). Secondary endpoints were changes in symptoms, cardio- and cerebrovascular vascular morbidity and total mortality. 1314 


\section{Methods}

\section{Design}

The intervention study presented here, was part of the 'Limburg PAOD Study', a research project conducted at the Maastricht University (the Netherlands) in close co-operation with 22 general practice centres. ${ }^{3} 15$ The design is a randomised controlled clinical trial in three study groups recruited from a population based cohort screened by ABPI measurements: aspirin, placebo and lifestyle advice only'. Apart from the cohort incident cases of PAOD were selected for the study in the participating practices during the selection period. While the allocation to the 'lifestyle advice only' group was not blinded to the general practitioner and the patient, the allocation to either aspirin or placebo was double blind.

\section{Study population}

In the 'Limburg PAOD Study' cohort, data on signs and symptoms of PAOD, vascular risk factors, and the ABPI were collected among patients aged between 40 and 75 years from 22 general practice centres. Incident cases of PAOD in the participating practices were also included in the trial.

The inclusion criterion was an ABPI lower than 95\% on two consecutive measurements within one week at the leg with the lowest ABPI (index leg).

Exclusion criteria were: present gastric complaints; history of gastric or duodenal ulcer; history of gastric bleeding; current treatment with oral anticoagulant drugs; current use of aspirin-like or platelet inhibitory drugs; previous vascular surgery or endovascular procedures of the index leg.

\section{Randomisation}

All patients eligible for the study were allocated to one of the three study groups according to a computer-generated randomisation scheme. In the office of the general practitioner (GP), a sealed envelope containing the allocation to lifestyle advice only' or to a medication group, was opened in the presence of the patient, after patients had given their written informed consent. In the medication group, the allocation to either aspirin or placebo was double blind.

\section{Interventions}

The duration of the study was planned to be 2 years of follow-up per patient. All patients were scheduled to visit the general practitioner every four months. All patients were instructed by their general practitioner to stop smoking and to do regular walking exercise. This instruction was handed out on a leaflet and repeated at every follow-up visit. 
Treatment medication consisted of a daily dosage of 300 milligrams aspirin in one capsule. Placebo was administered in identical capsules, not different in smell or taste. Treatment and placebo medication were handed out at every follow-up visit in small plastic containers with coded labels containing 130 capsules.

\section{Measurements and follow-up}

At each follow-up visit the GP interviewed the patient and filled in a PAOD questionnaire ${ }^{16}$, changes in the experienced walking distance, compliance of study medication, smoking behaviour, compliance of walking exercise and occurrence of adverse events. The patient record was checked for occurrence of recentlly diagnosed transient ischemic attack, stroke, angina pectoris, myocardial infarction, hypertension, diabetes mellitus or hypercholesterolemia. Changes in co-medication were noted. A physical examination was performed: weight, blood pressure, inspection of the legs, palpation of the skin, palpation of femoral, posterior tibial and dorsal pedal pulses, auscultation of the abdominal aorta and the femoral arteries.

The ABPI was assessed by a practice assistant with a hand-held Doppler device (Huntleigh Mini Dopplex D500, $8 \mathrm{MHz}$ ) and a sphygmomanometer. Systolic pressures were recorded on both arms and ankles with the patient lying in supine position. The ABPI for each leg was defined as the systolic pressure at the ankle divided by the highest systolic arm pressure.

\section{Sample size and statistical analysis}

In order to detect a minimal difference of $5 \% \mathrm{ABPI}$, accepting a type 1 error of $5 \%$ and a power of $80 \%$, at least 42 patients were required in each intervention group.

All data were analysed according to the intention to treat principle.

The ABPI data were analysed using a repeated measures model allowing for missing data ${ }^{17}$. The covariance structure for the model was estimated from the data. Thus the mean ABPI in each group for each visit was estimated while correcting for missing data. Furthermore, differences with respect to placebo were estimated while correcting for the baseline value, covariates and missing data. After vascular surgery of the index leg the value of the ABPI of the visit before surgery was used for analysis.

To test the treatment effect after 24 months at visit 7 we fitted a model testing the differences with a linear contrast on the respective visits in the two years of follow-up, correcting for baseline values of the ABPI and other baseline observations. The covariates were: age, sex, smoking, intermittent claudication, transient ischemic attack, stroke, angina pectoris, myocardial infarction, hypertension, diabetes mellitus or hyperchollesterolemia.

Cardio- and cerebrovascular morbidity (transient ischemic attack, stroke, angina pectoris, myocardial infarction) and total mortality after two years were 
analysed using Cox regression analysis. In the analysis of each event we included the more severe events, e.g. when analysing stroke, death was considered to be an event, not censoring. Censoring was assumed when a patient refused further co-operation, or was otherwise, not due to an event, not available for analysis. Covariates in the Cox regression analysis were the baseline ABPI and other baseline observations as described above.

In each analysis, a two sided significance level of 0.05 was applied.

\section{Ethical review}

The study has been approved by the Medical Ethics Committee of the University Hospital Maastricht.

\section{Results}

Among the 'Limburg PAOD Study' cohort $(n=3654) 458$ patients had an ABPI lower than $95 \%$. Excluded were 242 patients: 93 patients had current use of aspirin-like or platelet inhibitory drugs, 111 patients were not interested to take part in the intervention study and 38 patients had one or more of the other exclusion criteria. Eligible for the intervention study were 216 patients. In the participating practices 71 incident cases of PAOD were selected for the study.

Thus, a total of 287 patients were randomised: 98 patients in the aspirin group, 93 in the placebo group and 96 in the 'lifestyle advice only' group. For the follow-up visits 22 patients did not show up at any follow-up visit: ten in the aspirin group, five in the placebo group and seven in the 'lifestyle advice only' group. Of these 22 patients five died, three patients moved and fourteen were not interested anymore. The analysis of the treatment effect on cardio- and cerebrovascular morbidity was based on the remaining 265 patients. The baseline characteristics are shown in table 1. The analysis of the treatment effect on the outcome of the ABPI after two years was based on 221 patients with complete data. In the analysis of mortality the five patients who died before the first follow-up visit were included.

\section{Follow-up}

Figure 1 shows the trial profile. Thirty two patients did not complete the study: 6 patients moved, 22 patients were not interested to participate in the whole study and 4 patients stopped for other reasons.

Twelve patients died, four in each study group. Forty four patients missed one or more visits during the follow-up period, (aspirin 19; placebo 13; "lifestyle advice only" 12) After two years of follow up there were complete data on 221 patients (aspirin 69; placebo 75; 'lifestyle advice only' 77). 
Table 1. Patient baseline characteristics $(n=265)$ number (percentages)

\begin{tabular}{llll}
\hline characteristic & aspirin & placebo & "lifestyle advice only" \\
\hline n. & 88 & 88 & 89 \\
male/female & $37 / 51$ & $52 / 36$ & $44 / 45$ \\
age (SD)(yr.) & $64.2(8.9)$ & $62.7(9.0)$ & $62.7(8.9)$ \\
ABPI \% (SD) & $77.7(13.6)$ & $74.5(15.5)$ & $78.1(14.3)$ \\
intermittent & & & \\
claudication" & $54(62.8 \%)$ & $60(70.6 \%)$ & $56(63.6 \%)$ \\
current smoking & $51(58.0 \%)$ & $57(64.8 \%)$ & $53(59.6 \%)$ \\
diabetes mellitus & $24(27.3 \%)$ & $16(18.2 \%)$ & $12(13.5 \%)$ \\
hypertension & $42(47.7 \%)$ & $56(63.6 \%)$ & $46(51.7 \%)$ \\
hypercholesterolemia & $10(12.0 \%)$ & $9(10.3 \%)$ & $14(16.5 \%)$ \\
transient ischemic & & & $1(1.1 \%)$ \\
attack & $7(8.0 \%)$ & $3(3.4 \%)$ & $2(2.2 \%)$ \\
stroke & $5(5.7 \%)$ & $2(2.3 \%)$ & $15(16.9 \%)$ \\
angina pectoris & $16(18.2 \%)$ & $17(19.3 \%)$ & \\
myocardial & $9(10.2 \%)$ & $11(1.5 \%)$ & $13(14.6 \%)$ \\
infarction & & & \\
\hline
\end{tabular}

"missing $n=6$," missing $\mathrm{n}=10$,

Mean ABPIs and other baseline characteristics of the patients with incomplete data were not different from those of the total study population.

The results presented in table 2 are based on a follow-up time of two years.

\section{Compliance and side effects}

After two years of follow-up 98 patients (68\%) took the study medication per protocol: 47 patients $(68 \%)$ in the aspirin group and 51 patients (68\%) in the placebo group.

The overall compliance of the instructed walking exercise was $67 \%: 44$ patients $(64 \%)$ in the aspirin group, $51 .(68 \%)$ in the placebo and $52(67 \%)$ in the "lifestyle advice only" group.

In the course of the study 26 of the smokers (19\%) stopped smoking: eight $(18 \%)$ in the aspirin group eight, ten (21\%) in the placebo and eight patients (17\%) in the "lifestyle advice only" group.

Side-effects of the study medication were reported in both the aspirin and placebo group: nausea (aspirin $n=8$, placebo $n=1$ ), gastric complaints (aspirin $\mathrm{n}=10$, placebo $\mathrm{n}=8$ ). 
$54 \mid$ Chapter 6

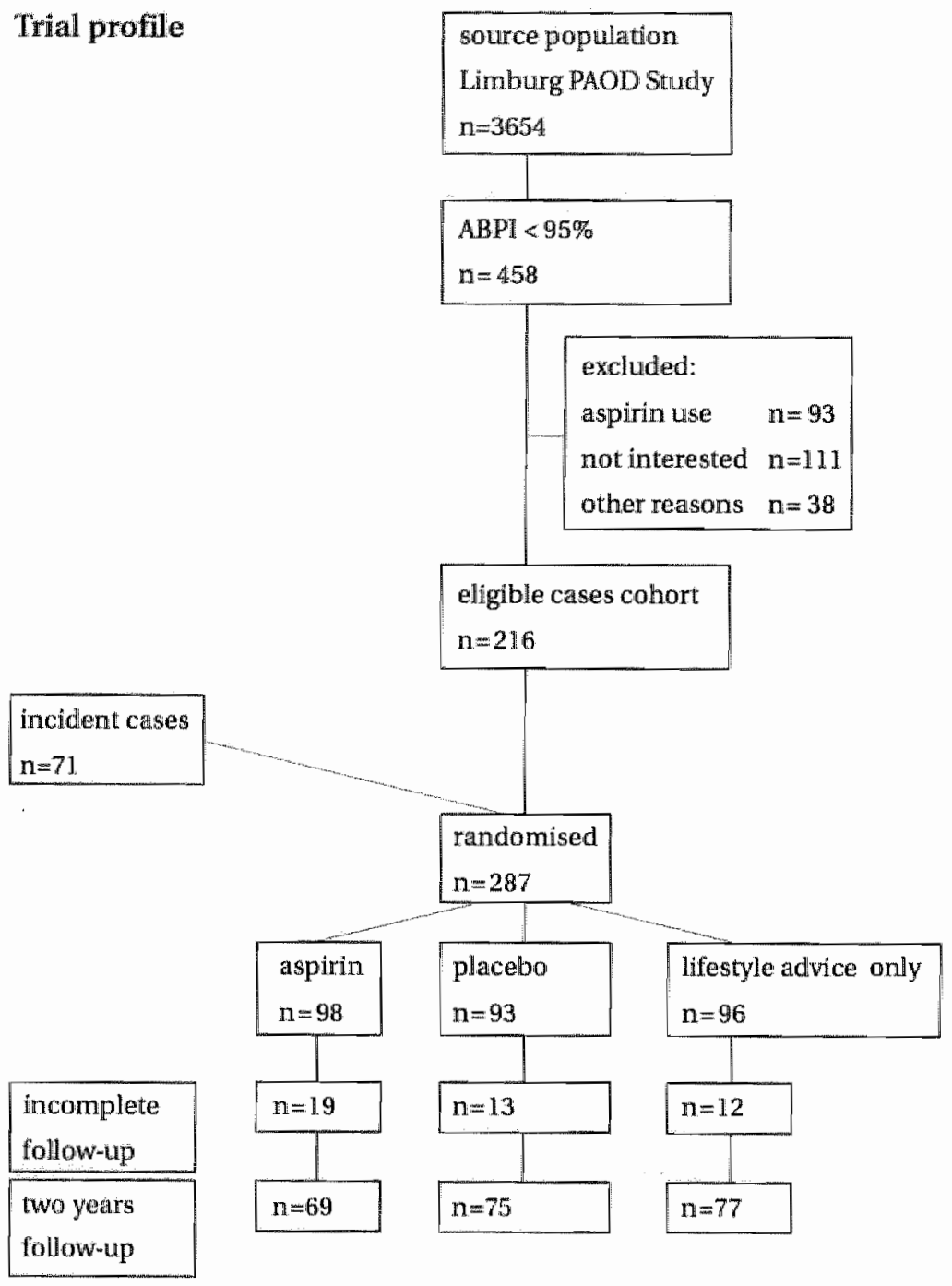

Figure 1. Trial profile. 
Table 2. Symptoms, ABPI and cardiovascular morbidity after two years follow-up. $(\mathrm{n}=221)$ number (percentage)

\begin{tabular}{|c|c|c|c|c|}
\hline & & aspirin & placebo & $\begin{array}{l}\text { 'lifestyle advice } \\
\text { only" }\end{array}$ \\
\hline \multirow{7}{*}{$\begin{array}{l}\text { male/ female } \\
\text { ABPI \% } \\
\text { intermittent } \\
\text { claudication }\end{array}$} & & 69 & 75 & 77 \\
\hline & & $32 / 37$ & $42 / 33$ & $38 / 39$ \\
\hline & $(\mathrm{SD})$ & $85.0(18.8)$ & $85.2(19.1)$ & $83.4(19.9)$ \\
\hline & baseline & 46 & 51 & 49 \\
\hline & improved & $14(30 \%)$ & $17(33 \%)$ & $18(37 \%)$ \\
\hline & stable & $28(61 \%)$ & $29(57 \%)$ & $26(53 \%)$ \\
\hline & deteriorated & $4(9 \%)$ & $5(10 \%)$ & $5(10 \%)$ \\
\hline \multirow{3}{*}{$\begin{array}{l}\text { experienced } \\
\text { walking } \\
\text { distancel }\end{array}$} & improved & $17(25 \%)$ & $25(35 \%)$ & $22(30 \%)$ \\
\hline & stable & $38(57 \%)$ & $37(52 \%)$ & $39(53 \%)$ \\
\hline & deteriorated & $12(18 \%)$ & $9(15 \%)$ & $13(17 \%)$ \\
\hline \multirow[t]{2}{*}{ smoking } & current & 36 & 37 & 39 \\
\hline & stopped & 8 & 10 & 8 \\
\hline \multicolumn{2}{|c|}{ total cardiovascular morbidity } & 9 & 7 & 7 \\
\hline & vascular surgery & 2 & 3 & 1 \\
\hline & transient ischemic attack & 1 & - & 3 \\
\hline & stroke & - & 1 & 1 \\
\hline & angina pectoris & 3 & 2 & 2 \\
\hline & myocardial infarction & 3 & 1 & 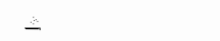 \\
\hline
\end{tabular}

1 missing $=9$

$A B P I$

In table 2 the mean ABPIs after two years are shown. Overall, there was a slight increase in the mean ABPI of 6.5\% ABPI (aspirin 7.4\%; placebo $8.0 \%$ : 'advice only' $4.0 \%$.

Table 3 shows the mean ABPIs at each visit in the three study groups corrected for baseline visit ABPI values, covariates and missing data. These differences between the ABPIs are very small and show no particular pattern in favour of aspirin.

The repeated measures model in table 4 also shows that the treatment effect (aspirin versus placebo) is very small and not significant. The estimate of covariates show that the ABPI after 2 years is significantly negatively influenced by $\mathrm{ABPI}$ at the start, higher age, smoking and a history of transient ischemic attack at baseline. Risk factors such as diabetes mellitus, hypertension, myocardial infarction and stroke did not influence the ABPI significantly. 
Table 3. Mean ABPIs at follow-up visits

\begin{tabular}{lcccccc}
\hline study group & months & N & Min & Max & Mean & Sitd. Deviation \\
\hline alspirin & 4 & 88 & 21 & 109 & 79.51 & 17.19 \\
& 8 & 86 & 42 & 145 & 83.90 & 1.8 .70 \\
& 12 & 84 & 24 & 139 & 81.80 & 21.37 \\
& 16 & 80 & 39 & 123 & 82.14 & 20.30 \\
& 20 & 78 & 33 & 133 & 83.86 & 20.04 \\
placebo & 24 & 69 & 38 & 126 & 85.06 & 19.57 \\
& 4 & 88 & 33 & 126 & 77.16 & 19.20 \\
& 8 & 87 & 32 & 134 & 79.57 & 20.94 \\
& 12 & 85 & 36 & 1.29 & 81.02 & 20.88 \\
& 16 & 83 & 30 & 155 & 80.67 & 22.49 \\
& 20 & 82 & 24 & 123 & 79.56 & 21.79 \\
'lifestyle & 24 & 75 & 34 & 118 & 82.48 & 19.13 \\
advice only' & 4 & 89 & 40 & 114 & 82.57 & 15.54 \\
& 8 & 87 & 40 & 122 & 80.30 & 16.48 \\
& 12 & 83 & 42 & 127 & 82.51 & 17.86 \\
& 16 & 82 & 40 & 129 & 81.92 & 19.29 \\
& 20 & 80 & 42 & 125 & 84.09 & 20.54 \\
& 24 & 77 & 42 & 131 & 82.05 & 20.20 \\
\hline
\end{tabular}

Table 4. Repeated measures model for the outcome of the ABPI after 2 years. $(n=221)$ Covariates are established at baseline

\begin{tabular}{lrll}
\hline variable & estimate & $\begin{array}{l}95 \% \text { confidence } \\
\text { interval }\end{array}$ & p-value \\
\hline "lifestyle advice only" & -1.45 & $(-6.6,3.7)$ & 0.58 \\
aspirin & 2.65 & $(-2.6,7.9)$ & 0.32 \\
ABPI $\%$ I=0 & 0.73 & $(0.6,0.8)$ & 0.00 \\
sex (mims. 1$)$ & 2.11 & $(-1.0,5.2)$ & 0.19 \\
age (year) & -0.37 & $(-0.5,-0.2)$ & 0.00 \\
intermittent claudication & 0.72 & $(-0.9,2.4)$ & 0.39 \\
current smoking & -6.18 & $(-9.5,-2.7)$ & 0.00 \\
diabetes mellitus & -0.76 & $(-4.8,2.2)$ & 0.71 \\
hypertension & 0.09 & $(-3.0,3.2)$ & 0.95 \\
hypercholesterolemia & -3.84 & $(-8.3,0.6)$ & 0.09 \\
stroke & 0.28 & $(-9.4,10.0)$ & 0.96 \\
transient ischemic attack & -11.55 & $(-21.2,-1.9)$ & 0.19 \\
angina pectoris & -0.65 & $(-5.2,3.9)$ & 0.76 \\
myocardial infarction & 4.65 & $(-0.4,9.6)$ & 0.06 \\
\hline
\end{tabular}

${ }^{1}$ compared with placebo: ${ }^{2}$ estimated difference in ABPI (per 10\% difference at baseline there is a $7.3 \%$ difference at the end). 


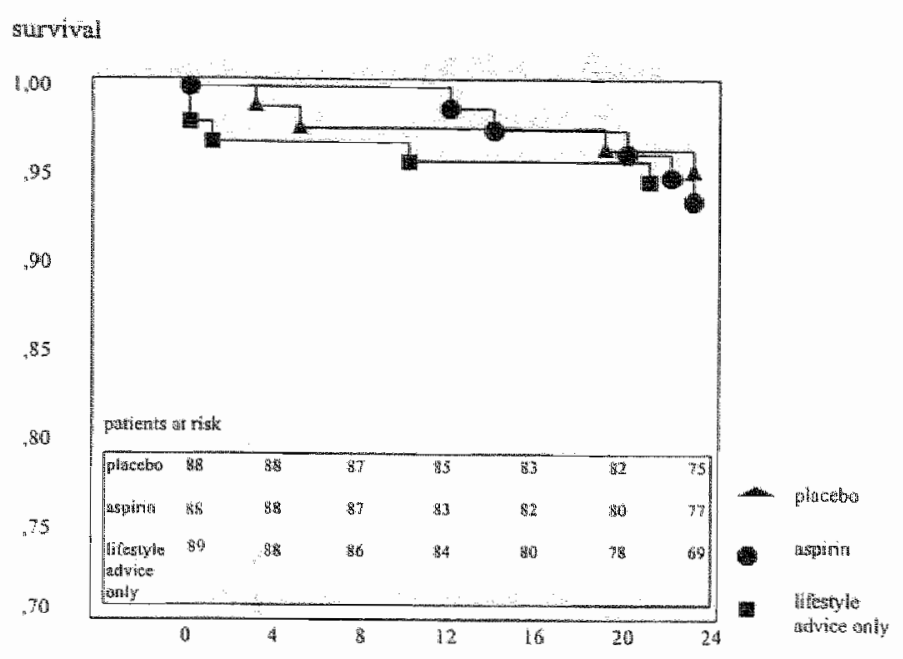

surnval-time dn months

Figure 2. Kaplan-Meier analysis of survival curves based on total mortality in aspirin, placebo and 'lifestyle advice only' group.

\section{Symptoms}

In table 2 the data on intermittent claudication and reported walking distance are given. Complaints of intermittent claudication were stable in $57 \%$ of the 1.46 patients, $10 \%$ deteriorated and $33 \%$ improved. Differences between the groups were not significant. New complaints of intermittent claudication developed in two years in 26 patients ( $35 \%$ ) who were asymptomatic at baseline (aspirin $n=9$, placebo $n=9$, 'lifestyle advice only' $n=8$ ).

Improvement of the walking distance was reported by $30 \%$ of all patients, $16 \%$ deteriorated and $54 \%$ were stable. Differences between the groups were not significant.

\section{Mortality}

In figure 2 the Kaplan-Meier curve on total mortality in the three different groups is shown. Mortality is very low after 2 years of follow-up (5 in the aspirin, 5 in the placebo and 7 in the 'lifestyle advice only' group). The logrank test was not significant $(\mathrm{p}=0.97)$.

In the Cox proportional hazards model we estimated the effect of the intervention on mortality taking the covariates into account. The treatment effect was not significant $(\mathrm{p}=0.90)$ 


\section{Morbidity}

The number of non-fatal cardiovascular events in the 2 years of follow-up was small. The total number of events was 7 in the aspirin 4 in the placebo group and 6 in the "lifestyle advice only" group.

In the Cox proportional hazards model the treatment effect (aspirin versus placebo) was not significant $(\mathrm{p}=0.97)$.

\section{Discussion}

In this study we could not demonstrate any beneficiall effect of aspirin on the course of PAOD. The mean ABPI showed a slight increase of $7.8 \%$ in two years in all patients. The differences in ABPI between the study groups were very small and showed no consistent pattern in time. From the repeated measures model the corrected treatment effect in favour of aspirin was small and not significant.

Complaints of intermittent claudication at baseline deteriorated in only $10 \%$ and improved in $35 \%$ of the patients. Patients asymptomatic at baseline developed complaints of intermittent claudication in $35 \%$. There were no significant differences between the groups. The experienced walking distance deteriorated in $16 \%$ and improved in $30 \%$ of all patients with no significant differences between the groups. In both the aspirin and placebo group $68 \%$ of the patients took the study medication per protocol. Walking exercises were carried out by $67 \%$ of patients in all groups. The advice to stop smoking was only followed by $19 \%$ of all smokers.

In the analysis of cardiovascular morbidity and total mortality there was no beneficial effect of aspirin either.

We had expected that platelet inhibition with aspirin would slow down the process of atherosclerosis in the peripheral arteries of the legs and expected that after follow - up the ABPI in the aspirin group would be significantly higher than in both other study groups. However, no difference in the mean ABPI was observed after two years of follow-up. In contrast to Hess et al. we could not show a beneficial effect of platelet inhibition. Hess demonstrated a progression reduction of angiographically established stenoses of the arteries in more advanced PAOD patients from a clinical population. Extrapolation of results from hospital population studies to a primary care population should be treated with caution. 19 Changes of the percentage stenosis is not directly proportional to the changes in ABP1. If the changes were below the critical zone changes in resting in ABPI could be missed. Aspirin as a platelet inhibitor plays a role in the progression of atherosclerotic plaques and secondary thrombogenesis. In existing atherosclerosis plaque fissuring and subintimal haemorrhage give rise to platelet activation resulting in thrombus formation which may lead to occlusion. In cerebro-and cardiovascular events the positive effect of aspirin is often attributed to the 
prevention of this thrombus formation. ${ }^{20}$ In the peripheral arteries of the legs the role of this secondary thrombogenesis may be less important which could explain the lack of effect of aspirin on flowparameters as used in our study.

The use of platelet inhibition in patients with intermittent claudication is often recommended, thereby extrapolating the positive results of platelet inhibition in secondary prevention of othen cardio - and cerebrovascular events. A recent review on the use of aspirin as secondary prophylaxis for vascular disease recommended that patients with intermittent claudication who have an increased vascular risk should be treated with aspirin. However, there was insufficient evidence to support the use of prophylactic aspirin in patients with intermittent claudication but no additional risk factors. $21-23$

In our study we used the change in ABPI as primary endpoint while in most of the studies on secondary prevention of cardio- and cerebrovascular events complaints of intermittent claudication were used as an endpoint. ${ }^{13} 14$ of the patients $35 \%$ were asymptomatic but had PAOD on the criterion of an ABPI lower than $95 \%$. Asymptomatic and symptomatic patients showed to have a comparable risk for cardio- and cerebrovascular events. ${ }^{24} 25$ From this Fowkes assumed that it is worthwhile to detect asymptomatic PAOD and treat these patients with aspirin to prevent major cardiovascular events. ${ }^{26}$

The trial was primarily designed to study the effect of aspirin on the ABPI and had a sufficient sample size for this purpose. Our study was not primarily designed on the effect of aspirin on cardiovascular events. Although we found no effect of aspirin in preventing major cardiovascular events, the statistical power to detect a possible difference was too small to draw final conclusions on this issue. Our results did not clarify the question whether aspirin will benefit patients with asymptomatic or symptomatic PAOD over a longer period.

Some risk factors had a significant effect (smoking, hypercholesterolemia), while other risk factors had no significant eflect on the course of the ABPI. In our study smoking had the largest effect. The deteriorating effect of smoking on the prognosis of PAOD has been well established. 27 Despite the advice to stop smoking in every patient at each visit the proportion of PAOD patients that quit smoking was only $19 \%$. This is consistent with other studies on success of smoking cessation strategies, revealing success in $5-25 \%$ of patients with cardiovascular diseases. $^{28}$

Walking exercise has shown to be effective in treating intermittent claudication. However, there is no consensus on the most effective exercise program in patients with PAOD. In our study the compliance of patients in doing regular exercises over a period of two years was $67 \%$. This is comparable to the compliance in exercise studies with a supervised 6 months program. 2930

For more advanced PAOD cases, since the introduction of percutaneous transluminal angioplasty there is discussion whether non-surgical conservative treatment is the first choice. Compared with exercise training angioplasty improves quality-adjusted life expectancy but at relatively high costs. ${ }^{31}$ 
In conclusion, we found no evidence to justify prescribing aspirin in PAOD to prevent progression of PAOD. Whether aspirin should be used as a secondary prevention for cardio or cerebrovascular morbidity in PAOD patients could not be answered by our study. To evaluate the prophylactic effect of aspirin in reducing cerebro-and cardiovascular events in patients with symptomatic and asymptomatic PAOD, larger studies with sufficient power and longer follow-up are needed.

In the treatment of intermittent claudication as a complaint exercise training and smoking cessation can still be considered the most effective. ${ }^{32}$ Future research on the management of $\mathrm{PAOD}$ should be focused on optimising exercise programs and stop smoking strategies and comparison of angioplasty with strictly conservative treatment of more advanced cases.

\section{Acknowledgements}

We thank the participating general practitioners for their contribution to this study: GHM Beusmans, WPM Vierhout, T van Merode, TGJ Lemmens" PA Stalenhoef, LGJ Huynen, GAHM Castermans, MPJM Peeters, FHJA Vissers (Maastricht), FI Guldemond (Ubachsberg), PBN Hulshof, RM Panhuysen, ETIM Guldemond-Hecker (Voerendaal), AA ten Berge, PFM van der Heyden (Roermond), WHM Nieuwdorp (Brunssum) H Logister ${ }^{\dagger}$, BTMG van der Werf (Heerlen), P. Athmer, G van Zanten, JJ Michels, WJ van der Wissel, A van Dam, C Hanssen, EHJF Hubbers, FLM Soomers, JMSIG Soomers-Turlings, PHM Passage, JHJ Drenth (Kerkrade), BHJM Otten (Merkelbeek), ESM Vijgen, TAH Vijgen-Hamers (Geleen), JHM Eussen, JAM Ypma, C Stuurman (Landgraaf), M van Bommel (Tilburg), Ph Govaert, RMFM Leclerg. (Stein). This part of the Limburg PAOD Study was supported by a research grant of the former "Praeventiefonds", now "Zorg Onderzoek Nederland" $(28-1323)$ and the Netherlands Organization for Scientific Research (900-715.154). The Doppler devices and the manufacturing and distribution of the study medication were donated by Asta Medica BV.

\section{References}

1. Lamberts H. Morbidity in general practice. Diagnosis related information from the monitoring Project. Utrecht: Huisartsenpers, 1984.

2. Hoogen HMM van den, Huygen FJA, Schellekens JWG, Straat JM, Van der Velden HGM. Morbidity figures from general practice. Data from four general practices 1978-1982. Nijmegen: NUHI; 1985.

3. Stoffers HEH, Rinkens PELM, Kester ADM, Kaiser V, Knottnerus IA. The prevalence of asymptomatic and unrecognized peripheral arterial occlusive disease. Int I Epidemiol 1996;25:282-90. 
4. Fowkes FGR, Housley E, Cawood EHH, Macintyre CCA, Ruckley CV, Prescott RI. Edinburgh Artery Study: Prevalence of asymptomatic and symptomatic peripheral anterial disease in the general population. Int I Epidemiol 1991;20:384-92.

5. Meijer WT, Hoes AW, Rutgers D, Bots ML, Hofman A, Grobbee DE. Peripheral arterial disease in the elderly: The Rotterdam Study. Arterioscler Thromb Vasc Biol. 1998; 18(2): $185-92$.

6. Coffman ID. Intermittent claudication. Be conserwative. N Engl I Med 1991;325:577-8.

7. Coffman ID. Vasodilator drugs in peripheral vascular disease. $\mathbb{N}$ Engl J Med 1979;300: 313-7.

8. Radack $K$, Wyderski RJ. Conservative management of intermittent claudication. Ann Int Med 1990;113:402-9.

9. De Smit P. Orale anticoagulantia en perifeer vaatlijden. Hartbulletin 1995;26:178-80.

10. Antiplatelet Trialists' Collaboration. Collaborative overview of randomised trials of antiplatelet therapy. 1. Prevention of death, myocardial infarction, and stroke by prolonged antiplatelet therapy in various categories of patients. BMI 1994;308:81-106.

11. Cameron HA, Walter PC, Ramsay LE. Drug treatment of intermittent claudication: a critical analysis of the methods and findings of published climical trials, 1965-1985. Br / Clin Pharm 1988;26:569-76.

12. Hess $H_{v}$ Mietaschk $A$, Deischel $G$. Drug induced inhibition of platelet function delays progression of peripheral occlusive arterial disease: a prospective double blind arteriographically-controlled trial. Lancet 1985:332:415-9.

13. Rutherford RB. Standards for evaluating results of interventional therapy for peripheral vascular disease. Circulation 1991;83 [stuppl 1]:I-6I-11.

14. Hiatt WR, Hirsch AT, Regensteiner JG, Brass EP. Clinical trials for claudication. Assessment of exercise performance, functional status, and clinical end points. Vascular Clinical Trialists. Circulation 1995;92:614-21.

15. Stoffers HEJH, Kester ADM, Kaiser V, Rinkens PELM, Koottnerus JA. Diagnostic value of signs and symptoms associated with peripheral arterial occlusive disease seen in general practice: a multivariable approach. Med Decis Making 1997:17:61-70.

16. Leng GC, Fowkes FGR. The Edinburgh Claudication Questionnaire; an Improved version of the WHO/Rose Questionnaire for use in epidemiological surveys. J Clin Epidemiol 1992;45:1101-9.

17. Jenmich RI, Schluchter MD. Unbalanced repeated-measures models with structured covariance matrices. Biometrics 1986;42:805\%20.

18. Stoffers HEH, Kester ADM, Kaiser V, Rinkens PELM, Kitslaar PJEHM, Knotmerus IA. The diagnostic value of the measurement of the ankle-brachial systolic pressure index in primary health care. J Clin Epidemiol 1996:49:1401-5.

19. Knottnerus JA. Medical decision making by general practitioners and specialists [editoriall. Fam Pract 1991;8(4):305-7.

20. Coccheri S, Palareti $G$, Fortunata $G$. Antitrombotic drugs in peripheral obiliterative arterial diseases. Haemostasis 1994;24:118-27. 
21. Eccles $M_{*}$ Fremantle $N$, Mason J. North of England evidence based guideline development project: guideline on the use of aspirin as secondary prophylaxis for vascular disease in primary care. BMI 1998;316:1303-9.

22. Consensus antitrombotic prophylaxis of vascular incidents in patients with manifest atherosclerotic vascular diseases. Central Guidance Organisation for Peer Review. Ned Tijdschr Geneeskd 1998: 142:83-88.

23. Antiplatelet Trialists' Collaboration. Collaborative overview of randomised trials of antiplateler therapy. 2. Maintenance of vascular graft or arterial patency by antiplatelet therapy. BMJ $1994 ; 308: 159-68$.

24. Leng GC, Lee AJ, Fowkes FGR, Whiteman M, Dumbar J, Housley E, Ruckley V. Incidence, natural history and cardiovascular events in symptomatic and asymptomatic peripheral arterial disease in the general population. Int J Epidemiol 1996;25:1172-81.

25. Hooi JD, Stoffers HEJH, Kester ADM, Rinkens PELM, Kaiser V, van Ree JW, Knottnerus IA Risk factors and cardiovascular diseases associated with asymptomatic peripheral arterial occlusive disease. The Limburg PAOD Study. Peripheral Arterial Occlusive Disease. Scand J Prim Health Care. 1998 Sep;16(3):177-82.

26. Fowkes FGR, Price JF. Targeting subclinical atherosclerosis. BMJ 1998;316:1764.

27. Jonason $T$, Bergstrom $R$. Cessation of smoking in patients with intermittent claudication. Effects on the risk of peripheral vascular complications, myocardial infarction and mortality. Acta Med Scand 1987;221:253-60.

28. Kottke TE, Battista RN, DeFriese GH, Brekke ML. Attributes of successful smoking cessation interventions in medical practice. A meta-analysis of 39 controlled trials. IAMA. $1988 ; 259: 2883-9$.

29. Brandsma JW, Robeer $\mathrm{BG}_{8}$ van den Heuvel S, Smit $B$, Wittens $\mathrm{CH}$, Oostendorp RA. The effect of exercises on walking distance of patients with intermittent clatudication: a study of randomized clinical trials. Phys Ther 1998;72:278-86.

30. Regensteiner JG, Gardner A, Hiatt WR. Exercise testing and exercise rehabilitation for patients with peripheral arterial disease: status in 1997. Vasc Med 1997;2(2):147-55.

31. Vhes de SO. Management strategies for intermittent claudication [PhD Thesis]. Groningen: Rijksuniversiteit Groningen, 1998.

32. Kitslaar PJEHM Consensus diagnosis and treatment of arterial intermittent claudication. Central Guidance Organisation for Peer Review. Ned Tijdschr Geneeskd 1997;141: $2396 \sim 400$. 
7 1 Prognostic indicators for outcome of peripheral arterial occlusive disease in general practice

Kaiser V, Kester ADM, Knottnerus JA, Leeuw de M, Stoffers HEJH 


\begin{abstract}
Objectives: to investigate the prognostic value of various known risk factors and the effect of conservative treatment on the course of peripheral arterial occlusive disease in general practice.

Design: prospective cohort study.

Setrimg: 22 general practices in Limburg, the Netherlands.

Subjects: 265 patients aged $45-70$ years with an ankle brachial systolic pressure index (ABPI) lower than 95\% att two consecutive measurements.

Outcome measures: mortality, first episode of stroke or myocardial infarction, progressive ischemia, deterioration of complaints, progression of symptoms, decrease in ABPI.

Results: the ABPI at diagnosis is a sigmificant prognostic determinant for mortality (HR 0.46). For myocardial infarction as outcome, ABPI (HR 0.48), previous stroke (HR 5.6) and previous angina pectoris (HR 2.37) had prognostic relevance. Although not significant, the effect of wallking exercise suggested a protective effect on mortality (HR 0.44, CI 0.16-1.23) and progressive ischemia (HR 0.67, $\mathrm{Cl} 0.28-1.21$ ).

Conclusion: the ABPI at diagnosis is the most consistent prognostic factor for adverse outcome events in the course of PAOD.
\end{abstract}




\section{Introduction}

PAOD has a relatively benign prognosis. In $25 \%$ of patients with intermittent claudication the disease will show progression as to complaints and/or tissue damage. In 1-10\% of patients with claudication vascular surgery is needed. In the management of patients with PAOD in general practice patients with symptomatic disease (intermittent claudication) are instructed to stop smoking and to do walking exercises ${ }^{2} 3$ However, the majority of patients with PAOD are asymptomatic and not known to their general practitioner. The clinical course in asymptomatic PAOD is less clear. 24

The best known unfavourable prognostic factors are smoking and stage of disease Since PAOD is a manifestation of general atherosclerosis and a predictor of other cardiovascular morbidity and mortality, risk factor management is of a more general interest. Also in asymptomatic PAOD there is an increased risk of vascular problems. ${ }^{6}$

Detecting patients with PAOD in high risk groups is advocated. ${ }^{7} 8$ The role of these risk factors is often studied separately. ${ }^{9}$ The combined effect of several risk factors is not clear. Accordingly, the effect of all efforts in risk management of cardiovascular disease is still a matter of debate. 10

Prognostic factors which can be influenced by patients and physicians as smoking, the amount of physical exercise, diabetes mellitus, hypertension, hypercholesterolemia and the use of vasoactive drugs, are of special interest. Studies on prognosis in general practice are of importance regarding the specific prognostic spectrum the primary care setting. ${ }^{11}$.

We studied the simultaneous prognostic value of various known risk factors and the effect of compliance with conservative treatment on the course of PAOD and the manifestation of other vascular events in patients with PAOD in general practice.

\section{Methods}

\section{Design}

The cohort study presented here, is part of the 'Limburg PAOD Study', a research project conducted at the Maastricht University (the Netherlands) and in close co-operation with 22 general practice centres. The study was first designed as a randomised controlled clinical trial. The results of this trial will be published elsewhere. [submitted]. In the prognostic factor analysis presented here, all patients of the trial were analysed as members of a cohort with a follow-up period of three years. Whille having data on medical history, physical examination and ABPI at every for monthly visit, we could determine prognostic models on these outcome measures. 
66 Chupuer 7

Table 1. Patient baseline characteristics $(n=265)$ number (percentages)

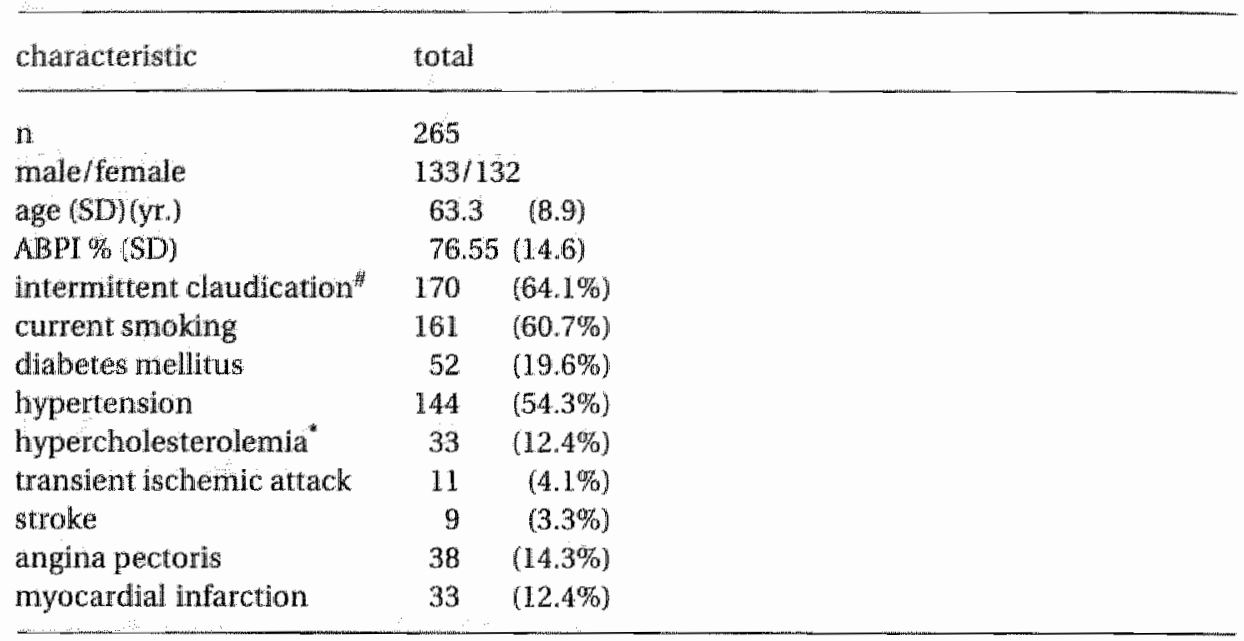

"missing $\mathrm{n}=6$, "missing $\mathrm{n}=10$,

\section{Study population}

In the 'Limburg PAOD Study' cohort, data on signs and symptoms of PAOD, vascular risk factors, and the ankle brachial pressure ratio (ABPI) were collected among patients aged between 40 and 75 years from 22 general practice centres.

Inclusion criterion was an ABPI lower than $95 \%$ on two consecutive measurements within one week at the leg with the lowest ABPI (index leg).

Exclusion criteria were the following conditions: present gastric complaints; history of gastric or duodenal ulcer; history of gastric bleeding; current treatment with oral anticoagulant drugs; current use of aspirin-like or platelet inhibitory drugs; previous vascular surgery or endovascullar procedures of the index leg.

A total of 287 patients were included. For the follow-up visits 22 patients did not show up: five died, three patients moved and fourteen were not interested anymore. The analysis on mortality was done on 287 patients. The baseline characteristics of the remaining 265 patients in the analysis are shown in table 1.

All patients were instructed by their general practitioner to stop smoking and to do regular walking exercise. This instruction was handed out on a leaflet and repeated at every visit.

All patients were scheduled to visit the general practitioner every four months.

\section{Measurements}

At each follow-up visit the GP interviewed the patient and filled in a PAOD questionnaire regarding changes in the experienced walking distance, compliance of 
study medication, smoking behaviour, compliance of walking exercise and occurrence of adverse events. The patient record was checked for occurrence of recently diagnosed transient ischemic attack, stroke, angina pectoris, myocardial infarction, hypertension, diabetes mellitus or hypercholesterolemia. Changes in comedication were noted. A physical examination was performed: weight, blood pressure, inspection of the legs, palpation of the skin, palpation of femoral, posterior tibial and dorsal pedal pulses, auscultation of the abdominal aorta and the femoral arteries.

The ABPI was assessed by a practice assistant with a hand-held Doppler device (Huntleigh Mini Dopplex D500, $8 \mathrm{MHZ}$ ) and a sphygmomanometer. Systolic pressures were recorded on both arms and the posterior tibial arteries with the patient lying in supine position. The ABPI for each leg was defined as the systolic pressure at the ankles divided by the highest systolic arm pressure.

\section{Independent variables}

As prognostic variables were included in the models the following base-line characteristics gender $(0=$ male, $1=$ female), age, intermittent claudication $(0=a b s e n t, \mathbb{1}=$ present), diabetes mellitus $(0=\mathrm{absent}, 1=$ present $)$, hypertension $(0=\mathrm{absent}, 1=$ present), hypercholesterolemia ( $0=a b s e n t, 1=$ present), angina pectoris $(0=a b s e n t$, $1=$ present), myocardial infarction ( $0=$ absent, $1=$ present), transient ischemic attack $(0=$ absent, 1 =present), stroke $(0=$ absent, $1=$ present $)$

\section{Time dependent variables}

To investigate the association of adherence to the instructed conservative measures during follow-up three time dependent variables were used in the models:

smoking: the number of smoked cigarettes at every visit

walking: patients were asked at each visit whether they performed their instructed walking exercises daily.

aspirin-use: compliance of study medication was checked at every visit. All patients were asked whether they took aspirin prescribed by any physician or on their own account beyond the study medication.

\section{Events}

Mortality: from the patients medical record date and cause of death of the patient were noted. Data on fatal stroke, myocardial infarction, sudden death, and abdominal aortic aneurysms were obtained. Death from other causes were also reported. All deaths were coded based on the International Classification of Primary Care.

Non-fatal cardiovascular events. 
The following conditions were noted as events.

Progressive ischemia when a patients needed reconstructive or percutaneous transluminal angioplasty or amputation.

Cerebrovascular events: first episode of transient ischemic attack (TIA) or stroke

Cardiovascular events: first episode of angina pectoris or myocardial infarction

Symptoms at physical examination: as an event indicative for deterioration of PAOD were noted: new occurrence of absent foot pulses, new occurrence of a bruit over the femoral artery and a new occurrence of a difference in skin temperature of both feet

Deterioration of complaints: deterioration of experienced walking distance and/or a first episode of nocturnal leg pain or a first episode of intermittent claudication in patients asymptomatic at the start of the study.

Decrease of $A B P I$ : a decrease of the ABPI of the index leg compared with the $\mathrm{ABPI}$ at the start was greater than $20 \% \mathrm{ABPI}$ at one occasion, or a decrease of at least $15 \%$ measured on two consecutive follow-up visits.

\section{Statistical analysis}

Patients' baseline characteristics were presented as percentages for categorical variables, and as mean and standard deviation for continuous variables. To investigate the association of adherence to the conservative measurements ("life-style advice') and the risk for events indicative for progression of PAOD, Cox proportional hazards regression models with time dependent covariables were used. Separate models were applied for each of the indicator events, while we assumed the hazard in each between-visits interval to be proportional to the protocol adherence in that interval. For all events, patients with a baseline history for that event were excluded. With the analysis of morbidity and events indicative for progression of PAOD, mortality was included as an event. Associations were deemed significant when the likelihood ratio chi-square p-value was $\leq 5 \%$.

\section{Results}

The baseline characteristics of the 265 in the analysis are shown in table 1 . The mean follow-up time was 31.6 months (SD 12.5, range 0-50 months). 33 patients (20.5\%) stopped smoking, 98 (36.9\%) did their walking exercises and $54(59.3 \%)$ took their aspirin study medication during their whole individual follow-up period. After two years of follow-up $68.0 \%$ took their aspirin. A number of 21 $(7.7 \%)$ patients of the non-aspirin randomisation groups took aspirin during the follow-up period on their own account or prescribed by a physician. 
mortality

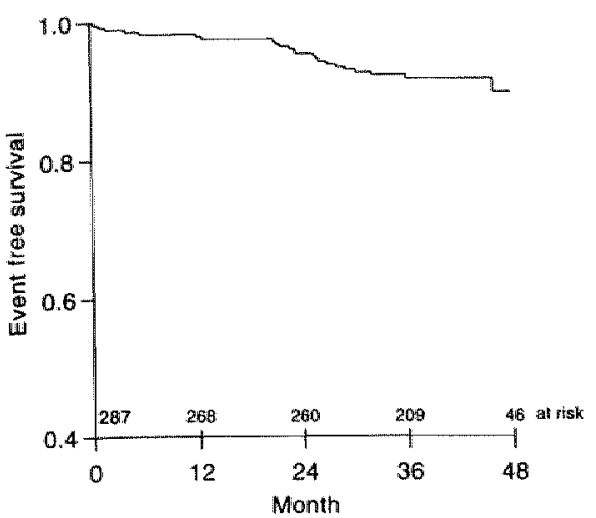

myocardial infarction

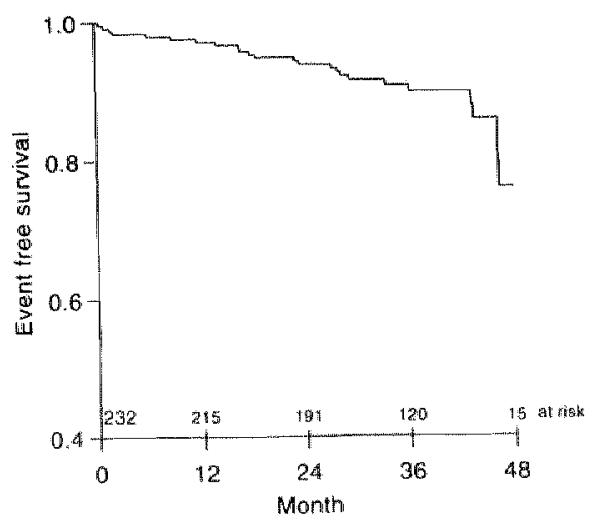

stroke

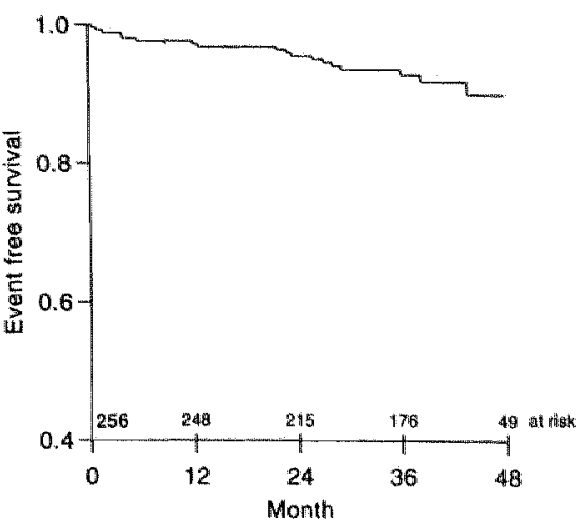

Figure 1. Event-free survival curves for mortality, stroke, myocardial infarction. 
$70 /$ Chapter 7

operation

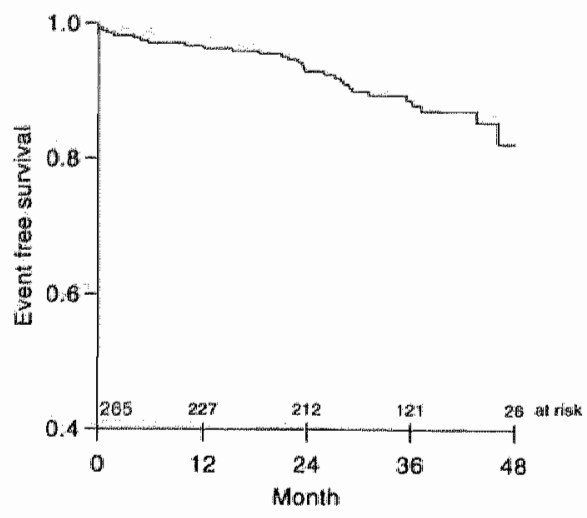

symptoms

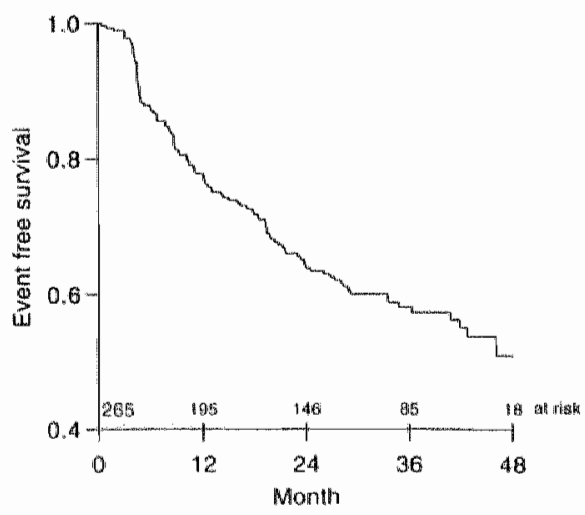

complaints

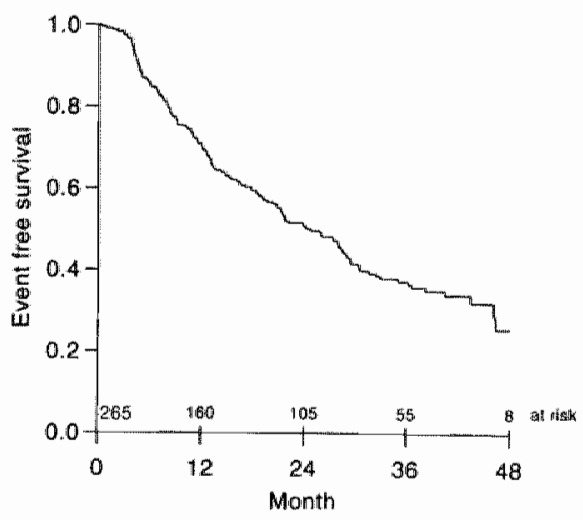

$\mathrm{ABPI}$

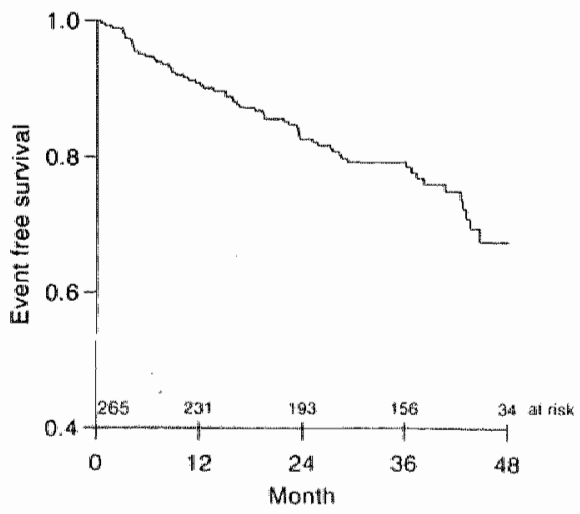

Figure 2, Event-firee surviwal curves for operation, complaints, symptoms, ABPI. 
Table 2. Adjusted hazard ratios (HR) of baseline characteristics and time dependent interventions (smoking, walking, aspirin use) on mortality, occurrence of first stroke and first myocardial infarction in patients with $\mathrm{PAOD} .(\mathrm{n}=265)$

\begin{tabular}{|c|c|c|c|c|c|c|}
\hline \multirow[t]{2}{*}{ Variables } & \multicolumn{2}{|c|}{ mortality } & \multicolumn{2}{|c|}{ stroke } & \multicolumn{2}{|c|}{ myocardial infarction } \\
\hline & $\mathrm{HR}$ & $(95 \% \mathrm{Cl})$ & $\mathrm{HR}$ & $(95 \% \mathrm{Cl})$ & HR & $(95 \% \mathrm{Cl})$ \\
\hline $\mathrm{AEPI}(\mathrm{t}=0)$ & 0.46 & $(0.26-0.80)$ & 0.57 & $(0.28-1.12)$ & 0.48 & $(0.25-0.94)$ \\
\hline gender $\mathrm{r}^{\text {fH }}$ & 1.01 & $(0.37-2.77)$ & 0.56 & $(0.18-1.69)$ & 0.42 & $(0.16 \cdot 1.14)$ \\
\hline age & 0.99 & $(0.55-1.78)$ & 1.46 & $(0.73-2.95)$ & 1.44 & $(0.79 \cdot 264)$ \\
\hline intermittent claudication* & 0.39 & $(0.04-4.05)$ & 0.71 & $(0.09 \cdot 5.84)$ & 0.85 & $(0.17-4,22)$ \\
\hline diabetes mellitus* & 1.61 & $(0.59-4.40)$ & 0.99 & $(0.31-3.21)$ & 0.62 & $(0.18-2.13)$ \\
\hline hypertension* & 0.38 & $(0.14-1.05)$ & 0.85 & $(0.31-2.33)$ & 0.59 & $(0.23-1.55)$ \\
\hline hyypercholesterolemia* & 0.64 & $(0.14-2.86)$ & 0.88 & $(0.19 \cdot 4.10)$ & 1.25 & $(0.30-5.18)$ \\
\hline myocardial infarction* & 1.92 & $(0.55-6.64)$ & 1.20 & $(0.29-4.99)$ & - & \\
\hline angina pectoris & 1.99 & $(0.65 \cdot 6.13)$ & 1.58 & $(0.45-5.63)$ & 3.42 & $(1.15-10.16)$ \\
\hline transient ischenic attack* & 0.38 & $(0.03-4.38)$ & & - & 0.99 & $(0.14-6.82)$ \\
\hline stroke $e^{*}$ & 4.45 & $(0.62-31.68)$ & & - & 5.60 & $(1.06-29.51)$ \\
\hline smoking & 1.11 & $(0.37-3.36)$ & 1.02 & $(0.32-3.24)$ & 1.92 & $(0.69-5.33)$ \\
\hline walking & 0.44 & $(0.16-1.23)$ & 0.39 & $(0.13-1.10)$ & 0,40 & $(0.15 \cdot 1.07)$ \\
\hline$a_{s p i r i n}{ }^{+}$ & 1.84 & $(0.71-4.76)$ & 1.39 & $(0.48-3.97)$ & 2.37 & $(0.94-6.00)$ \\
\hline
\end{tabular}

*absent; $1=$ present; 0 =male $1=$ female; $* 0=$ not compliant, $1=$ compliant.

\section{Events}

Mortality: in the total follow-up period 23 patients died $(8.0 \%)$ : 19 patients had a cardiovascular death (myocardial infarction/heartfailure $n=15$, cerebrovascular death $n=4$ ), three patients died from gastrointestinal cancer and one died from lungcancer.

Non-fatal cardiotascular events: a first episode of stroke during the follow-up period occurred in 19 patients (7.4\%). First myocardial infarction was diagnosed in 24 patients (10.3\%).

Surgical or endovascular intervention was needed in 31 patients (11.6\%). Deterioration of complaints occurred in 146 patients (55.1\%). In 109 patients (41.1\%) abnormalities were detected at physical examination. A relevant decline in ABPI was detected in 62 patients (23.4\%).

In figure 1 the cumulative probability of event-free survival for mortality, first stroke and first myocardial infarction are shown.

In figure 2 the cumulative probability of event-free survival for progressive ischemia, deterioration of complaints first diagnosed abnormalities at physical examination and decline in ABPI are shown.

Prognostic value of baseline characteristics and time-dependent variables on mortality, stroke and myocardial infarction. 


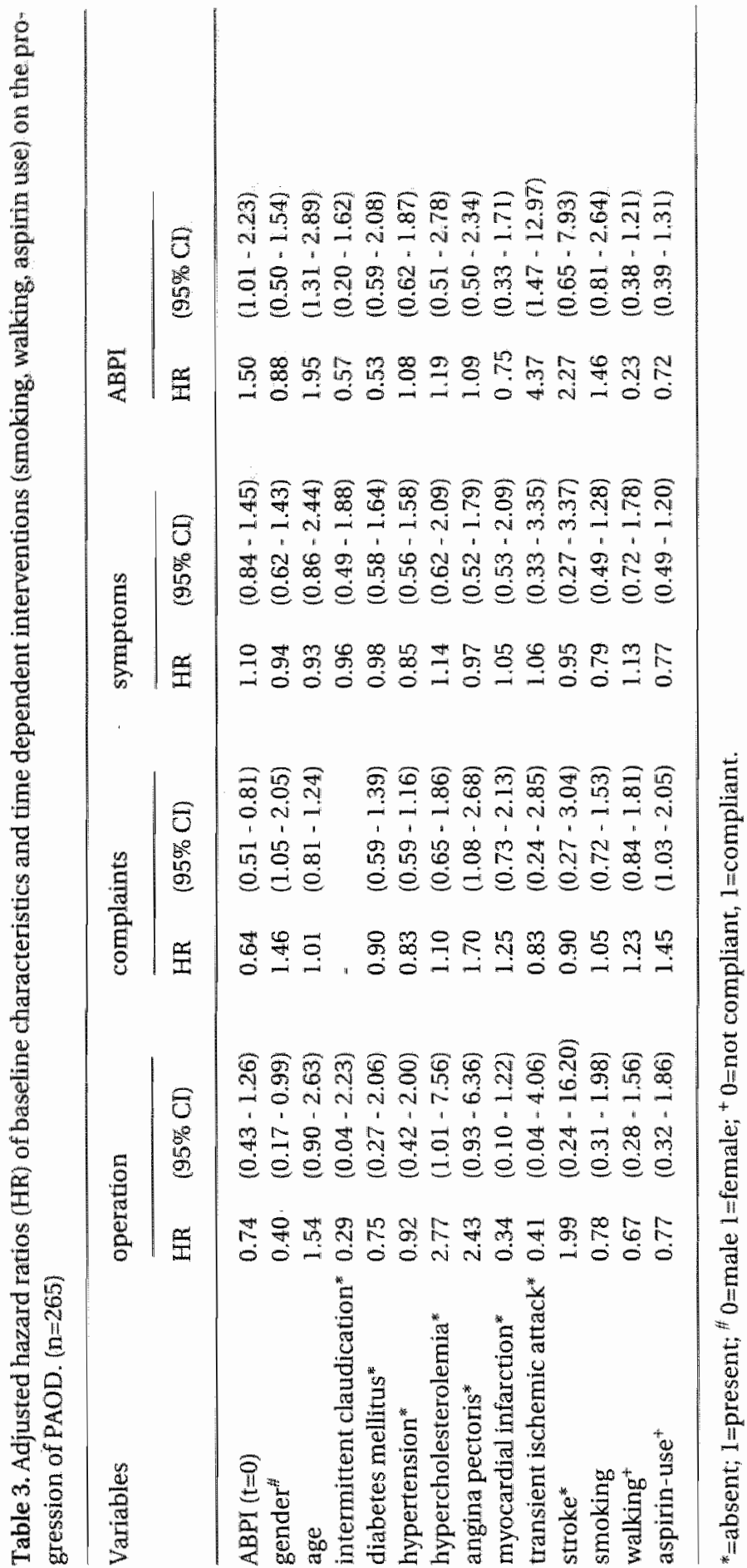


In table 2 the adjusted hazard ratios of baselline characteristics and time dependent variables on mortality cardio- and cerebrovascular morbidity are given.

Mortality: the ABPI at baseline was a significant negative predictor (HR 0.46 , $95 \%$ CI $0.26-0.80$ ) for overall mortality. Patients who did their daily walking exercise and patients with hypertension possibly had a lower risk for death but statistical significance was not reached.

Stroke: there were no significant prognostic variables in the prognostic model of stroke. The ABPI at baseline, gender and walking were suggestive prognostic determinants.

Myocardial infarction: the occurrence of first diagnosed myocardial infarction was significantly predicted by the ABPI at start, previous stroke and previous angina pectoris. Gender and walking were suggestive prognostic factors.

Prognostic value of baseline characteristics and time-dependent variables on progressive ischemia, development of complaints, findings at physical examination and decrease in $A B P I$.

In table 3 the adjusted hazard ratios of baseline characteristics and time dependent variables on events indicative for progression of PAOD are given.

Progressive ischemia: male gender (HR $0.4095 \% \mathrm{Cl} 0.17-0.99$ ) and hypercholesterolemia (HR $2.795 \% \mathrm{CI}$ 1.01-7.56) showed to be prognostic determinants for progressive ischemia. The ABPI at baseline, intermittent claudication, myocardial infarction, transient ischemic attack and walking possibly had a prognostic relevance but statistical relevance was not reached.

Progression of complaints. ABPI at start, female gender and previous angina pectoris were significant predictors of progression of complaints .

Physical examination: in the model on new findings at physical examination there were no significant or suggestive prognostic variables.

Decrease of $A B P I$ : the decrease of $A B P I$ was significantly predicted by the ABPI at start (HR 1.5, 95\% CI 1.01-2.23), age (HR 1.95, 95\% CI 1.31-2.89) and previous transient ischemic attack (HR 4.37, 95\% Cl 1.47-12.97).

\section{Time dependent variables}

Aspirin-use: the effect of the time dependent variables 'aspirin-use' in the models on consecutive events was only significant in the model on complaints. Patients who took aspirin had a higher probability of deterioration of complaints. The effect of aspirin on mortality was although non significant, not expected to be in the determinated direction. The reason of taking aspirin beyond the study protocol could possibly caused bias by indication. In an additionally analysis there were no death in the patients who took aspirin beyond the study protocol and there were not more cardio-/cerebrovascular events. 
Walking: this variable did not reach significance in any of the models. $A$ beneficial effect was suggested from the models on mortality, stroke, myocardial infarction, progressive ischemia and decrease of ABPI.

Smoking the effect of the amount of smoking on the models was small and non-significant.

\section{Discussion}

The results of the present study show that the ABPI at diagnosis is a significant prognostic determinant for mortality. In the progmostic model of myocardial infarction, ABPI, previous stroke and angina pectoris had prognostic relevance.

Progressive ischemia developed in $11.6 \%$ of the patients. This is large compared with the number of patients in the Framingham Study $14.3 \%$ after 18 years) and the Edinburgh Artery Study (2.2\% after 5 years). ${ }^{812}$ Surprisingly, factors as smoking, diabetes mellitus, complaints or presence of other cardiovascular disease were not of prognostic rellevance for this outcome event. The intervention in earlier stages of disease with the percutaneous transluminal angioplasty could explain the difference.

Progression of complaints was reported in $55.1 \%$ of the patients. Walking exercises showed to have a negative prognostic effect on progression of complaints.

In several studies the ABPI has been determined as a strong predictor of mortality and cardiovascular morbidity in patients with both symptomatic and asymptomatic PAOD. ${ }^{4} 71314$

In the Cardiovascular Health Study Newman found in a population of patients above 65 years old, both symptomatic and asymptomatic, a statistically decline of survival at each $10 \%$ decrement of $\mathrm{ABPI} .{ }^{15}$ This is consistent with our finding of a hazard ratio of 0.46 . In a retrospective survival analysis $\mathrm{McD}$ ermott showed a $H R$ of 1.8 for death in patients with a very low ABPI $(<30 \%) 16$

While the role of lifestylle advice in the management of PAOD is recommended, we determined the simultaneous prognostic effect of conservative management in terms of smoking behaviour, compliance to walking exercises and the use of aspirin. From the Edinburgh Artery Study we learn that there is a possible protective effect of exercise on the progression of disease. In our study the effect of daily walking exercise was not significant but suggested a protective effect on mortality (HR 0.44 CI 0.16-1.23) and on progressive ischemia (HR $0.67 \mathrm{Cl} 0.28-1.21$ ). ${ }^{2}$

Surprisingly, smoking behaviour and the use of aspirin were not of significant prognostic relevance for any adverse outcome events. The small proportion of patients who actually stopped or diminished smoking may be a reason for this. 17

The population of our study consisted of patients selected for a randomised clinical trial on the effect of aspirin on the course of PAOD. This cohort consisted of both symptomatic and asymptomatic PAOD patients. Since the increased risk 
of vascular problems also in asymptomatic patients has been established, conser vative treatment in terms of risk management and lifestyle advice is advocated.

Exclusion criteria may have caused some bias. Cardio- and cerebrovascular patients treated with aspirin were excluded. The number of patients with previous stroke and/or transient ischemic attack are relatively small. The relatively "healthy" PAOD patient remained within the cohort. Even with these limitations the selected population is rellevant for general practice.

In conclusion, our results show that known risk factors as diabetes mellitus, hypertension, hypercholesterolemia and concomitant cardio-cerebrovascular disease had no relevant prognostic relevance. The ABPI showed to be the most consistent prognostic factor for various adverse outcome events of PAOD. No protective effect of aspirin in combination with other lifestyle advice has been demonstrated. There might be a positive effect of walking exercise on the prognosis of PAOD related events, but the protective effect on other atherosclerotic events seems larger.

Further research on the prognosis in both symptomatic and asymptomatic patients with PAOD is required. Especially the effect of walking exercise needs further evaluation.

\section{Acknowledgements}

We thank the participating general practitioners for their contribution to this study: GHMI Beusmans, WPM Vierhout, T van Merode, TGI Lemmens ${ }^{\dagger}, \mathrm{PA}$ Stalenhoef, LGJ Huynen, GAHM Castermans, MPJM Peeters, FHJA Vissers (Maastricht), FI Guldemond (Ubachsberg), PBN Hulshof, RM Panhuysen, ETIM Guldemond-Hecker (Voerendaal), AA ten Berge, PFM van der Heyden (Roermond), WHM Nieuwdorp (Brunssum) H Logister ${ }^{\dagger}$, BTMG van der Werf (Heerlen), P. Athmer, G van Zanten, JJ Michels, WJ van der Wissel, A van Dam, C Hanssen, EHJF Hubbers, FLM Soomers, JMSJG Soomers-Turlings, PHM Passage, IHJ Drenth (Kerkrade), BHJM Otten (Merkelbeek), ESM Vijgen, TAlH VijgenHamers (Geleen), JHM Eussen, JAM Ypma, C Stuurman (Landgraaf), M van Bommel (Tilburg), Ph Govaert, RMFM Leclerq (Stein). This part of the Limburg PAOD Study was supported by a research grant of the former "Praeventiefonds", now "Zorg Onderzoek Nederland" (28-1323) and the Netherlands Organization for Scientific Research (900-715.154). The Doppler devices and the manufacturing and distribution of the study medication were granted by Asta Medica BV.

\section{References}

1. Dormandy JA, Mahir MS. Fate of the patient with chronic leg ischaemia. I Cardiovasc Surg 1989;30:50-7. 
2. Stoffer HEIH. Rinkens PELM. Kester ADM. Kaiser V. Knotinerus JA. The prevalence of asymptomatic and unrecognized peripheral arterial occlusive disease. Int I Epidemiol $1996,25: 282-90$.

3. Kitslaar PJEHM. Consensus diagnosis and treatment of arterial intermittent claudication. Central Gudance Organisation for Peer Review. Ned Tijdschr Geneeskd 1997; 141:2396-400.

4. Meijer WT. Peripheral arterial disease in the elderly. [Thesis]. Rotterdam, 1999.

5. Hooi ID, Stoffers HEH, Knottnerus JA, van Ree IW. The prognosis of non-critical limb ischaemia: a systematic review of population-based evidence. Br J Gen Pract 1999; 49: 49-55.

6. Leng GC, Lee Al, Fowkes FGR, Whiteman M, Dunbar J, Housley E, Ruckley CV. Incidence, natural history and cardiovascular events in symptomatic and asymptomatic peripheral arteriall disease in the general population. Int J Epidemiol 1996;25(6):1172-81.

7. Hooi JD, Stoffers HEJH, Kester AD, Rünkens PE, Kaiser V, van Ree JW, Knottmerus JA . Risk factors and cardiovascular diseases associated with asymptomatic peripheral arterial occlusive disease. The Limburg PAOD Study. Peripheral Arterial Occlusive Disease. Scand J Prim Health Care. 1998;16(3): 177-82.

8. Fowkes FGR. Housley E. Cawood EHH. Macintyre CCA. Rucklley CV. Prescott RJ. Edinburgh Artery Study: Prevalence of asymptomatic and symptomatic peripheral arteria] disease in the general population. Int J Epidemiol 1991;20:384-92.

9. Smit AJ. Combined cardiovascular risk intervention: a briclge between primary and secondary prevention? Neth J Med 1996;48:125-7.

10. Radack $\mathrm{K}$, Wyderski RJ. Conservative management of intermittent claudication. Ann Int Med 1990;113:135-46.

11. Knottnerus JA. Medical decision making by general practitioners and specialists leditorial]. Fam Pract 1991;8(4):305-7.

12. Kannel WB, McGee DL. Update on some epidemiological features of intermittent claudication: the Framingham study. I Am Geriatr Soc 1985;33:13-18.

13. Vogt MT, McKenna M, Anderson SJ, Wolfson SK, Kuller LH. The relationship between ankle-arm index and mortality in older men and women. J Am Geriatr Soc 1993;41 (5):523-30.

14. Kornitzer $M$, Dramaix M, Sobolski J, Degre $S$, De Backer G. Ankle/arm pressure index in asymptomatic middle-aged males: an indlependent predictor of ten-year coronary heart disease mortality. Anglology. 1995:46(3):211-9.

15. Newman B, Shemanski L, Manolio TA, Cushman M, Mittelmark M, Polak IF, Powe NR. Siscovick D. Ankle-arm index ats a predictor of cardiovascular disease and mortality in the Cardiovascular Health Study. The Cardiovascular Health Study Group. Arterioscler Thromb Vasc Biol. 1999;19(3):538-45.

16. McDermott MM, Feinglass J, Slavensky $R$, Pearce WH. The ankle-brachial index as a predictor of survival in patients with peripheral vascular disease. I Gen Intern Med 1994; $9(8): 445-9$.

17. Kottke TE. Battista RN, DeFriese GH. Brekke ML. Attributes of successful smoking cessation interventions in medical practice. A meta-analysis of 39 controlled trials. JAMA $1988 ; 259: 2883-9$. 


\title{
$8 \mid$ Conducting a clinical trial in a primary health care setting
}

\author{
B.W. Koes, V. Kaiser, L.M. Bouter
}

published in. T. Soc. Gezondheidsz. 1991,69:407-412 


\section{Abstract}

Conducting a clinical trial in a primary health care setting involves a number of practical problems. In planning a trial, consideration must be given to: a study of the literature, inclusion and exclusion criteria, measurement instruments, patient selection, organisation of the study, participating professionals, tandomisation procedure, monitoring, the trial protocol and ethical review of the protocol. The most important practical problems are: selecting the participating professionals " difficulty in recruiting enough suitable patients and deviation from the trial protocol. Designing and conducting a trial in a primary health care setting turns out to be no easy task, as: (a) the diseases studied are often less than clearly defined, (b) adequate measurement instruments are often not available, (c) prevalence and/or incidence may be lower, (d) often a large number of participating centres are needed, with the result that more logistical problems are likely. Given the differences between primary (outpatient) and inpatient care, one needs to consider when designing a trial, which setting is most suitable. The enthusiasm of the researcher and the participants is one of the factors determining the success of the study. 


\section{Introduction}

Studies of the effectiveness of primary health care are becoming increasingly common. The preference is to use the type of study known in the Anglo-Saxon literature as the 'randomised clinical trial' or RCT. This means a study designed as a randomised, and sometimes placebo controlled experiment. 12 In this article, the term 'clinical trial' will be used. This design of study is widely acknowledged to be the best way to compare two or more forms of treatment, or to compare one form of treatment with a placebo or the spontaneous (untreated) outcome ${ }^{3-5}$. This article looks at the practical aspects of the planning and conduct of clinical trials in primary health care settings. It attempts to draw on the authors' experiences in designing and carrying out clinical trials in collaboration with general practitioners and physiotherapists. ${ }^{67}$ The discussion begins with some aspects of planning a clinical trial in a primary health care setting which deserve specific attention. An analysis follows of the practical problems which may arise in gathering data for a clinical trial.

\section{Preparation}

The theoretical structure of a clinical trial is not discussed in this paper. A number of Dutch language introductory texts are available on this. 1.289 For more detailed information on this type of research, there are two well-known handbooks in English. ${ }^{10} 11$ The ten points addressed below concern the planning of clinical trials.

\section{Study of the literature}

In daily medical practice, a common issue is what treatment is best for a particular disease. The available literature can be searched for possible answers. Where questions still remain, it may be necessary to carry out a clinical trial. Besides information on the disease to be treated and the possible treatments, the literature can provide the basis for an initial choice of patient selection criteria, relevant outcome measures, and suitable measurement instruments.

\section{Patient selection.}

A fundamental decision is how to find the patients to be included in the study. It is. not necessary, in order to be able to measure the effect of the intervention, for the study population to be similar in all respects to the group of patients to whom the results of the research will be applied. What is important is that there should be no differences between the two populations in relation to factors which may be expected to influence the effectiveness of the treatment under investigation. 
There are different methods of finding patients. Each method has consequences for the extrapolation of the results. The choice of one of these patient selection methods will obviously be influenced by the nature of the question and the target population. With curative clinical trials, (especially with acute diseases) the 'reception counter" method will be the preferred option. With preventive trials, the general preference will be for screening of a population, whether or not on the basis of risk factors. The following methods of patient selection can be distinguished:

- Screening of an entire population: this means all members of a population (e.g. people registered in a GP's practice or people in a town) are checked for eligibility for participation. With this method, in principle all patients can be traced. The probability of selection distortion is small with this method, however it is very time-consuming for the researchers, and not very efficient where there is a low prevalence of the disease under study.

- Screening according to risk factors: here researchers consider the eligibility for participation of everyone exposed to a number of risk factors. So for example, in selecting patients with vascular constriction, people with an increased risk of developing this (hypertension, smoking, diabetes) are screened. A prerequisite however is an adequate and accessible system of records with which patients can be traced. This method is more efficient than the first one. There is a chance of selection distortion, as there may be patients who do not have the relevant risk factors. They will not then be included in the study.

- 'Reception' screening: Patients attending their GP's surgery who satisfy the inclusion criteria are asked to participate. Although the patients can easily be selected and approached with this method, it requires an alert and proactive attitude is needed from the participating doctor and good instructions from the assistant. The 'yield' from this form of patient selection is often lower than expected. This may be due to an over-optimistic estimate before recruitment. In most published articles, no attention is paid to the problems experienced in patient recruitment. The impression is given that it was not particularly difficult. However, the long recruitment period and the (too) low patient numbers often indicate that there were problems.

- External patient recruitment: patients can be approached to participate in a study by appeals in the press (advertisements and similar) or through patient associations. This method usually results in a high rate of response. For example, in a recent study of the effects of physiotherapy and manual therapy, patients were initially selected at the participating GPs" surgeries (reception method). ${ }^{9}$ Despite optimistic advance estimates of the number of available patients, the numbers recruited were disappointing. Appeals in the regional press to inform patients of the study (external recruitment) gave such a large response that the recruitment was brought back on schedule. Selection distortion is a possibility with this method. Although all patients have to satisfy inclusion and exclusion 
criteria laid down in advance, there may be prognostic factors which are unknown (or hard to measure) which affect the outcome of the therapy.

\section{Inclusion and exclusion criteria}

The effect of an intervention can only be assessed properly if the patients in the trial are reasonably similar to each other. Well described inclusion and exclusion criteria are needed to achieve a homogenous trial population. The trial group must be chosen in such a way that an observable effect may be expected from the intervention being studied. The more heterogeneous the trial population is, the greater the number of patients needed to be able to show an effect. However, the inclusion and exclusion criteria have a direct effect on the available supply of patients. Extensive exclusion criteria can sharply reduce the patient supply. Furthermore, although good, narrowly defined inclusion and exclusion criteria improve homogeneity, they may also influence the relevance of the trial if applied too rigidly.

\section{Measurement instruments}

Depending on the question posed and whether or not suitable measurement instruments are available, instruments may need to be developed or adapted to the setting in which they will be used. Measurement instruments which have been assessed for reliability, validity and responsiveness in an inpatient setting will generally have to be reassessed for use in a primary health care setting. The degree of reassessment needed will of course depend on the extent of the research already carried out on validity and reliability. Consideration must also be given to how well the instrument can be used (amount of equipment needed, cost of equipment, ease of use, user-friendliness for doctor's assistant).

It will be clear that preference should be accorded to measurement instruments which put the least burden on the GPs and patients involved. For example: in a study of vascular constriction of the lower extremity, finally a choice was made to measure ankle pressure by using a pocket Doppler instead of tests in a vascular lab. However, the diagnostic facilities in a vascular lab are more extensive and give a 'better' diagnosis. The burden on the patient, the limited availability of vascular labs and the ease of use of a pocket Doppler played a large role in this decision. ${ }^{12}$

\section{Randomisation procedure}

If randomisation is carried out using closed envelopes containing a note of the treatment, the researcher is dependent on the good faith of the person carrying out the randomisation. There can be a strong temptation to open the next envelope if the assigned treatment does not seem very suitable for the patient concerned. Central randomisation by telephone does not have this disadvantage. 
The problem here can be the accessibility of the central person. Commercial bureau's can offer a solution here as they carry out such work on a 24 -hour basis. In clinical trials where the person carrying out the randomisation is not "blind", telephone randomisation is preferable. This does not apply to double blind trials (e.g. using pre-packed medication).

\section{Organisation of the study}

Given the numbers of patients required for most trials, it is usually necessary to include several centres in a study. The multicentre character of a clinical trial has specific consequences, especially for its organisation. A recent publication summarises points for consideration in preparing a multicentre trial. ${ }^{13}$ Before the trial, an explicit agreement will be necessary between the researchers and the participating GPs on the content and definition of the therapies to be used in the trial, the formulation of inclusion and exclusion criteria, as well as the logistics of patient selection and randomisation. The final working agreements must be unambiguous, so that each person working on the study can check up on what they are supposed to be doing for the study at any time. "The most important aid here is a detailed strategy document with a set of standard forms for the data to be recorded.

\section{Participating professionals}

Reasons for GPs to take part in trials include: interest in the subject, the importance of the resullts for daily practice, and an acceptable burden for the doctor and/or the patient. Motives for not taking part are: unacceptable burdens on the doctor and/or patient, no interest in the question being addressed, and too much disruption of the daily running of the practice. It is particularly important for the GP in a solo practice that the study can be carried out alongside all the normal work of the practice GPs value being well informed in advance, particularly about the amount of time involved and the amount of any remumeration. The preference is to have this information in writing with the researcher going over it orally later ${ }^{7}$ 14 15 . It is difficult to tell which GPs are most suitable for participation. Good motivation is essential. Interest in and knowledge of research methodology also appears to be important ${ }^{16}$. Besides these, previous experience with research. including incorporating it into the daily running of a practice, is of course a prerequisite. It can sometimes be a problem to find enough GPs who are prepared to take part in a trial ${ }^{16}$. In a recently published study of the willingness of GPs to take part in pharmacological research, no particular characteristics of doctors personally or of practices were found to characterise GPs who did take part in drug trials. ${ }^{1318}$ The GP's attitude to research appears to be important in determining willingness to take part in trials. 


\section{Trial protocal}

The result of all the preparations is generally laid down in a trial protocol. "This includes a precise description of the question being addressed, the structure of the trial and the detailed strategy document. It is very advisable at this stage to test all aspects of the trial protocol. This is done in one or more so-called "pilot studies". This involves going through the trial with only a few patients. After the pilot study, the experience gained is used to decide on any necessary improvements to the trial protocol.

\section{Ethical review}

Although no legal framework is yet in place, the trial protocol will generally be assessed (before the pilot study) by a medical ethical committee (MEC) ${ }^{19}$ In principle, the research will often involve risks for the participating patients. The protocols are assessed by the MEC with regard to the scientific value of the study and the presence of an adequate informed consent procedure.

\section{Monitoring}

The quality of the data gathered should be monitored carefully throughout the course of the trial. A number of factors may impair the quality:

- Lack of experience at the start of the trial in using the lists and instruments concerned. Training and instruction before the trial begins can help here.

- As the trial proceeds, sloppiness can creep in as people become less attentive. For this reason the project managers should keep an eye on the data and give feed-back quickly.

- Disappointing numbers of patients recruited can lead to demotivation. ${ }^{7} 14$

Besides monitoring the follow-up of the individual patients, it is also important to supervise and continue to motivate the participating centres. It is essential to make information available on how things are going during the trial. Regulat personal contact between the research co-ordinator and the participating GPs is preferable. If problems with the trial protocoll are notified, they can be addressed. immediately. It is also useful to organise meetings to discuss the progress of the trial and any problems in carrying it out. A simple way of keeping researchers informed of progress is to send out written bulletins.

\section{Implementation and data collection}

However well a trial is planned, there are bound to be unexpected problems with collecting data. Logistical problems are especially likely in trials involving large numbers of participating practices. ${ }^{13} 19$ In the paragraphs below, a number of 
commonly occurring problems will be discussed and the primary health care aspects claborated.

\section{Patient recruitment}

During the trial, patient numbers often turn out to be a problem. Once recruitment has been completed, the numbers of patients who are suitable for the study appear to increase again. Some researchers have cynically referred to this as the 'black hole phenomenon' or as the 'Lasagna's law'. 20

Possible explanations for this 'study bound" phenomenon are:

- The GP is not sufficiently focused on whether patients are eligible for the trial. There is a very wide variety of patients in general practice. The proportion of patients who are eligible is usually small. They escape the GP's attention because of pressure of time and/or the GP's unverified assumption that a patient will not be willing to take part in the trial in question.

- Not all patients with the disease in question will be consulting the GP about that problem.

- Extensive exclusion criteria intended to make the patient population more homogenous have the effect of greatly reducing the numbers of eligible patients. The numbers lost as a result of exclusion criteria are generally difficult to infer from the literature and the availlable registration system, and are often much underestimated prior to the study.

What measures could be taken to solve the patient supply problem?

There are ways of keeping doctors focused on the study: an easily recognisable registration form or other reminder on the doctor's desk, or a weekly telephone call to ask whether any new patients have been accepted into the trial.

A poster or leaflets in the waiting room or items in the practice newsletter can encourage patients to mention to their doctor that they might be interested.

Given the fact that patient recruitment is always (to some extent) found disappointing, it is sensible to take this into consideration even at the preparation stage. The numbers of available patients can be estimated on the basis of: (a) existing morbidity records (b) a list kept un one or more general practices or clinics over a certain period, (c) a pilot study. Options (b) and (c) give better estimates because the inclusion and exclusion criteria can often be applied to these better than to the existing records. After estimating the numbers of patients required and the calculating the number of participating GPs required on that basis, it is still advisable to adopt a very wide margin (e.g. double).

If during the trial it turns out that the patient influx is less than expected, choices will have to be made:

1. to continue the trial but base it on fewer patients;

2. to extend the inclusion criteria or limit the exclusion criteria;

3. to increase the number of practices involved;

4. to increase the activities directed at recruiting patients; 
5. to increase the funding so that the length of the trial can be increased.

Option 1 has the disadvantage that the question posed will receive an answer with less precision (power). Option 2 has the disadvantage of altering the characteristics of the trial population, which has consequences for the interpretation and extrapolation of the results. In general option 2 is not to be recommended.

Option 3 is often preferred. If the numbers of patients entering the trial appears too low at the beginning, the number of GPs participating must be increased quickly. The problem is not usually resolved by waiting. Option 4 should only be chosen if increasing the number of participating GPs has also failed to solve the problem. Extra patient recruitment, other than by the participating GP or research co-ordinator, is possible by information in the waiting room and items about the trial in the local press. Option 5 also does little to harm the initial research question, but will often be difficult to achieve.

\section{Deviation from the protocol}

The starting point in carrying out a trial should be to follow the protocol strictly. If deviations have nonetheless taken place, they should be carefully recorded (for example in a log book) so that they can be taken into account in analysing the trial data. The records should also cover patients dropping out of the trial (with reasons) and compliance with the therapy.

In spite of giving 'informed consent', patients will often still have a preference for a certain therapy. If they are randomised to a different therapy, they may be more likely to drop out. This can obviously lead to a distortion in the trial results. It is therefore important to explain to patients (again) just before randomisation about the types of intervention involved and the consequences of participating in the research. This allows the patient to decide not to participate after all without jeopardising the validity of the trial. Another possibility is to take baseline measurements of patients first, and ask them to come back after, say, three weeks. After this initial period, the baseline measurements are repeated, and then the actual randomisation of suitable patients takes place. Patients who do not come back after the three weeks are not randomised. These will presumably be those less likely to comply, or those who find on reflection that they would rather not take part in the trial after all. ${ }^{1}$

Patients often find it difficult to go through with the follow-up procedure of measuring effects. The reasons for this can be feeling ashamed if they have not kept to the rules of the trial, but also any dissatisfaction they feel with the treatment allotted to them and/or the results of the treatment (including side effects). During the trial, the doctor or researcher should therefore keep motivating the patient to continue their participation. Dropping out or failing to comply can also be prevented by limiting the measurements of effects to what is really necessary to answer the question posed in the trial. Making measurements and recording data which are not to be included in the trial should be avoided. 
For the duration of the trial, the participating GP wears two hats; as researcher and as treating doctor. This can lead to a number of problems.

- In selecting patients (before randomisation) a doctor may favour a therapy for an individual patient which is not included in the trial. ${ }^{22}$ This can increase the pre-randomisation drop-out rate and contribute to low patient recruitment.

- If the selection of patients is not carried out by one person, there can be variation in how the diagnostic criteria are applied, even if these have been drawn up by consensus and formulated explicitly.

- If the patient also attends the surgery for other complaints, the doctor"s concentration on the issues covered by the trial may weaken.

- The doctor or paramedic may decide after randomisation not to give the treatment to which the patient has been randomised, but another treatment which they believe is more suitable for the patient.

- The protocol can sometimes be disrupted by doctors making their own judgements in the context of the trial. General practitioners are not, or not yet, accustomed to working strictly according to a diagnosis and treatment protocol. Individual interpretation of the protocol does not help the comparability of the results from different centres.

The problems described above can be reduced by involving GPs at the earliest possible stage of designing the trial. The researcher should also critically assess the patient data gathered during the recruitment stage of the trial, in order to spot any noticeable differences between centres in the numbers of patients randomised and/or patients dropping out. This may be a reason to discuss the issue with the relevant centre and to check whether the factors described above are playing a role, and how the protocol can best be maintained despite them. A solution for the third problem can be to plan activities connected to the trial for times outside surgery hours.

\section{Discussion}

It appears from the above that designing and implementing a clinical trial is no simple task. This applies to trials in primary health care settings as well as in hospitals. We have looked at the problems which may occur in designing and implementing trials in primary care centres. Some differences between this and hospital trials are:

- adequate measurement instruments are often not yet available or cannot easily be applied in a primary care centre, and may therefore need to be developed or adapted;

- lower prevalence and/or incidence will often mean several centres have to be included in the trial in order to achieve the necessary patient numbers;

- more logistical problems may be encountered due to the larger number of participating centres. 
Given the problems which may arise in carrying out a clinical trial in a primary health care setting, it is important to give prior consideration to the trial's feasibility. It is entirely conceivable for a question relevant for primary health care (such as the effectiveness of a certain drug) to be more suitable for investigation in a hospital setting, for example if a trial can be carried out in one centre with a large concentration of suitable patients. A prerequisite is of course that the results should be relevant to the primary health care setting.

However careful the planning, a degree of tension will always remain between theory and practice when it comes to researching the effectiveness of different interventions. The researcher"s enthusiasm for finding an answer to the question posed, and the extent to which participating GPs can be similarly enthused will be among the factors determining the success of such research.

\section{References}

1. Knottnerus JA, de Vet HCW. Effectiviteitsonderzoek in de huisartspraktijk. 2: Gecontroleerd interventie-onderzoek op basis van randomisatie. Huisarts Wet 1987; 30: 72-5.

2. Knottnerus IA, Volovics A. Gecontroleerd interventie-onderzoek op basis van randomisatie. Huisarts Wet 1988;31:301-7.

3. Miettinen, O.S., Theoretical epidemiology. New York, Wiley 1985.

4. Feinstein, A.R., Clinical epidemiology: the architecture of clinical research. Philadelphia Saunders 1985.

5. Vandenbroucke JP. De plaats van het klinische experiment in de geneeskunde. Ned Tijdschr Geneesk 1988;132:2014-6.

6. Koes BW, Bouter LM, Knipschild PG, van Mameren H, Essers AHM, Houben JP, Verstegen GMJR, Hofhuizen DM. The effectiveness of manual therapy, physiotherapy and continued treatment for chronic non-specific back and neck complaints: design of a randomized trial. I Manipulative Physiol Ther 1992;15:16-23.

7. Stoffers $H E J H$, Kaiser $V$, De uitvoering van patientgebonden aandoeningsgericht wetenschappelijk onderzoek in de huisartspraktijk. In: J.C. van Es e.a., Het medisch faar 1990. Utrecht, Bohn Scheltema en Holkema, 1990.

8. Tijssen JGP, Lubsen $L_{v}$ Roelandt ${ }_{R} R T C$. Grondslagen van interventie-onderzoek. Ned Tijdschr Geneesk 1988;132:2006-10.

9. Bouter LM, Knipschild PG. Het experiment als paradigma voor interventie-onderzoek in de fysiotherapie. Ned Tijdsch Fysiotherapie 1987;97:56-61.

10. Pocock SJ. Clinical Trials: a practical approach. Chicester, Wiley 1983.

11. Meinert C. Clinical Trials: design, conduct and analysis. Oxford, Oxford University Press, 1986.

12. Kaiser V. Stoffers HEJH. Peripheral arterial obstructive disease in general practice: diagnosis, natural history and intervention. Abstract EGPRW meeting Amsterdam 7-10 may 1987. Allgemein Medizin 1988.

13. Warlow C. Organise a multicentre trial: how to do it. BMJ 1990;300:180-3. 
$8 8 \longdiv { \text { Chapter } 8 }$

14. Prenger-Duchateau AMH, Op weg naar een betere samenwerking. Scriptie huisartsenopleiding Rijksuniversiteit Limburg, Maastricht 1989.

15. Kocken WJ, Prenger-Duchateau A, Smeets-Rinkens PELM, Knottnerus IA. Het oordeel van huisartsen over deelname aan wetenschappelijk onderzoek. Huisarts Wet 1992;35: $32-4$.

16. Borgiel AEM, Dunn EV. Recruting family physicians as participants in research. Fam Practice 1989;6:168-72.

17. Taylor KM, Kelner M. Interpreting physician participation in randomized clinical trials: the physician orientation profile. J. Health Soc Behav. 1987;28:389-400.

18. Bock GH de, van der Veen BW, van Doorn BA. Onderzoeksbereidheid bij huisartsen. T. Soc.Gezondheidsz. 1991;69:132-6.

19. Lang $\mathrm{R}$ de. Voorwaarden voor klinisch geneesmiddelenonderzoek in de huisartspraktijk. The Practitioner (Ned) 1987;741-8.

20. Offerhaus L. Klinisch geneesmiddelenonderzoek: uitvoerbaarheid, uitvoering en beoordeling in de praktijk. Ned Tijdschr Geneesk. 1988;132:2010-13.

21. Gore SM. Assessing clinical trials: first steps. BM] 1981;282:1605-7.

22. Lankhorst, GJ. Clinical trials; de toelaatbaarheid van generalisatie van de uitkomsten. Ned Tijdschr Geneesk. 1987;131:2118-20. 
$9 \mid$ General discussion

\section{General discussion}

In this chapter the results of the Limburg PAOD study are discussed. The discussion will focus on the studies presented in this thesis. In addition, methodological issues are summarised and implications for general practice are discussed. Recommendations for further research are made.

\section{Reproducibility of the ABPI}

When designing our main study on the effect of aspirin on the course of PAOD in general practice we had to decide on the effect measure. We chose for reasons stated later the Ankle Brachial Pressure Index (ABPI).

Data on reproducibiluty and validity in the setting of general practice are published by Stoffers earlier. ${ }^{12}$ In the study presented in this thesis we concluded that the reproducibility of the ABPI is influenced significantly by the level of experience of the observers in measuring the ABPI. Within the same observers there was only a slight increase of the intra-observer variability in two years.

From the three studies in the Limburg PAOD study part 1 and part 3 on the reproducibility and validity of the ABPI measurement and the presented study in this thesis it can be concluded that the ABPI measurement is suitable in epidemiological, diagnostic and in follow-up studies of patients with PAOD. The reported intra- and inter observer SDs can be important in the planning of studies based on the AB ratio. For large studies with multiple observers one would not likely assume that observers could become very experienced, and then the "less experienced" between-observer SD (13.8 AB ratio of) should be used in the planning of the study. For smaller studies maybe all measurements could feasibly be done by the same observer, one might use the smaller "most experienced" intra-observer SD $(7.3 \%)$ in planning.

In the setting of the general practitioner the use of the ABPI in diagnosing PAOD has shown to be valid in a study in which the level of experience of the observers was comparable with that in the present study. It is important that one or two assistants per group of 3000-4000 patients should perform ABPI measurements only in order to maintain a reasonable level of experience. 


\section{Randomised clinical trial: the effect of aspirin on the course of PAOD in general practices}

The benefits of using aspirin in secondary prevention of myocardial infarction and stroke have been convineingly shown in some larger studies. ${ }^{34}$

In our study we could not demonstrate any beneficial effect of aspirin on the course of PAOD. In contrast to Hess et al. we could not show a beneficial effect of platelet inhibition, no difference in the mean ABPI was observed after two years of follow-up, 5

A recent review on the use of aspirin as secondary prophylaxis for vascular disease recommended that patients with intermittent claudication who have an increased vascular risk should be treated with aspirin. However, there was insufficient evidence to support the use of prophylactic aspirin in patients with intermittent claudication but no additional risk factors. ${ }^{6}$ In our study we used the change in $A B P I$ as primary endpoint while in most of the studies on secondary prevention of cardio- and cerebrovascular events complaints of intermittent claudication were used as an endpoint. ${ }^{7}$ Of our patients $35 \%$ were asymptomatic but had PAOD on the criterion of an ABPI lower than $95 \%$. Leng et al. showed that asymptomatic and symptomatic patients have a comparable risk for cardio-and cerebrovascular events. From this it is assumed that it is worthwhile to detect asymptomatic PAOD and treat these patients with aspirin to prevent major cardiovascular events. ${ }^{8-10}$

The trial was primarily designed to study the effect of aspirin on the ABPI and had a sufficient sample size for this purpose. Our study was not primarily designed on the effect of aspirin on cardiovascular events. Although, we found no effect of aspirin in preventing major cardiovascular events, the statistical power to detect a possible difference was too small to draw final conclusions on this issue.

In our study the ABPI was mostly affected by smoking. This has also been found in other observational and follow-up studies on PAOD. The deteriorating effect of smoking on the prognosis of PAOD has been well established.11-13 Despite the advice to stop smoking in every patient at each visit the number of PAOD patients that quit smoking was only $19 \%$. This is consistent with other studies on success of smoking cessation strategies revealing success in $5-25 \%$ of patients with cardiovascular diseases. 14

Walking exercise has shown to be effective in treating intermittent. claudication. However, there is no consensus on the most effective exercise program in patients with PAOD. ${ }^{15} 16$ In our study the compliance of patients in doing regular exercises over a period of two years was $67 \%$. This is comparable to the compliance in exercise studies with a supervised 6 months program. 17 our outcome measure of "experienced walking distance" was rather subjective. Apart from practical considerations regarding this primary care based trial including also asymptomatic patients, this choice is conceptually appropriate with the ABPI as the primary endpoint and the importance of subjective assessment of improvement. ${ }^{18}$ 


\section{Prognostic indicators of PAOD in general practice}

We studied the simultaneous prognostic value of various known risk factors and the effect of compliance with conservative treatment on the course of $\mathrm{PAOD}$ and the manifestation of other vascular events in patients with PAOD in general practice.

The results of the present study show that the initial ABPI is a significant prognostic determinant for mortality. In the prognostic model of myocardial infarction ABPL, previous stroke and angina pectoris had prognostic relevance.

Progressive ischemia developed in $11.6 \%$ of the patients. This is large compared with the number of patients in the Framingham Study (4.3\% after 18 years) and the Edinburgh Artery Study (2.2\% after 5 years) ${ }^{819}$ Surprisingly, factors as smoking, diabetes mellitus, complaints or presence of other cardiovascular disease were not of prognostic relevance for this outcome event. The intervention in earlier stages of disease with the percutaneous transluminal angioplasty could explain the difference.

Progression of complaints was reported in $55.1 \%$ of the patients. Walking exercises showed to have a negative prognostic effect on progression of complaints.

In several studies the ABPI has been determined as a strong predictor of mortality and cardiovascular morbidity in patients with both symptomatic and asymptomatic PAOD. $20-24$

In a retrospective survival analysis McDermott showed a HR of 1.8 for death in patients with a very low ABPI $(<30 \%){ }^{25}$ In the Cardiovascular Health Study Newman found in a population of patients above 65 years old, both symptomatic and asymptomatic, a statistically decline of survival at each $10 \%$ decrement of ABPI. 26

Since the role of lifestyle advice in the management of PAOD is recommended, we determined the simultaneous prognostic effect of conservative management in terms of smoking behaviour, compliance to walking exercises and the use of aspirin. From the Edinburgh Artery Study we learn that there is a protective effect of exercise on the progression of disease. ${ }^{8}$ In our study the effect of daily walking exercise was suggestive of a protective effect on mortality (HR $0.44 \mathrm{CI} 0.16-1.23$ ) and on progressive ischemia (HR 0.67 CI 0.28-1.21).

Smoking behaviour was not of significant prognostic relevance for any adverse outcome events. The small proportion of patients who actually stopped or diminished smoking may have caused lacking statistical power. Even the emphasis on smoking cessation every four months by the general practitioner showed not to be effective. Despite the known risk of smoking in cardiovascular disease smoking cessation strategies revealed success in $5-25 \%$ in patients with symptomatic disease. 27

In conclusion our study shows:

- the ABPI showed to be the most consistent prognostic factor for various adverse outcome events of PAOD. 
- there is no protective effect of aspirin in combination with other lifestyle advice.

- conclusions on the effect of smoking could not be made because of the small number of patients who actually did stop smoking.

- there might be a positive effect of walking exercise on the prognosis of PAOD related events; but the protective effect on other atherosclerotic events seems larget.

\section{Methodological considerations}

\section{Design}

We used a randomised controlled clinical trial (RCT) to investigate the effect of aspirin on the course of PAOD. A RCT is the recommended study design to investigate therapeutically effects. Prevention of bias and confounding is warranted by random allocation to the treatment groups and a double-blinded design.

\section{Choice of intervention}

Intervention regarding etiologic factors is the keystone in the management of cardiovascular disease. In PAOD smoking and diabetes mellitus are the most important risk factors. 28

The goals of medical treatment of intermittent claudication are reduction of complaints and prevention of complications. Several drugs have been used to treat intermittent claudication.

Vasodilator drugs are still used. They have not proven to be effective in relieving symptoms of PAOD. In combination with the various side-effects vasodilatation drugs are not recommended anymore in the treatment of PAOD. 2930

Rheologic agents (pentoxyfilin, buflomedil) pretend to be effective by the positive effect on flow parameters in the smaller arterioles of the post-stenotic vesselbed. From literature we learn that the effect on walking distance is significant but clinically not relevant. ${ }^{31} 32$

The disappointing results of existing drugs used in intermittent claudication raised the question whether the use of anti platelet drug could be useful in diminishing the progression of PAOD and in preventing complications of PAOD. The use of platelet inhibition in patients with intermittent claudication is often recommended thereby extrapolating the positive results of platelet inhibition in secondary prevention of other cardio- and cerebrovascular events. ${ }^{6}$ The effect of aspirin on the course of PAOD is theoretically a slow effect. Platelet inhibition in the way of aspirin plays a role in the progression of atherosclerotic plaques and secondary thrombogenesis. In existing atherosclerosis plaque fissuring and subintimal haemorrhage give rise to platelet activation resulting in thrombus 
formation which may lead to occlusion. In cerebro-and cardiovascular events the positive effect of aspirin is often attributed to the prevention of this thrombus formation. Whether this effect is the same in the relatively large arteries in the leg was not clear. From angiographical data there was some evidence of preventing progression of obstruction. Hess demonstrated a progression reduction of angiographically established stenoses of the arteries in more advanced PAOD patients from a clinical population. The effect on walking distance and number of complaints was small and not significant. ${ }^{5}$ We chose aspirin as our treatment because there were promising results in the treatment of vascular disease in. general and since the administration of aspirin has a simple regimen and could be a helpful extra in the treatment of PAOD. Since the general practitioner has a central role in the prevention of chronic diseases this relatively simple and cheap intervention was worthwhile to study in a clinical trial in the setting of general practice.

The dose of aspirin in the prevention of cardiovascular disease was matter of debate in the eighties and still there is some controversy on which is the optimal choice. The first studies were performed with $1200 \mathrm{mg}$ aspirin. At the time of the planning of the study the first reports of a dose of $100 \mathrm{mg}$ in the prevention of cerebrovascullar events came out and were not yet conclusive. The number of side effects in aspirin is dose dependent. With the information available at that time $300 \mathrm{mg}$ aspirin was considered the best choice. ${ }^{34} 35$

\section{Effect measure}

In reports on treatment of PAOD different effect measures are used. Walking distance is often used as the main effect measure in studies on conservative or drug treatment of PAOD. In surgery flow parameters and patency rates of bypasses or Dotter procedures are used. ${ }^{7}$ In the setting of general practice the measurement of the effect measure should be relatively simple with a minimum of equipment and personnel staff.

Walking distance in a quantitative manner is determined on a treadmill. The reported experienced walking distance by the patient is not reliable. Walking distance is influenced by comorbidity. Older age, disabling disease of hip and knee, COPD, heart failure may deteriorate walking distance seriously. The patient often underestimates his maximal walking distance compared to the treadmill. The experienced walking distance in qualitative terms can be used to get an impression of the impact of walking abillity on daily life. $36-40$

For logistical reasons the use of a standardised treadmill test in the setting of general practice is not feasible.

The use of a pedometer to estimate walking distance was considered but the problem of standardisation of the walking condition made less feasible (walking in hill-sides is not comparable with tlat conditions). 
Changes are signs and symptoms of PAOD are often given in reports on PAOD but seldom given as effect measure. "The presence of intermittent claudication as such. could lead to underestimate progression of disease when patients adapt their walking and daily activity to their diminished capacity.

Non-invasive pressure measurement by using ultrasound has proven to be a valid diagnostic tool in PAOD. In the setting of the general practitioner a handhold pocket Doppler is available with which pressure measurements at the ankle can be performed. ${ }^{2}$ The ankle brachial pressure ratio (ABPI) is a good parameter of flow disturbance in the proximal artery. ${ }^{41}$ Data on reproducibility and diagnostic power in general practice were scarce in the period of designing our study . 4243 For this we investigated before and during the Limburg PAOD study the use of this technique in generall practice. In the first part of the PAOD study on prevalence and diagnosis of PAOD, we were interested in the observer variability and the diagnostic power of the ABPI. From these studies we learned that the ABPI is a good test with a reasonably good reproducibility. The observer variability was $12.5 \% \mathrm{ABP}$. The study on diagnostic validity showed that the optimal cut-off value of the ABPI was between 0.92 and 0.97 . The positive predictive value is higher than $95 \%$ if the ABPI is below 0.88 and the negative predictive value is $99 \%$ if the ABPI is higher than 0.98 .1

Next to these figures of the $\mathrm{ABP}$ I we were interested in the power of detecting a given difference in ABPI in the course of time. From these studies we can estimate that that the difference between two measurements of the same patient by the same observer should be at least $29 \%$ to have a $95 \%$ certainty that this difference is not due to intra-observer error. With a degree of certainty of $80 \%$ the difference should be at least $19 \%$.

At the start of the Limburg PAOD study the participating practices observers were fairly inexperienced. Although we carried out intensive training and instruction of the GPs and their assistants, we were not sure whether the level of experience did influence our data on reproducibility. We repeated the first reproducibility study after two years. We added two very experienced vascular laboratory assistants (more than two measurements per day compared with $2 \times 4$ measurements in a week) to the observers in order to study the effect of experience on the intra observer variability. Another adaptation in the protocol was the use of random zero sphygmomanometers to ensure the independence of repeated measurements by the same observer in the same patient. The effect of experience was considerable, the intra-observer variability in the most experienced was $7.3 \%$, and $13.8 \%$ in the less experienced.

Comparing the results of both studies with regard to the reproducibility of the ABPI by the participating GPs and their practice assistants showed that the variability of inter-and intra observer variability only slightly increased.

From this we may conclude that the ABPI measured with the Doppler stethoscope was a reasonable choilce as the ourcome measure of our study. 


\section{Study duration}

The effect of aspirin on PAOD is probably a slow effect. The study duration should be long enough to develop a change in progression. At the time of the start of the study there was no consensus on the duration of trials with aspirin. There was a wide range of follow-up time in studies on drug treatment in PAOD. For reasons of feasibility we decided to monitor the patients every four months for at least two years.

\section{Selection procedure}

Case finding of PAOD in the setting of general practice in the time we designed the study was difficult. We expected the prevalence of PAOD to be in the range of 0.5-2\%. To detect prevalent cases we had to investigate numerous patients unless we could detect people with enhanced risk for PAOD. In order to achieve this we made a postal questionnaire on complaints (pain while walking, cold feet) and risk factors for PAOD (smoking more than 15 cigarettes a day, hypertension, diabetes mellitus, history of cardiovascular disease or a family history of cardiovascular disease). Patients with the highest risk were invited to be examined by their general practitioner. The objective to use these data for a cross-sectional study on the prevalence and diagnosis of PAOD led to a more complex selection procedure. Reason for this was that the methodology of prevalence studies and diagnostic studies need patients in the total range of risk. The details of this procedure are described by Stoffers. ${ }^{44}$ The consequence was that more patients had to be examined by their GP. The inclusion period for the trial had to be prolonged because the participating practices had only a limited capacity to examine patients for the study in addition to their usual work. In some practices patients were included in the trial and followed for more than a year while still patients were included. "The logistics of the combination of a long inclusion period and a long and frequent follow-up was very difficult for both the participating practices and the research workers. A central role in the management of the study played the research assistants. They provided the necessary input in the computer 30.000 names and addresses from patients for the postal questionnaire; data on medical history, physical examination, ABPIs of more than 3.500 patients; data of follow-up of 300 patients, preparing the database for analysis). The monitoring of the follow-up in 20 practices together with the researchers was a time-consuming task. When we started the study personal computers were just introduced. Knowledge and skills on using computers for research has gained and increased during the time of the study. Nowadays, the skills of research assistants on computerised data management are a prerequisite to prevent problems in the final analysis.

In the selection procedure for the RCI a considerable number of patients were excluded. Especially the use of aspirin was higher than expected. The reason for 
toms of PAOD are often given in reports on PAOD but ure. The presence of intermittent claudication as such fe progression of disease when patients adapt their seldom given as effect $m$ their diminished capacity.

could lead to underesti geasurement by using ultrasound has proven to be a walking and daily activity 1 . In the setting of the general practitioner a handhold

Non-invasive pressur with which pressure measurements at the ankle can be valid diagnostic tool in P prial pressure ratio (ABPI) is a good parameter of flow pocket Doppler is availab ${ }^{\text {al }}$ artery. ${ }^{41}$ Data on reproducibility and diagnostic performed. ${ }^{2}$ The ankle bi ${ }^{2}$ re scarce in the period of designing our study. 4243 For power in general practice and during the Limburg PAOD study the use of this this we investigated befo $y^{c e}$. In the first part of the PAOD study on prevalence technique in general pra were interested in the observer variability and the and diagnosis of PAOD, $P$ P. From these studies we learned that the ABPI is a diagnostic power of the $1 y$ good reproducibility. The observer variability was good test with a reason $y_{j}$ agnostic validity showed that the optimal cut-off value $12.5 \%$ ABPI. The study on 92 and 0.97 . The positive predictive value is higher than of the ABPI was between 0.6 and the negative predictive value is $99 \%$ if the ABPI is $95 \%$ if the ABPI is below 0 .

higher than $0.98 .^{1}$

Next to these figures of the ABPI we were interested in the power of detecting a given difference in ABPI in the course of time. From these studies we can estimate that that the difference between two measurements of the same patient by the same observer should be at least $29 \%$ to have a $95 \%$ certainty that this difference is not due to intra-observer error. With a degree of certainty of $80 \%$ the difference should be at least $19 \%$.

At the start of the Limburg PAOD study the participating practices observers were fairly inexperienced. Although we carried out intensive training and instruction of the GPS and their assistants, we were not sure whether the level of experience did influence our data on reproducibility. We repeated the first reproduclbility study after two years. We added two very experienced vascular laboratory assistants (mote than rwo measurements per day compared with $2 \sim 4$ measurements in a week to the observers in order to study the effect of expertence on the intrabobeter variability. Another adaptation in the protocol was the use of random zero sphygmomanometers to ensure the independence of repeated measurements by the same observer in the same patlent. The effect of experience was considerable, the intra observer variability in the most experienced was $7.3 \%$, and $13.8 \%$ in the less experenced.

Comparing the resuls

ABPI by the participating 0 both studies with regard to the reproducibility of the ability of inter-and intra of Ps and their practice assistants showed that the vari-

From this we may con gerver variability only slightly increased. scope was a reasonable ch ude that the ABPI measured with the Doppler stetho-

lice as the outcome measure of our study. 


\section{Study duration}

The effect of aspirin on PAOD is probably a slow effect. The study duration should be long enough to develop a change in progression. At the time of the start of the study there was no consensus on the duration of trials with aspirin. There was a wide range of follow-up time in studies on drug treatment in PAOD. For reasons of feasibility we decided to monitor the patients every four months for at least two years.

\section{Selection procedure}

Case finding of PAOD in the setting of general practice in the time we designed the study was difficult. We expected the prevalence of PAOD to be in the range of $0.5-2 \%$. To detect prevalent cases we had to investigate numerous patients unless we could detect people with enhanced risk for PAOD. In order to achieve this we made a postal questionnaire on complaints (pain while walking, cold feet) and risk factors for PAOD (smoking more than 15 cigarettes a day, hypertension, diabetes mellitus, history of cardiovascular disease or a family history of cardiovascular disease). Patients with the highest risk were invited to be examined by their general practitioner. The objective to use these data for a cross-sectional study on the prevalence and diagnosis of PAOD led to a more complex selection procedure. Reason for this was that the methodology of prevalence studies and diagnostic studies need patients in the total range of risk. The details of this procedure are described by Stoffers. ${ }^{44}$ The consequence was that more patients had to be examined by their GP. The inclusion period for the trial had to be prolonged because the participating practices had only a limited capacity to examine patients for the

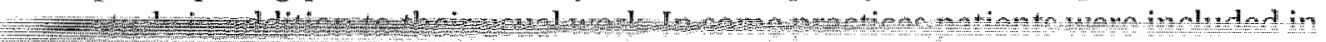


that was that in that particular period neurologist implemented the use of aspirin in the prevention of cerebrovascular accidents. Since a great part of patients with PAOD has cerebro- and cardio-vascular disease as comorbidity we had to exclude more patients than expected. The population selected for the trial represented the more "healthier" part of the patients with PAOD in general practice. A population with a more advanced stage of disease or with a higher proportion of comorbidity could have had possibly more benefit from the intervention with aspirin. On the other hand, the patients included in the trial represented that part of the patients. with PAOD not already treated with aspirin because of other cardiovascular disease and such early cases might be more sensitive to aspirin intervention. From this we may conclude that the external clinical validity of the selected population is reasonable, especially from the perspective of general practice.

During the trial there was considerable loss of follow-up. In our analysis of the trial we checked for differential loss of follow-up but found no possible source of bias for this reason.

\section{Practical implications for general practice.}

The Limburg PAOD Study on prevalence, diagnosis, treatment and prognosis of PAOD in general practice resulted in a number of publications on this issue. The scientific papers are mostly published in international papers. Next to this there are several publications in national papers. The authors contributed to clinical guidelines on the management of PAOD, published by the Dutch College of General Practitioners. Together with clinical experts (vascular surgeons, intervention radiologists, cardiologists and patient organisations) the authors contributed to the consensus on diagnosis and therapy of arterial intermittent claudication. ${ }^{12}$ 2744

From the prevalence and diagnostic study we leam that prevalence of asymptomatic and symptomatic PAOD is higher than expected. The general practitioner is unaware of $68 \%$ of all PAOD patients in his practice. The general practitioner is well equipped to rule out PAOD by medical history taking and physical examination. The ABPI measured with a Doppler stethoscope in general practice is a valid and reproducible diagnostic tool. Using the ABPI may reduce diagnostic uncertainty.

The Limburg study part II consisted of a randomised trial on the effect of aspirin on PAOD. We could not confirm a beneficial effect of aspirin. The role of strict conservative management in terms of stopping smoking, performing regular walking exercises and treatment of known risk factors is of great relevance for providing optimal conservative management.

The intluence of experience on the reproducibility of the ABPI was shown to be considerable. In order to maintain a reasonable level of experience the ABPI 
measurements should be restricted to one or two assistants in a group practice. The observer variability in time has shown to be small.

From the prognostic study we learn that the ABPI is also a relevant prognostic indicator for the mortality and morbidity of atherosclerotic disease. The importance of detecting asymptomatic patients with PAOD is discussed by Hooi, ${ }^{22}$ For the GP it may be useful to screen middle-aged and elderly subjects with one or more atherosclerotic risk factors for PAOD who visit his office (anticipative care).

\section{Recommendations for further research.}

Our results do not show a significantly positive effect of aspirin on the course of POAD. Whether aspirin is useful in the prevention of cardio- and cerebrovascular events in patients with PAOD is still not clear. Further research on the effect on mortality and comorbidity of aspirin or other antiplatelet agents in patients with both symptomatic and asymptomatic PAOD is needed. Other drugs of interest may be folic acid in patients with hyperhomocystenemia and the use of statines in patients with hypercholesterolemia.

The effectiveness of strict risk factor management PAOD is often recommended. Our prognostic study showed a small effect of various risk factors simultaneously. It is possible that a more precise and randomised effect study on risk factor management in PAOD could yield more clear insight. The effect of regular walking exercise had a positive effect on mortality. The gain of quality of life with optimal walking exercises is a topic of special interest in future researches. The optimal strategy of smoking cessation is still an issue that needed special attention in studies on risk modification.

Further research on the effectiveness of detecting and treating asymptomatic PAOD in patients with one or more cardiovascular risk factors is needed.

\section{References}

1. Stoffers HEJH, Kaiser V, Kester ADM, Schouten HJA, Knottnerus IA. Peripheral arterial occlusive disease in general practice: the reproducibility of the ankle-arm systolic pressure ratio. Scand J Prim Health Care 1991;9:109-14.

2. Stoffers HEJH, Kester ADM, Kaiser V, Rinkens PELM, Kitslaar PJEHM, Knottnerus JA. The diagnostic value of the measurement of the ankle-brachial systolic pressure index in primary health care. I Clin Epidemiol. 1996;49(12):1401-5.

3. Antiplatelet Trialists' Collaboration. Collaborative overview of randomised trials of antiplatelet therapy. 1. Prevention of death, myocardial infarction, and stroke by prow longed antiplatelet therapy in various categories of patients. BM] $1994 ; 308: 81-106$. 


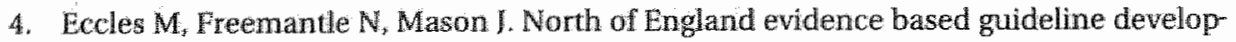
ment project: guideline on the use of aspirin as secondary prophylaxis for vascular disease in primary care. BMI 1998;316:1303-9.

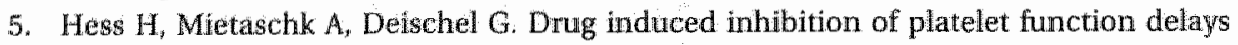
progressiton of peripheral occlusive arterial disease: a prospective double-blind arteriographically controlled trial. Lancet 1985;330:415-9.

6. Antiplatelet Trialists' Collaboration. Collaborative overview of randomised trials of antiplatelet therapy. 2. Maintenance of vascular graft or arterial patency by antiplatelet therapy. BMJ 1994;308:159-68.

7. Rutherford RB. Standards for evaluating results of interventional therapy for peripheral vascular disease. Circulation 1991;83 [suppl I]:[-6I-11.

B. Fowkes FGR, Housley E, Cawood EHH, Macintyre CCA, Ruckley CV, Prescott RJ. Edinburgh Artery Study: Prevalence of asymptomatic and symptomatic peripheral arterial disease in the general population. Int J Epidemial 1991;20:384-92.

9. Leng GC, Lee Al, Fowkes FGR, Whiteman M, Dumbar J, Housley E, Ruckley CV. Incidence, natural history and cardiovascular events in symptomatic and asymptomatic peripherall arterial disease in the general population. Int J Epidemiol 1996;25:1172-81.

10. Hooi JD, Stoffers HEJH, Kester ADM, Rinkens PELM, Kaiser V, van Ree JW, Knotmerus JA. Risk factors and cardiovascular diseases associated with asymptomatic peripheral arterial occlusive disease. The Limburg PAOD Study. Peripheral Arterial Occlusive Disease. Scand J Prim Health Care. 1998:16(3):177-82.

11. Jelnes $R$, Gaardsting $O$, Hougaard Jensen $K$, et al. Fate in intermittent claudication: outcome and risk factors. BMJ 1986;293:1137-40.

12. Cavender JB, Rogers WJ, Fischer LD, Gersh BJ, Coggin CJ, Myers WO. Effects of smoking on survival and morbidity in patients randomized to medical or surgical therapy in the Coronary Artery Study (CAS); 10 year follow-up. J Am Coll Cardiol 1992;20:287-92.

13. Cole CW, Hill GB, Farzad E, Bouchard A, Moher D, Rody K, et al. Cigarette smoking and peripheral arterial occlusive disease. Surgery 1993;114:753-6.

14. Kottke TE, Battista RN, DeFriese GH, Brekke ML. Attributes of successful smoking cessation interventions in medical practice. A meta-analysis of 39 controlled trials. IAMA. $1988: 259: 2883-9$.

15. Brandsma JW, Robeer BG, van den Heuvel $S$, Smit B, Wittens CH, Oostendorp RA. The effect of exercises on walking distance of patients with intermittent claudication: a study of randomized clinical trials. Phys Ther 1998;72:278-86.

16. Regensteiner $J G$, Gardner A, Hiatt WR. Exercise testing and exercise rehabilitation for patients with peripheral arterial disease: status in 1997. Vasc Med 1997;2(2):147-55.

17. Andriessen MP, Barendsen GJ, Wouda AA, de Pater L. The effect of six months intensive physical training on the circulation in the legs of patients with intermittent claudication. Vasa. 1989;18(1):56-62.

18. Wullink M, HEJH Stoffers, H. Kuipers. Functional walking exercise near home for patients with intermittent claudication. Fam Practice 1998;15:383.

19. Kannel WB, MCGee DL. Update on some epidemiological features of intermittent claudication: the Framingham study. J Am Geriatr Soc 1985;33:13- 18. 
20. Leng GC, Fowkes FGR, Lee AJ, Dunbar J, Housley E, Ruckley CV Use of ankle brachial pressure index to predict cardiovascular events and death: a cohort study BMO. $1996 ; 313(7070): 1440-4$.

21. McKenna $M$, Wolfson $S$, Kuller $L$. The ratio of ankle and arm arterial pressure as an independent predictor of mortality. Atherosclerosis. 1991;87(2-3):119-28.

22. Hooi JD. Peripheral arterial occlusive disease: incidence, progmosis and determinants. A population-based study in a primary care setting [PhD Thesis]. Maastricht:Unigraphic 1998.

23. Hooi JD, Stoffers HEJH, Knottnerus JA, van Ree JW. The prognosis of non-critical limb ischaemia: a systematic review of population-based evidence. Br I Gen Pract 1999;49: 49-55.

24. Meijer WT. Peripheral arterial disease in the elderly. [Thesis]. Rotterdam, 1999.

25. McDermott MM, Feinglass J, Slavensky R, Pearce WH. "The anklle-brachial index as a predictor of survival in patients with peripheral vascular disease. ] Gen Intern Med 1994* $9(8): 445-9$.

26. Newman B, Shemanski L, Manolio TA, Cushman M, Mittelmark M, Polak J1" Powe NR, Siscovick D. Ankle-arm index as a predictor of cardiovascular disease and mortality in the Cardiovascular Health Study. The Cardiovascular Health Study Group. Arterioscler Thromb Vasc Biol. 1999;19(3):538 45.

27. Kitslaar PJEHM Consensus diagnosis and treatment of arterial intermittent claudication. Central Guidance Organisation for Peer Review. Ned Tijdschr Geneeskd $1997 ; 141: 2396-400$.

28. Bewan EG, Waller PC, Ramsay LE. Pharmacologicall approaches to the treatment of intermittent claudication. Drugs Aging 1992;2:125-36.

29. Cameron HA, Walter PC, Ramsay LE. Drug treatment of intermittent claudication: a critical analysis of the methods and findings of published clinical trials, 1965-1985. Br J Clin Pharm 1988;26:569-76.

30. Coffman JD. Vasodilator drugs in peripheral vasculat disease. N Engl J Med 1979;300: 313-7.

31. Clissold SP, Lynch $S$, Sorkin EM. Buflomedil. A review of its pharmacodynamic and pharmacokinetic properties, and therapeutic efficacy in peripheral and cerebral vascular diseases. Drugs 1987;33:430-60.

32. Enst E. Pentoxifylline for intermittent claudication. A critical rewiew. Angiology. 1994; $45(5): 339-45$

33. Clissold SP, Lynch S, Sorkin EM. Buflomedil. A review of its pharmacodynamic and pharmacokinetic properties, and therapeutic efficacy in peripheral and cerebral vascular diseases. Drugs 1987;33(5):430-60.

34. Hirsch J, Dalen JE, FusterV, Harker LB, Salzman EW. Aspirin and other platelet-active drugs: the relationship between dose, effectiveness, and side effects. Chest 1992;102 (suppl 4):327S-336S.

35. Goldhaber SZ, Manzon JE, Stampfer MJ, et al. Low-dose aspirin and subsequent periplheral arterial surgery in the Physicians Health Study. Lancet 1992;340:143-5. 
36. Bouchet JY, Franco A, Morzol B, Beani IC Evaluation objective de la claudication intermitente arterielle par l'epreuve de marche. Etude comparative de la marche physiologique et sur tapis roulant. J Mal Vasc 1980;5(3):177-9.

37. Carter $S A_{i}$ Hamel ER, Paterson IM, Snow CJ, Mymin D. Walking ability and ankle systolic pressures: observations in patients with intermittent claudication in a short-term walking exercise prograri. J Vasc Surg. 1989; 10(6):642-9.

38. Bendall MJ, Bassey EJ, Pearson MB. Factors affecting walking speed of elderly people. Age Ageing. 1989;18(5):327-32.

39. Hylkema BS. Diagnostiek van arteriele circulatiestoomissen in de benen door bloeddrukmetingen met behulp wan ultrageluid. [The diagmosis of obliterative arteriosclerotic disease of the legs by ultrasonic determination of blood pressures]. Ned Tijdschr Geneeskd 1976:120:133-41.

40. Carter SA. Clinical measurement of systolic pressures in limbs with arterial occlusive disease. JAMA 1969;207:1869-74.

41. Criqui Mh, Fronek A, Barret-Connor E et al. The prevallence of peripheral arterial disease in a defined population. Circulation 1985;71:510-5.

42. Stoffers HEJH, Kester ADM, Kaiser V, Rinkens PELM, Knotinerus JA. Diagnostic value of silgns and symptoms associated with peripheral arterial occlusive disease seen in general practice: a multiwariable approach. Med Decis Making 1997;17:61 70.

43. Bonsema $K$, Boutens EJ, Kalser V, Stoffers HEIH. NHG-Standaard Perifeer arterieel vaatlijden. In: Rutten GEHM, Thomas S (eds.). NHG-Standaarden voor de huisarts. Utrecht: Nederlands Huisartsen Genootschap/Bunge, 1993.

44. Henri EJH Stoffers. Peripheral arterial occlusive disease. Prevalence and diagnostic management in general practice [PhD Thesis] University Maastricht, 1995. 


\section{Summary}

This thesis describes the second part of the Limburg PAOD study. The main topic of this thesis is the clinical course of peripheral arterial obstructive disease in general practice and the effectiveness of aspirin in the conservative treatment of PAOD.

Chapter 1 presents the background and aims of the Limburg PAOD study, part 2.

The Limburg PAOD study started in 1986. The first part of the Limburg PAOD study addressed the prevalence and diagnostics of PAOD The third project that started in 1994 was the Limburg PAOD Longitudinal Study, on the natural course and prognostic determinants of symptomatic and asymptomatic PAOD.

The aims of the Limburg PAOD study part 2 are:

1. to study the natural course of symptomatic and asymptomatic PAOD in general practice.

2. to investigate the effect of aspirin on the natural course of PAOD in general practice.

In relation to these research questions the results of a study on the reproducibility of the $A B P I$ in general practice are reported. Additionally reviews on the risk management and drug treatment in PAOD are presented.

Chapter 2 describes briefly the study on prevalence of $\mathrm{PAOD}$ in general practice of the Limburg PAOD study part 1. Prevalence figures of PAOD range from 0.2 to $11.7 \%$ according to the selected population and the criteria for diagnosis. In morbidity studies in general practices symptomatic PAOD patients (intermittent claudication) are selected. Prevalence ranged from 0.2 to $0.7 \%$. In unselected population studies prevalence of intermittent claudication was from $1.7 \%$ to $4.8 \%$. Asymptomatic PAOD can be detected with the use of a pocket Doppler stethoscope measuring the Ankle-Brachial pressure index (ABPI). Prevalence of PAOD measured with the ABPI (symptomatic and asymptomatic) rises to $11.7 \%$

In the population of the Limburg PAOD study PAOD was determined with a pocket Doppler and the prevalence was $6.1 \%$. (ABPI $<95 \%$ on two consecutive measurements). The amount of asymptomatic patients was considerable. The relevance of detecting asymptomatic PAOD at that time was still not clear.

Chapter 3 is a literature review on the most important and influencable risk factors in the diagnosis and prognosis of PAOD. Smoking is the most prominent etiologic and prognostic factor of PAOD. Despite the beneficial effect of stop smoking, the number of patients who actually quit smoking is disappointing. Only $5-25 \%$ of the smokers realise to stop smoking. 
Other known risk factors as hypertension, diabetes mellitus, hypercholesterolemia, adiposity and homocysteinemia are discussed.

Chapter 4 is a literature review on drugs used in the conservative treatment of symptomatic PAOD. Comparison of results in trials dealing with treatment of intermittent claudication is difficult depending on the choice of study population and effect measure.

Vasodilating drugs are often prescribed in the conservative treatment intermittent claudication. The body of evidence from clinical trials is lacking. Reological agents (buflomedil, pentoxyfilin) have shown a small effect in patients with very short painfree walking distance.

Chapter 5 describes a study on the reproducibility of the Ankle-Brachial systolic pressure index measurements in general practice The ankle-brachial systolic pressure ratio (ABPI) is a quantitative measurement used in diagnostic and therapeutic studies on peripheral arterial occlusive disease (PAOD) and in clinical practice. This study was performed to estimate the intra observer variability of the measurement of the ABPI and to compare the reproducibility of the measurements by very experienced vascular laboratory assistants and by less experienced general practice personnel. To estimate the variability repeated measurements of ABPI by general practitioners (GPs), GP-assistants and vascular laboratory assistants using a pocket Doppler device and a random zero sphygmomanometer were analysed. The ABPI was measured in six patients with various degrees of PAOD by two experienced observers (vascular laboratory assistants) and by 24 less experienced observers ( 18 practice assistants, 6 GPs). The overall intra-observer variability estimate was $11.8 \%$ ABPI. The intra-observer variability was $7.3 \%$ in the experienced observers and $12.0 \%$ in the less experienced observers. The difference of variability between experienced and less experienced observers was significant. The ABPI is suitable in follow-up studies where repeated measurements are needed. Gain in certainty about differences between measurements can be achieved by performing repeated measurements or to use more experienced observers.

Chapter 6 addresses the results of the therapeutical trial on aspirin in patients with PAOD. To investigate the effect of aspirin on the course of symptomatic and asymptomatic peripheral arterial occlusive disease in general practice a randomised controlled trial was designed recruited from 22 general practices. 265 patients aged 45-70 years with an ankle brachial systolic pressure index (ABPI) lower than $95 \%$ at two consecutive measurements were selected and randomised in three groups: $300 \mathrm{mg}$ aspirin, placebo or 'lifestyle' advice only. Change in ankle brachial systolic pressure index after two years of follow up was the primary endpoint. Secondary endpoints were changes in symptoms, cardiovascular morbidity and total mortality.

After two years of follow-up there were no differences in the mean ABPI between the intervention groups. Mean ABPI improved from $77 \%$ to $85 \%$. High age, smoking and low ABPI at start contributed most to deterioration of the ABPI. 
There were no differences in morbidity and mortality between the intervention groups.

We concluded that aspirin has no effect on the course of PAOD measured with the ABPI. Future research would probably best focused on optimising walking exercise and smoking cessation strategies in the conservative management of PAOD.

Chapter 7 describes the study on the prognostic indicators for outcome of PAOD in general practice. A prospective cohort study was done to investigate the prognostic value of various known risk factors and the effect of conservative treatment on the course of peripheral arterial occlusive disease in general practice. 265 patients aged 45-70 years with an ankle-brachial systolic pressure index (ABPI) lower than $95 \%$ at two consecutive measurements were followed for more than three years. Outcome measures were mortality, first episode of stroke or myocardial infarction, progressive ischemia, deterioration of complaints, progression of symptoms, and decrease in ABPI.

Using a Cox proportional hazard regression model for each of the outcome measures a hazard ratio (HR) was estimated. The ABPI at diagnosis showed to be a significant prognostic determinant for mortality (HR 0.46). For myocardial infarction as outcome, ABPI (HR 0.48), previous stroke (HR 5.6) and previous angina pectoris (HR 2.37) had prognostic relevance. Although not significant, the effect of walking exercise suggested a protective effect on mortality (HR 0.44, CI 0.16-1.23) and progressive ischemia (HR 0.67, CI 0.28-1.21). From these results we may conclude that the $\mathrm{ABPI}$ at diagnosis is the most consistent prognostic factor for adverse outcome events in the course of PAOD. No protective effect of aspirin in combination with other lifestyle advice has been demonstrated. There might be a positive effect of walking exercise on the prognosis of PAOD related events, but the protective effect on other atherosclerotic events seems larger.

Chapter 8 deals with the practical problems of conducting a clinical trial in a primary health care setting. In planning a trial, consideration must be given to: a study of the literature, inclusion and exclusion criteria, measurement instruments, patient selection, organisation of the study, participating professionals, randomisation procedure, monitoring, the trial protocol and ethical review of the protocol. The most important practical problems are: selecting the participating professionals, difficulty in recruiting enough suitable patients and deviation from the trial protocol. Designing and conducting a trial in a primary health care setting turns out to be no easy task, as: (a) the diseases studied are often less than clearly defined, (b) adequate measurement instruments are often not available, (c) prevalence and/or incidence may be lower, (d) often a large number of participating centres are needed, with the result that more logistical problems are likely. Given the differences between primary (outpatient) and impatient care, one needs to consider when designing a trial, which setting is most suitable. The enthusiasm of the researcher and the participants is one of the factors determining the success of the study. 
In chapter 9, the general discussion, next to the main results, methodological issues are summarised and implications for general practice are discussed. Recommendations for further research are made.

From the prevalence and diagnostic study we learn that prevalence of asymptomatic and symptomatic PAOD is higher than expected. The general practitioner is unaware of $68 \%$ of all PAOD patients in his practice. The general practitioner is well equipped to rule out PAOD by medical history taking and physical examination. The ABPI measured with a Doppler stethoscope in general practice is a valid and reproducible diagnostic tool. Using the ABPI may reduce diagnostic uncertainty.

The Limburg study part II consisted of a randomised trial on the effect of aspirin on PAOD. We could not confirm a beneficial effect of aspirin. The role of strict conservative management in terms of stopping smoking, performing regular walking exercises and treatment of known risk factors is of great relevance for providing optimal conservative management.

From the prognostic studies we learn that the ABPI is also a relevant prognostic indicator for the mortality and morbidity of atherosclerotic disease Our results do not show a significantlly positive effect of aspirin on the course of PAOD. Whether aspirin is usefull in the prevention of cardio- and cerebrovascular events in patients with PAOD is still not clear. Further research on the effect on mortality and comorbidity of aspirin or other antiplatelet agents in patients with both symptomatic and asymptomatic PAOD is needed. The gain of quality of life with optimal walking exercises is a topic of special interest in future researches. The optimal strategy of smoking cessation is still an issue that needed special attention in studies on risk modification. 


\section{Samenvatting}

Dit proefschrift beschrijft het tweede deel van de Limburg PAOD studie. Het hoofdonderwerp van deze studie is het klinische beloop van perifeer arterieel abstructief vaatlijden (PAV) in de huisartspraktijk en het effect van aspirine in de conservatieve behandeling van PAV.

In Hoofdstuk 1 worden de achtergronden en doelstellingen van de Limburg PAOD studie deel 2 gepresenteerd. De Limburg PAOD studie is in 1986 van start gegaan. Het eerste deel van de Limburg PAOD studie behandelt de prevalentie en de diagnostiek van PAV. Het derde project onderdeel is in 1994 van start gegaan met als onderwerp het natuurlijk beloop en prognostische determinanten van symptomatisch en asymptomatisch PAV.

De doelstellingen van deel 2 van de Limburg PAOD studie zijn:

1. het bestuderen van het natuurlijk beloop van PAV in de huisartspraktijk

2. het nagaan van het effect van aspirine op het natuurlijk beloop van PAV in de huisartspraktijk.

Behalve voomoemde onderzoeksvragen worden de resultaten beschreven van een studie naar de reproduceerbaarheid van de Enkel-Arm index meting in de huisartspraktijk en de invloed van de mate van ervaring op deze reproduceerbaarheid. Aanvullend worden twee literatuur overzichten gepresenteerd over risico management en medicamenteuze behandeling van PAV.

Hoofdstuk 2 is een verkorte weergave van de prevalentie studie uit deel 1 van de PAOD studie. Prevalentie cijfers van PAV variëren van $0.2 \%$ tot $11.7 \%$ naar gelang de onderzochte onderzoekspopulatie en de gehanteerde criteria voor de diagnose van PAV. In morbiditeit studies in de huisartspraktijk worden vanouds de symptomatische patiënten (claudication intermittens) geselecteerd. In deze studies wisselt de prevalentie van 0.2 tot $0.7 \%$ van de totale praktijk populatie. In ongeselecteerde populatie studies varieert de prevalentie van 1.7 tot $4.8 \%$. Met behulp van een pocket Doppler stethoscoop kan ook bij patiënten zonder klachten aan de hand van de gemeten Enkel-Arm index (E/A-index) vaatlijden worden opgespoord. Prevalentie cijfers van PAV gemeten aan de hand van de E/A-index (zowel symptomatisch als ook asymptomatisch) lopen op tot $11.7 \%$. In de populatie van de Limburg PAOD studie is aanwezigheid van PAV vastgesteld met behulp van de E/A-index. (twee maal achtereenvolgens $<95 \%$ ) De prevalentie in onze studie bedroeg $6.2 \%$ Het aantal asymptomatische PAV patiënten was aanzienlijk. De relevantie van het opsporen van asymptomatisch PAV was toentertijd nog niet duidelijk. 
Hoofdstuk 3 bestaat uit een literatuuroverzicht over de belangrijkste risicofactoren met betrekking tot het ontstaan en de prognose van PAV. Roken is de belangrijkste etiologische en prognostische factor van PAV. Ondanks het gedocumenteerde positieve effect van het stoppen van roken op het beloop van PAV bedraagt thet aantal patiènten dat ook daadwerkelijk stopt met roken slechts 5-25\%. Andere bekende risicofactoren als hypertensie, diabetes mellitus, hypercholesterolemie, overgewicht en homocysteinemie worden besproken.

Hoofdstuk 4 is een literatuuroverzicht over geneesmiddelen die worden gebruikt bij de conservatieve behandeling van PAV. Het vergelijken van de resultaten van deze trials wordt bemoeilijkt door het gebruik van verschillende effect maten en zijn sterk afhankelijk van de keuze van de onderzoekspopulatie. Vasodilaterende geneesmiddelen werden veel voorgeschreven. Het effect in klinische studies naar PAV is echter niet aangetoond. Rheologische middelen als buflomedil en pentoxyfiline hebben slechts een beperkt indicatie gebied.

Hoofdstuk 5 beschrijft de studie naar de reproduceerbaarheid van de E/Aindex meting in de huisartspraktijk. De E/A-index is een kwantitatieve maat voor vaatlijden die wordt gebruikt in diagnostische en therapeutische studies over PAV. In deze studie is de intra beoordelaars variatie van de E/A-index meting berekend en worden de resultaten van zeer ervaren vaatlaborantes vergeleken met minder ervaren huisartsen of assistentes. Om deze variatie te meten zijn herhaalde metingen van de E/A-index met behulp van de Doppler stethoscoop en random zero bloeddrukmeters verricht. De E/A-index is gemeten bij zes patiënten met verschillende ernst van PAV door 2 ervaren vaatlaborantes en 22 minder ervaren doktersassistentes of huisartsen. The totale intra waarnemer variatie bedroeg $11.8 \% \mathrm{E} / \mathrm{A}$-index. De intra waarnemer variatie bedroeg bij de ervaren waarnemers $7.3 \%$ en bij de minder ervaren waarnemers $12.0 \%$. Het verschil in variatie tussen de ervaren en mindler ervaren waarnemers was statistisch significant. De E/A-index is een bruikbare maat voor het volgen van PAV in studies met herhaalde metingen. Voldoende mate van zekerheid over de gevonden verschillen tussen metingen kan worden bereikt door meerdere keren per gelegenheid te meten of door meer ervaren observatoren te gebruiken.

Hoofdstuk 6 behandelt de resultaten wan de effect studie wan aspirine bij patiënten met PAV in de huisartsenpraktijk. Om het effect van aspirine op het beloop van zowel symptomatisch als ook asymptomatisch PAV in de huisartspraktijk te bestuderen is een gerandomiseerde en gecontroleerde studie verricht in 22 huisarts praktijken. 265 patiënten in de leeftijd tussen 45 en 70 jaar met een E/A-index lager dan $95 \%$ bij 2 herhaalde metingen werden geselecteerd en gerandomiseerd over 3 groepen: $300 \mathrm{mg}$ aspirine, placebo en "lifestyle" adviezen. De primaire eindmaat van deze studie was de veranderingen in de E/A-index na 2 jaar follow-up. Secundaire eindmaten waren veranderingen in klachten, cardiovasculaire morbiditeit en totale mortaliteit.

$\mathrm{Na}$ twee jaar follow-up konden geen verschillen in gemiddelde E/A-index tussen de studiegroepen worden aangetoond. De gemiddelde E/A-index steeg in 
alle groepen van $77 \%$ tot $85 \%$. Hoge leeftij, roken en een lage E/A-index aan het begin van de studie. Morbiditeit en mortaliteit in de studiegroepen waren gelijk.

Onze conclusie was dat aspirine geen aantoonbaar effect heeft op het beloop van PAV gemeten met de E/A-index. Toekomstig onderzoek naar de conservatieve behandeling van PAV zal naast de medicamenteuze behandeling meer gericht moeten worden op het optimaliseren van looptraining en rookstop strategieën.

Hoofdstuk 7 beschrijft de studie naar de prognostische indicatoren voor het beloop van PAV in de huisartspraktijk. Om de prognostische waarde van de verschillende bekende risicofactoren te onderzoeken en het effect van rookstop adviezen en looptraining in de conservatieve behandeling van PAV in de huisarts praktijk hebben we een prospectieve cohort studie verricht. 265 patienten in de leeftijdscategorie van 45 tot 70 jaar met een E/A-index kleiner dan $95 \%$ werden gedurende meer dan 3 jaar gevolgd. Uitkomst maten waren mortaliteit, een eerste episode van een cerebro vasculair accident (CVA) of een hartinfarct, vasculaire complicaties, toename van ischemische klachten, veranderingen bij lichamelijk onderzoek en een daling van de E/A-index.

Hazard ratios (HR) werden voor elke uitkomstmaat berekend met behulp van een Cox proportional regressie model. De hoogte van de E/A-index bij het stellen van de diagnose was de belangrijkste prognostische determinant voor sterfte (HR 0.46). Van prognostisch belang voor de uitkomst hartinfarct waren de E/A-index (HR 0.48), eerder doorgemaakt CVA (HR 5.6) en eerder bestaande angina pectoris (HR 2.37). Het effect van looptraining op de sterfte was niet significant maar wel suggestief voor een beschermend effect op de sterfte (HR 0.44, CI 0.16-1.23) en

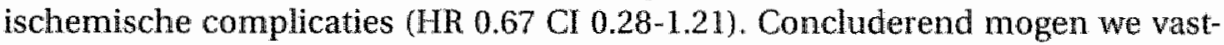
stellen dat de E/A-index bij het stellen van de diagnose de meest consistente prognostische factor voor het beloop van PAV. Van aspirine in combinatie met andere leefadviezen kon geen duidelijk effect worden aangetoond. Mogelijk dat er een positief effect van looptraining op het beloop van PAV zelf is maar het effect op andere atherosclerotische complicaties lijkt groter te zijn.

Hoofdstuk 8 is een beschrijving van de praktische problemen die kumen voorkomen bij de uitvoering van een klinische trial in een eerstelijns setting. Bij de opzet van een trial komen verschillende elementen aan de orde: literatuurstudie, het vaststellen van in- en exclusie criteria, de keuze van meetinstrumenten, de patiẻnt selectie de organisatie van de studie, werven van deelnemers, de uitvoering van de randomisatie, het uitwerken van een protocol en het voorleggen van het protocol aan een medisch ethische commissie. De belangrijkste problemen zijn: het werven wan deelnemende praktijken, moeite om het vereiste aantal geschikte patiënten te selecteren en afwijkingen van het protocol. Met name voor de planning van een studie in de eerstelijns setting zijn er een antal specifieke problemen: (a) de bestudeerde ziektebeelden zijn vaak minder scherp omschreven, (b) geschikte meetinstrumenten zijn vaak niet voorhanden, (c) prevalentie/incidentie van de betreffende ziekte is lager dan in een geselecteerde klinische populatie, (d) logistieke problemen door het vereiste grote aantal deel- 
nemende praktijken. Het enthousiasme van de onderzoekers en van de deelnemende praktijken blijkt een van de belangrijkste factoren te zijn voor het welslagen van de vitvoering van patientgebonden onderzoek.

In hoofdstuk 9, de algemene beschouwing, worden naast de belangrijkste resultaten van de studie tevens een aantal methodologische aspecten besproken, het belang van deze resultaten voor de huisartspraktijk, en enkele aanbevelingen voor verdere studie.

In de prevalentie en de diagnostische studie (PAOD study deel 1 ) is aangetoond dat de prevalentie van asymptomatisch en symptomatisch vaatlijden inde huisartspraktijk hoger is dan verwacht. $68 \%$ van alle PAV patiënten is niet bekend bij de huisarts. De huisarts is goed in staat om met behulp van zijn anamnese en lichamelijk onderzoek PAV uit te sluiten. De meting van de E/A-index met een pocket Doppler in de huisartspraktijk is een valide en reproduceerbare diagnostische methode gebleken. De mate van diagnostische onzekerheid kan met het gebruik van de E/A-index worden verkleind.

De uitkomsten van deel 2 van de Limburg PAOD study lieten geen duidelijk effect van aspirine op het beloop van PAV zien. Het nut van aspirine in de preventie van andere hart-vaat ziektes bij patiënten met aangetoond PAV is nog niet duidelijk. In de conservatieve behandeling van PAV in de huisartspraktijk verdient het stoppen met roken, het verrichten van looptraining en het behandelen van bekende risicofactoren de meeste aandacht.

De prognostische studies hebben aangetoond dat de E/A-index een belangrijke prognostische determinant van sterfte en van uitingen van atherosclerotisch vaatlijden is.

Toekomstig onderzoek naar het effect van aspirine of andere plaatjes remmers op mortaliteit en vasculaire morbiditeit bij zowel symptomatisch als ook asymptomatisch PAV is van belang. Studies naar looptraining en kwaliteit van leven bij PAV zijn gewenst. Speciale aandacht vragen ook studies naar de optimale methode om patiënten te doen stoppen met roken. 


\section{Dankwoord}

Een dankwoord schrijven 15 jaar nadat de eerste stappen voor dit PAV-project gezet zijn is een delicate kwestie. Naast mijn werk als beginnend onderzoeker heb $i k$ in dezelfde periode als startend huisarts een praktijk overgenomen en verder uirgebouwd. Beide activiteiten heb ik kunnen voltooien in samenwerking met velen. Het gevaar iets of iemand te vergeten is groot. Zeker bij een project van deze omvang en tijdsduur. Zij die niet genoemd worden maar wel meegewerkt hebben op welke wijze dan ook, bij voorbaat excuses.

They Lemmens was de grote initiator van een aantal projecten binnen de capaciteitsgroep Huisartsgeneeskunde. Samen met Cees de Geus, hoogleraar Huisartsgeneeskunde, en Paul Jörning, chirurg, heeft hij de basis gelegd voor een project dat uiteindelijk drie proefschriften heeft opgeleverd. Helaas heeft hij door zijn te vroege overlijden dit niet mogen meemaken. Op zijn eigen, onnavolgbare Bourgondische wijze heeft hij me altijd in positieve zin weten te prikkelen.

Telle Stoffers, in eerste instantie als mede-onderzoeker en later als copromotor, is de stuwende kracht geweest achter de afronding van dit proefschrift. Een jaar na de start van het project kwam hij als huisarts-onderzoeker in opleiding de projectgroep versterken. In de beginjaren hebben we als collega onderzoekers de gemeenschappelijke dataverzameling verricht. Ook aan de gegevensverzameling van de follow-up heeft hij zijn actieve bijdrage geleverd. Na het afronden van zijn eigen promotie heeft hij met een grote vasthoudendheid de taak als co-promotor op zich genomen. Jelle, ik denk wel eens dat het begeleiden van deze promovendus misschien nog meer energie heeft gekost dan je eigen promotie.

André Knottnerus, hoogleraar Huisartsgeneeskunde, was mijn promotor en projectleider. In goede en slechte tijden heb je me altijd weer de goede richting gewezen. Je subtiele manier van kritiek leveren en leiding geven heeft er uiteindelijk voor gezorgd dat ik mijn proefschrift heb afgerond.

Peter Kitslaar, hoogleraar Heelkunde, is als opvolger van Paul Jörning lid van de projectgroep geworden. Als mijn tweede promotor heeft hij als vaatchirurg een opbouwend kritische bijdrage aan dit proefschrift gegeven. Als voorzitter van de CBO-groep "diagnostiek en behandeling van arteriële claudicatio intermittens" heeft hij de huisartsgeneeskundige inbreng in de totstandkoming van deze consensus van onze kant duidelijk gestimuleerd.

Karin Aretz was onze eerste research-assistente. Zij heeft met name de praktische gang van zaken geregeld en de basis gelegd voor een gedegen dataverzameling. Met de in huidige termen, gebrekkige hulpmiddelen van die tijd is het haar gelukt om de data voor mij in een analyseerbaar bestand te gieten. 
Paula Rinkens is na enige tijd de gelederen van de research-assistentie komen versterken. Samen met Karin heeft ze ook in de follow-up gezorgd dat alle informatie daar kwam waar die moest zijn.

Jos Hamers is als research assistent actief geweest in analyseerbaar maken van het follow-up bestand.

Arnold Kester, statisticus heeft samen met Marion de Leeuw een belangrijke rol gespeeld in de uiteindelijke analyses van dit proefschrift. Het terug vertalen van de uitkomsten van met name de meer ingewikkelde statistiek is en blijft een boeiende exercitie.

Uiteraard wil ik de deelnemende huisartsen en hun assistentes bedanken. Voor aandoeningsgericht patiëntgebonden onderzoek is de medewerking van huisartspraktijken onontbeerlijk.

GHMI Beusmans, WPM Vierhout, T van Merode, TGJ Lemmenst, PA Stalenhoef, LGI Huynen, GAHM Castermans, MPJM Peeters, FHJA Vissers (Maastricht), FI Guldemond (Ubachsberg), PBN Hulshof, RM Panhuysen, ETIM GuldemondHecker (Voerendaal), AA ten Berge, PFM van der Heyden (Roermond), WHM Nieuwdorp (Brunssum) H Logister†, BTMG van der Werf (Heerlen), P. Athmer, G van Zanten, JJ Michels, WJ van der Wissel, A van Dam, C Hanssen, EHJF Hubbers, FLM Soomers, IMSIG Soomers-Turlings, PHM Passage, JHJ Drenth (Kerkrade), BHJM Otten (Merkelbeek), ESM Vijgen, TAH Vijgen-Hamers (Geleen), JHM Eussen, JAM Ypma, C Stuurman (Landgraaf), $\mathrm{M}$ van Bommel (Tilburg), $\mathrm{Ph}$ Govaert, RMFM Leclerq (Stein). Als deelnemers aan een van de eerste grotere patiëntgebonden onderzoeken van de capaciteitsgroep makkten ook zij een sprong in het diepe. Ondanks de grote belasting die dit project voor de praktijken betekende hebben we de dataverzameling tot een goed einde weten te brengen. Ik hoop dat door hun deelname aan dit onderzoek de interesse voor vaatlijden is gegroeid.

Daarnaast wil ik alle patiënten bedanken voor hun deelname. Het merendeel van de patiënten heeft trouw de huisarts om de 4 maanden bezocht voor weer een onderzoek en weer een nieuwe pot met pillen.

Fer Willemse, huisarts in Eygelshoven, heeft me de gelegenheid geboden om als huisarts aan de slag te kumnen.

Jan Veldhuizen, mijn huidige maat in de praktijk. Ik denk dat onze samenwerking het begrip 'maatschap' een aparte inhoud geeft. Als reeds gepromoveerd huisarts heb je in periodes van twijfel mij ervan weten te overtuigen om 'het' toch af te maken. Als ik al een steek liet vallen heb je die zonder al teveel morren opgepakt. Nu ook ik die kleine 's' kan wegstrepen kunnen we met recht spreken van een academische praktijk.

Ingrid Meurs, Cindy Janssen en Claudia Hinzen, onze praktijkassistentes, jullie zorgen ervoor dat de praktijk blijft draaien, wat er ook gebeurt.

Pap, Mam, ut buschje is veedig, noe kenne vuur ee kling fesje viere. 
Lidwine, Jules en Paul, ik weet dat ik vele van onze uurtjes gestolen heb voor dit proefschrift. Toch heb je me, Lidwine, gestimuleerd om vooral door te gaan en het af te maken. 


\section{Curriculum vitae}

Victor Kaiser werd geboren op 2 juni 1959 geboren in Heerlen in de toenmalige Vroedvrouwenschool. Als vierde zoon van een bakkersdochter en een bankemploye groeide hij op in een gezin met vijf zonen en twee dochters in Spekholzerheide, een wijk van Kerkrade. In 1977 behaalde hij aan het katholiek gymnasium "Rolduc" te Kerkrade zijn eindexamen B. Hij studeerde Geneeskunde aan de Universiteit van Maastricht van 1977 tot 1983. Van 1983 tot 1984 heeft hij de huisartsopleiding gevolgd te Maastricht met als opleiders Jo Berden en Huub op de Kamp te Blerick-Venlo. De experimentele huisarts-onderzoekersopleiding te Maastricht heeft hij gevolgd van 1984 tot 1985. In samenwerking met Frans Verstappen (Fysiologie) en Eugene Janssen (Humane Biologie) heeft hij binnen het Marathon-project een deelonderzoek gedaan naar hematologische veranderingen bij duursport. Tijdens de onderzoekersopleiding heeft hij als huisarts gewerkt in de praktijk van Fons Vluggen en Fons van der Poel te Kerkrade.

Vanaf 1985 is hij betrokken bij het door They Lemmens opgestarte onderzoeks project Perifeer arterieel obstructief vaatlijden in de huisartspraktijk (Limburg PAOD study) waarvan in dit proefschrift mede verslag wordt gedaan.

Vanaf 1986 werkzaam in deeltijd als huisarts in de praktijk van Fer Willemse te Eygelshoven. Vanaf 1990 heeft hij de praktijk voortgezet in samenwerking met Jan Veldhuizen. Vanuit deze geacademiseerde huisartspraktijk is hij werkzaam als begeleider en opleider binnen het Praktisch Medisch Onderwijs in de Huisartspraktijk en als opleider voor de Huisartsopleiding te Maastricht. 